\title{
ELECTRICAL CONDUCTIVITY AND MECHANICAL PROPERTY MEASUREMENTS ON A COLD WORKED AUSTENITIC STAINLESS STEEL
}

\author{
C. A. Reeves, Jr.
}

Oak Ridge Y-12 Plant

P.O. Box Y, Oak Ridge, Tennessee 37830

operated for the U.S. ATOMIC ENERGY COMMISSION bY UNION CARBIDE CORPORATION-NUCLEAR DIVISION under Contract W-7405-eng-26

Date Issued - July 30, 1972

This report is based on a study by the author as partial fulfillment of requirements for the degree of Master of Science in Physics from The University of Tennessee.

This report was prepared as an account of work sponsored by the United States Government. Neither the United States nor the United States Atomic Energy Che Unised states any of their employees, nor any of their contractors, subcontractors, or their employees, their contractors, subcontractors, or their or assumes any legal liability or responsibility for the accuracy, comlogates of usefuness of any information, apparatus, product or process disclosed, or represents that its use would not infringe privately owned rights. 


\section{DISCLAIMER}

This report was prepared as an account of work sponsored by an agency of the United States Government. Neither the United States Government nor any agency Thereof, nor any of their employees, makes any warranty, express or implied, or assumes any legal liability or responsibility for the accuracy, completeness, or usefulness of any information, apparatus, product, or process disclosed, or represents that its use would not infringe privately owned rights. Reference herein to any specific commercial product, process, or service by trade name, trademark, manufacturer, or otherwise does not necessarily constitute or imply its endorsement, recommendation, or favoring by the United States Government or any agency thereof. The views and opinions of authors expressed herein do not necessarily state or reflect those of the United States Government or any agency thereof. 


\section{DISCLAIMER}

Portions of this document may be illegible in electronic image products. Images are produced from the best available original document. 
The author would like to express his sincere appreciation to all who have assisted him in the completion of this study. Particular appreciation is given to Dr. W. E. Deeds and Dr. Caius V. Dodd for their many suggestions and guidance throughout the course of this study. The author is deeply indebted to personnel of Union Carbide's Y-12 Plant, operated for the U. S. Atomic Energy Commission, in particular to members of the Mechanical Properties and Metallography Laboratories of the Physical Testing Department, for their support and assistance in this research. Particular appreciation is also given to W. A. Simpson, Jr., for his assistance in familiarizing the author with the eddy current equipment involved, and the computer programs associated therewith. Acknowledgement is also given to Mrs. Alice N. Fry who graciously typed and retyped this manuscript. Finally the author would like to express his appreciation to his wife and son for their thoughtful understanding and assistance throughout the course of his pursuit of a Master of Science degree. 


\section{ABSTRACT}

Measurements were made on a sheet of well documented 316 stainless steel in order to determine the effects of cold working upon the electrical conductivity and mechanical properties of the material. The sheet was cut into smaller sheets, and these were cold rolled in increments of approximately $10 \%$ from $0 \%$ to $50 \%$. Mechanical property measurements were then made on these plates both parallel and perpendicular to the rolling direction. A computer controlled testing machine system was utilized for most of these tests, which allowed determination of mechanical property results to an overall accuracy of at least $1-2 \%$. Electrical conductivity measurements were made by two techniques: the first was the time honored one of D.C. measurements which were made on the mechanical property test specimens prior to testing, and the second was the relatively new method of non-destructive measurement by eddy current methods. Excellent agreement was obtained between the eddy current and D.C. measurements as well as excellent correlation being obtained with the mechanical property test results. A total change in conductivity of approximately $3 \%$ was noted by these methods for a $50 \%$ increase in cold working. An increase of approximately $6.5 \%$ in the tensile strength of the material was evident over the same range of cold working. 
TABLE OF CONTENTS

CHAPTER

PAGE

I. INTROUUCTION ................... 1

II. INITIAL CHARACTERIZATION AND COLD

WORKING OF THE 316 SS PLATE . . . . . . . . . . 3

Plate Specifications and Initial

Characterization ............ . 3

Cold Working . . . . . . . . . . . . . 15

Plate Sampling for Further Tests . . . . . . . . 24

Microhardness Measurements of the Cold

Worked Plates ............... 24

III. D.C. ELECTRICAL RESISTIVITY/CONDUCTIVITY

MEASUREMENTS . . . . . . . . . . . . . . 35

Introduction and Theory . . . . . . . . . . 35

Conductivity/Resistivity Relationships . . . . . . 40

l.letallurgical Mechanisms ............ 43

Apparatus ................. 44

Test Results.................. 52

IV. MECHANICAL PROPERTY TEST RESULTS . . . . . . . . . . . 74

Introduction ................. 74

Test Method ................. 77

Test Results................. 85

V. EDDY CURRENT MEASUREMENTS . . . . . . . . . . . 104

Introduction and Theory ............ . 104 
CHAPTER

PAGE

Apparatus .................. 106

Test Results................. 115

VI. ANALYSIS OF RESULTS NND DISCUSSION OF ERROR . . . . . 148

Sources of Error . . . . . . . . . . . . 149

VII. CONCLUSIONS . . . . . . . . . . . . . 154

BIBLIOGRAPIIY . . . . . . . . . . . . . . . 157

APPENDICES . . . . . . . . . . . . . . . . . 161

A. LIST OF SYMBOLS ................ 162

B. THE CALCULATOR SYSTEM USED FOR THIS STUDY . . . . . 165

C. THE COMPUTERIZED TESTING MACHINE SYSTEM. . . . . . . 169 VITA . . . . . . . . . . . . . . . . . . . 176 
I. Chemical Analyses of the $316 S S$ Plate . . . . . 4

II. Vendor Mechanical Property Results ... . . . . 5

III. Nominal Properties for 31655 from the ASM Metals Handbook . . . . . . . . . . 7

IV. Initial Mechanical Properties of the As Received 316SS Plate . . . . . . . . 8

V. Microhardness of the Three Photomicrographic Specimens . . . . . . . . . . . . . 18

VI. Plate Thickness Mleasurements after Cold Working . . . . . . . . . . . 20

VII. Grain Length-to-Height Ratios for Various Degrees of Cold Working ............ 25

VIII. Least Squares Functions for $\mathrm{L} / \mathrm{H}$ Ratios

Versus Percent Cold Work . . . . . . . 27

IX. Averages of Microhardness Readings from the Cold Worked Plates............ 31

X. The Parabolic Function for Figure 12 . . . . 33

XI. DPH Values Measured from the Cold Worked Specimens . . . . . . . . . . . . 34

XII. Resistivity Relationships from ASTM B187 . . . . 41

XIII. Potential Knife Edge Spacing . . . . . . . . 51

XIV. Tensile Specimen Area Measurements

$$
\text { (As-Rolled) . . . . . . . . . . . . } 54
$$


XV. Average Electrical Resistivity/Conductivity Measured from the As-Rolled Specimens . . . . 60

XVI. Individual Specimen Data for the Electrical Resistivity/Conductivity Measured from the As-Rolled Specimens . . . . . . . . 63

XVII. Tensile Specimen Area Measurements

(Polished) . . . . . . . . . . . . 65

XVIII. Average Electrical Resistivity/Conductivity

Measured from the Polished Specimens . . . . 68

XIX. Individual Specimen Data for the Electrical

Resistivity/Conductivity Measured from

the Polished Specimens . . . . . . . . . 70

$X X$. Least Squares Parabolic Functions for the

Resistivity versus Percent Cold Work Plots... 73

XXI. Mechanical Property Test Results -

Tensile Strength . . . . . . . . 86

XXII. Mechanical Property Test Results -

Yield Strength at $0.2 \%$ offset . . . . . . 87

XXIII. Mechanical Property Test Results -

Yield Strength at $1.0 \%$ Extension ....... 88

XXIV. Mechanical Property Test Results -

Modulus of Elasticity . . . . . . . . . 89

XXV. Mechanical Property Test Results -

Energy to 1.0\% Strain ............ 91 
viii

TABLE

PAGE

XXVI. Functions Calculated from the Second

Order Fits to the Mechanical

Property Test Results . . . . . . . . . . 98

XXVII. Summary of the Mechanical Property

Test Results.............. 100

XXVIII. Eddy Current Probe Coil Dimensions . . . . . . 116

XXIX. Circuit Parameters Used for the Eddy

Current Measurement ............ 118

XXX. Summary of Eddy Current Test Results from

the Three-inch Square Plates . . . . . . . . 121

XXXI. Eddy Current Measurements on the Three-

inch Square Plates . . . . . . . . . . 126

XXXII. Second Order Functions Calculated for

Figures 38 and 39 . . . . . . . . . . . . . 128

XXXIII. Calculated Values of $\phi_{\sigma}$ and $\phi_{\mu}$ from Data

for the Three-inch Square Plates . . . . . . . 129

XXXIV. Second Order Functions Calculated for

Figures 40 and 41 ............. . . 132

XXXV. Summary of the Eddy Current Test Results

from the Large Tensile Specimens . . . . . . 137

XXXVI. Second Order Functions Calculated for

Figure 44 . . . . . . . . . . . . . 139

XXXVII. Eddy Current Measurements on the Large

Tensile Specimens . . . . . . . . . . 140 
XXXVIII. Calculated Values of $\phi_{\sigma}$ and $\phi_{\mu}$ from Data for the Large Tensile Specimens . . . . . . 144

XXXIX. Functions Calculated for Figures

45 and 46 ................... 147

XXXX. Estimate of Total Error of D.C.

Resistivity Measurements . . . . . . . . 151

XXXXI. Estimate of Errors in the Nechanical

Property Tests . . . . . . . . . . . . 152 
1. Corner of the 86-inch by 61-inch Plate

Showing Initial Sampling . . . . . . . . 10

2. Flat Tensile Specimen Used for the Mechanical

Property Tests . . . . . . . . . . . . 12

3. Photomicrograph of a Specimen from the Plate

in the Initial (Annealed) Condition . . . . . . 13

4. An Enlargement of Figure 3 . . . . . . . . . . 14

5. Same Specimen as shown in Figures 3 and 4 , Reannealed ................ 16

6. $r_{\text {.cting Schedule for Plates to be Rolled . . . . . } 17}$

7. Photomicrog aphs of Specimens from the Cold

Worked Plates - Normal Etch . . . . . . . . 22

8. Photomicrographs of Specimens from the Cold

Worked Plates - Special Etch . . . . . . . . 23

9. Least Squares Plots of $\mathrm{L} / \mathrm{H}$ Values versus

Perr snt Cold Working ............. 26

10. Cutting Schedule for Plates for Further Study . . . . 28

11. A Typical Series of Microhardness Readings

Taken on One of the Micro Specimens

(50\% Cold Work) . . . . . . . . . . . . 30

12. Plot of Average DPH Values versus Percent

Cold Work . . . . . . . . . . . . . . . 32 
13. Plot of Conductivity (\% IACS) versus Resistivity $(\mu \Omega-\mathrm{cm})$. . . . . . . . . . 42

14. The Apparatus Used to Measure D.C. Resistivity . . . 45

15. The Four-Terminal Technique . . . . . . . . . . 47

16. Close-up of the Resistivity Fixture . . . . . . . . 49

17. A Tensile Specimen in the As-Rolled Condition . . . . 58

18. A Tensile Specimen After Polishing . . . . . . . 59

19. Plot of Average Resistivity/Conductivity versus

Percent Cold Work for the As-Rolled

Specimens . . . . . . . . . . . . . . 62

20. Plot of Average Resistivity/Conductivity versus

Percent Cold Work for the Polished

Specimens .................. 69

21. A Typical Load versus Strain Plot with Resulting

Measured Quantities ............. 76

22. Tensile Specimens - Gaged and Ungaged . . . . . . . 79

23. The Wheatstone Bridge . . . . . . . . . . 80

24. The Testing Wachine used for the Mechanical

Property Tests . . . . . . . . . . . . 82

25. Close-Up of the Tensile Specimen and Grips . . . . . 84

26. Plot of the Average Tensile Strength versus

Percent Cold Work ................ . 93

27. Plot of the Yield Strength at .2\% Offset versus

Percent Cold Work . . . . . . . . . . . . 94 
28. Plot of the Yield Strength at $1 \%$ Extension versus Percent Cold Work ............ 95

29. Plot of the Modulus of Elasticity versus Percent Cold Work . . . . . . . . . . . 96

30. Plot of the Energy to $1 \%$ Strain versus Percent Cold Work . . . . . . . . . . . 97

31. A Reflection-Type Probe in the Presence of a Conductor ................ 107

32. Block Diagram of the Phase Sensitive Eddy Current Instrument . . . . . . . . . . 108

33. Simplified Diagram for an Eddy Current Reflection-Type Probe . . . . . . . . . . . 111

34. Phase Shift due to a $5 \%$ Conductivity Variation, and Percent Error Due to Lift-Off versus "M" Value . . . . . . . . . . . . . . . 113

35. The Reflection-Type Eddy Current Probe Coil Above a Two Conductor Plane . . . . . . . . . 117

36. The Specimens Used for the Eddy Current Tests.................... . 119

37. Measurement Locations for the Measurements on the Three-inch Square Plates .......... 122

38. Plot of Eddy Current Phase Shift versus Percent Cold Work at 50 and $500 \mathrm{KHz}$. on the Unpolished Surface of the Three-inch Square Plates . . . . . . . . . . . . . 124 
39. Plot of Eddy Current Phase Shift versus Percent Cold Work at 50 and $500 \mathrm{KHz}$. on the Polished Surface of the Three-inch Square Plates . . . . 125

40. Plot of $\phi_{\sigma}$ and $\phi_{\mu}$ as Calculated from Data for the Three-inch Square Plates versus Percent Cold Work (Unpolished Surface) . . . . . . . . . . . . . 130

41. Plot of $\phi_{\sigma}$ and $\phi_{\mu}$ as Calculated from Data for the Three-inch Square Plates versus Percent Cold Work (Polished Surface) . . . . . 131

42. Plot of Phase Shift due to Conductivity versus Average Resistivity (Unpolished Surface) . . . . 135

43. Plot of Phase Shift due to Conductivity versus Average Resistivity (Polished Surface) . . . . 136

44. Plot of the Phase Shift versus Percent Cold Work for 50 and $500 \mathrm{KHiz}$. on the Large Tensile Specinens............. 138

45. Plot of the ${ }^{\phi_{\sigma}}$ and $\phi_{\mu}$ versus Percent Cold Work for the Large Tensile Specimens . . . . . . 145

46. Plot of the Phase Shift due to Conductivity versus Average Resistivity for the Large Tensile Specimens . . . . . . . . . . 146

47. The Calculator System . . . . . . . . . . 166 48. A Simplified Block Diagram of the Testing Machine System ................ 171 


$$
\text { xiv }
$$

$\begin{array}{ll}\text { FIGURE PAGE } & \text { PAG }\end{array}$

49. The Delta Function ............... 173

50. A Sample Printout from the Computer . . . . . . . 175 
CHAPTER I

INTRODUCTION

Cold worked stainless steels have been utilized for many years in applications where the corrosion resistant properties of these steels were needed along with higher strengths than would be obtained from the material in the annealed condition. The use of 316 stainless steel in nuclear reactor construction and development has been fairly extensive in the past few years due to its excellent corrosion resistance, and it has been determined that cold working the material by $20-30 \%$ produces the properties desired for applications involving small bore tubing. Recently it has also been shown that cold worked 316 stainless steel is less sensitive to void formation than some steels, such as 304 or $304 \mathrm{~L}$, under intense nuclear irradiation such as would occur in a reactor environment (Straalsund and Brager, 1971). With such extensive usage of cold worked stainless steel, more informative mechanical property data for various degrees of cold working is needed (Taylor, 1961). Such measurements have been performed with a precision heretofore unavailable, because these tests were performed on a computerized testing machine system which allowed measurements of strengths and other quantities to a precision of greater than .2-.3\%. Overa11 accuracy of the measurements is estimated to be on the order of $1 \%$. With such extensive usage of this cold worked material, methods should be available to verify the degree of cold working in the material. We would prefer such methods to be non-destructive in nature so that the tubing or other items could be inspected in the finished condition after 
all machining, bending, or other operations have been performed. With this objective in mind, investigations have been made to perform electrical conductivity measurements on the cold worked 316 stainless steel in order to attempt to correlate eddy current response with conductivity, and thus also to the degree of cold working. The latter correlation should be il, evidence, because cold work raises the strength and decreases the conductivity due to generation of new lattice defects, or imperfections, such as vacancies and intersitial atoms, as well as dislocations (Stanley, 1963). The transformation from austenite (gamma phase to martensite (alpha phase) as the material is cold worked also con1 ibut s somewhat to this change in conductivity. Also, the material should have a preferred crystal orientation as it is cold worked, and hence the anisotropy of resistivity or conductivity should increase as the amount of cold working is increased. In order to verify and to add substance to the eddy current measurements, direct current resistivity measurements have also been made on the cold worked material, both parallel and perpendicular to the rolling directions. A change in resistivity of from $1.5 \%$ to $2.7 \%$ for a corresponding change of $50 \%$ cold work was noted for two different measurement series in the parallel direction. No appreciable difference was noted between results taken perpendicular to rolling and those taken parallel to rolling. A change in tensile strength of approximately $6.5 \%$ was in evidence over the same range of cold working. 
INITIAL CHARACTERIZATION AND COLD WORKING

OF THE 316SS PLATE

\section{Plate Specifications and Initial Characterization}

Initially, in order to correlate these test results with others which had been performed, material of a particular chemical analysis was desired. This desired analysis is given in Table I. A1so shown in the table is the vendor supplied chemical analysis, and the results of the chemical analysis performed at $\mathrm{Y}-12$, of the plate which was procured for this study.

As can be seen from the table, all of the vendor data lie well within the tolerances allowed, as are the $\mathrm{Y}-12$ measurements except for one nickel measurement. This measurement was repeated, which is the second given, and obviously the second measurement listed does verify the vendor data.

The plate was obtained from Sandmeyer Steel Company, Philadelphia, Pennsylvania, and was from heat number 114682 . The plate size was approximately 86 inches long, by 61 inches wide and 5/16 of an inch thick. This thickness was specified so as to allow a $50 \%$ reduction and still have at least $1 / 8$ of an inch of material thickness, and the size was chosen to allow adequate material for this and future studies. Mechanical property results, as reported by the vendor are given in Table II.

No attempt is made in this table to report any sort of accuracies, for none were reported by the vendor, but it is expected that the tensile 
TABLE I

CHEMICAL ANALYSES OF TIE 316SS PLATE

\begin{tabular}{|c|c|c|c|}
\hline \multirow[b]{2}{*}{ Element } & \multicolumn{3}{|c|}{ Weight Percentage } \\
\hline & Desired & Vendor Results & Y-12 Results \\
\hline Carbon & $.04-.06$ & .047 & .0645 \\
\hline Manganese & $1.00-2.00$ & 1.67 & 1.73 \\
\hline Phosphorus & $.03 \max$ & .025 & .029 \\
\hline Sulfur & $.03 \max$ & .017 & .016 \\
\hline Silicon & $.75 \max$ & .41 & .386 \\
\hline Nickel & $12-14$ & 12.50 & $10.83 / 12.20$ \\
\hline Chromium & $16-18$ & 17.50 & 17.62 \\
\hline Molybdenum & $2-3$ & 2.65 & 2.715 \\
\hline Copper & $.2 \max$ & 0.15 & 0.0573 \\
\hline Cobalt & $.1 \max$ & 0.12 & 0.10 \\
\hline Boron & $.001 \max$ & a & $\mathrm{a}$ \\
\hline Nitrogen & $.02-.03 \max$ & a & .045 \\
\hline Iron & Balance & a & $\mathrm{a}$ \\
\hline
\end{tabular}

a Not measured. 
TABLE II

VENDOR MECHANICAL PROPERTY

RESULTS

\begin{tabular}{|c|c|}
\hline Quantity & Value \\
\hline Tensile Strength (psi) & 82,581 \\
\hline $\begin{array}{l}\text { Yicld Strength (psi) } \\
\text { (assumed } .2 \% \text { offset) }\end{array}$ & 37,097 \\
\hline $\begin{array}{l}\text { Percent Elongation } \\
\text { (assumed in } 2 \text { inches) }\end{array}$ & 62 \\
\hline Percent Reduction in Area & 71 \\
\hline $\begin{array}{l}\text { Hardness } \\
\quad \text { (assumed Rockwel1-B) }\end{array}$ & $75-77$ \\
\hline
\end{tabular}


and yield strengths should not have been reported to more than three significant figures. Note also that the specific type of yield strength, percent elongation and hardness measurement was not given, but the author has inferred the type they must have been, and these are listed.

The American Society for Metals (ASM) Metals Handbook (Taylor, 1961) lists properties for annealed 316 stainless steel as shown in Table III. Obviously the plate would seem to have been in the fully annealed condition if one is to believe the vendor supplied data. These mechanical property results were remeasured at $\mathrm{Y}-12$ in order to verify data prior to the study, for the annealed condition corresponds to the completely "unworked" state which served as the baseline for the study. These values are reported in Table IV. These mechanical properties results were measured from specimens taken from one corner of the plate, with the "L" specimens taken along the width of the plate (smallest dimension) and the "T" specimens taken perpendicular to the "L" specimens. Two $1 / 2$ inch square specimens for photomicrographic analysis and one specimen for the chemical analysis were also taken adjacent to the "T" specimens. The cutting schedule used is shown in Figure 1.

Specimens were taken perpendicular to each other to ascertain that the working from the rolling which the vendor undoubtedly had to perform had been removed by annealing. If this had not been the case, one would expect to see an anisotropicity in the mechanical properties; most notably, the tensile and yield strengths would be higher in the direction transverse to rolling. No such anisotropy exists, and from these data one would infer that the vendor was correct, and that the plate was in the annealed condition. The specimen utilized in these measurements is 
TABLE III

NOMINAL PROPERTIES FOR 316SS FROM

TIIE ASM METALS HANDBOOK

\begin{tabular}{|c|c|}
\hline Quantity & Value \\
\hline Tensile Strength (psi) & 85,000 \\
\hline Yield Strength a $.2 \%$ offset (psi) & 35,000 \\
\hline Percent Elongation & 55 \\
\hline Percent Reduction in Area & 70 \\
\hline \multicolumn{2}{|l|}{ Hardness } \\
\hline Rockwell B & 80 \\
\hline Brine11 & 150 \\
\hline $\begin{array}{l}\text { Izod Impact Strength (ft-1b) } \\
\text { (at room temperature) }\end{array}$ & $95-125$ \\
\hline Modulus of Elasticity $\left(\times 10^{6} \mathrm{psi}\right)$ & 28 \\
\hline Density $\left(\mathrm{gm} / \mathrm{cm}^{3}\right)$ & 8.00 \\
\hline Electrical Resistivity (microohm-cm) & 74 \\
\hline Magnetic Permeability & 1.003 \\
\hline
\end{tabular}


TABLE IV

INITIAL MECHANICAL PROPERTIES OF THE AS RECEIVED $316 S S$ PLATE

\begin{tabular}{|c|c|c|c|c|c|c|c|}
\hline $\begin{array}{l}\text { Specimen } \\
\text { Number }\end{array}$ & $\begin{array}{r}\text { Rockwel } \\
\text { Hardn } \\
\text { Average }^{2}\end{array}$ & $\begin{array}{l}1-B \\
\text { ess } \\
S^{C}\end{array}$ & $\begin{array}{c}\text { Tensile } \\
\text { Stręngth } \\
\left(\times 10^{3} \text { psi }\right)\end{array}$ & $\begin{array}{c}\text { Yield } \\
\text { Strength } \\
\text { a } .2 \% \text { offset } \\
\left(\times 10^{3} \text { psi }\right)\end{array}$ & $\begin{array}{l}\text { Parcent } \\
\text { Elongation } \\
\text { in } 1 \text { inch }\end{array}$ & $\begin{array}{l}\text { Percent } \\
\text { Reduction } \\
\text { in Area }\end{array}$ & $\begin{array}{l}\text { Modulus } \\
\text { of Elasticity } \\
\left(\times 10^{\circ} \text { psi) }\right.\end{array}$ \\
\hline$A-L-1$ & 81.9 & 1.56 & 84.2 & $\mathrm{~b}$ & 70 & 68 & $\mathrm{~b}$ \\
\hline 2 & 77.6 & 1.77 & 83.7 & $\mathrm{~b}$ & 68 & 64 & $\mathrm{~b}$ \\
\hline 3 & 79.2 & 0.75 & 83.3 & $\mathrm{~b}$ & 67 & 69 & b \\
\hline 4 & 78.9 & 0.97 & $\mathrm{~b}$ & 37.6 & b & $\mathrm{b}$ & 28.3 \\
\hline 5 & 77.6 & 0.49 & b & 37.2 & $b$ & $\mathrm{~b}$ & 28.8 \\
\hline Average & 79.0 & -- & 83.7 & 37.4 & 68.3 & 67.0 & 28.53 \\
\hline$s^{c}$ & 1.76 & -- & 0.451 & 0.200 & 1.53 & 2.65 & 0.252 \\
\hline$A-T-1$ & 79.8 & 1.33 & 83.7 & $a$ & 65 & 64 & $b$ \\
\hline 2 & 79.4 & 0.97 & 83.2 & $\mathrm{a}$ & 65 & 65 & $\mathrm{~b}$ \\
\hline
\end{tabular}


TABLE IV (continued)

\begin{tabular}{|c|c|c|c|c|c|c|c|}
\hline $\begin{array}{l}\text { Specimen } \\
\text { Number }\end{array}$ & $\begin{array}{r}\text { Rockwe } \\
\text { Hardn } \\
\text { Average }\end{array}$ & $\begin{array}{l}\text { ell-B } \\
\text { ness } \\
\operatorname{sic}^{c}\end{array}$ & $\begin{array}{c}\text { Tensile } \\
\text { Strȩngth } \\
\left(\mathrm{X} 10^{3} \text { psi }\right)\end{array}$ & $\begin{array}{c}\text { Yield } \\
\text { Strength } \\
0.2 \% \text { offset } \\
\left(\mathrm{X} 10^{3} \text { psi }\right)\end{array}$ & $\begin{array}{l}\text { Percent } \\
\text { Elongation } \\
\text { in } 1 \text { inch }\end{array}$ & $\begin{array}{l}\text { Percent } \\
\text { Reduction } \\
\text { in Area }\end{array}$ & $\begin{array}{l}\text { Modulus } \\
\text { of Elasticity } \\
\left(\times 10^{6} \text { psi) }\right.\end{array}$ \\
\hline$A-T-3$ & 78.9 & 1.07 & 83.2 & $\mathbf{a}$ & 64 & 62 & b \\
\hline 4 & 80.1 & 1.69 & b & 37.9 & b & b & 28.4 \\
\hline 5 & 79.5 & 1.30 & b & 37.7 & b & b & 28.4 \\
\hline Average & 79.5 & -- & 83.4 & 37.8 & 64.7 & 63.7 & 28.4 \\
\hline$s^{c}$ & .451 & -- & .289 & .100 & .577 & 1.53 & 0 \\
\hline
\end{tabular}

a Average of five readings per tensile specimen.

b These values were not determined - see text.

c Estimate of standard deviation. 


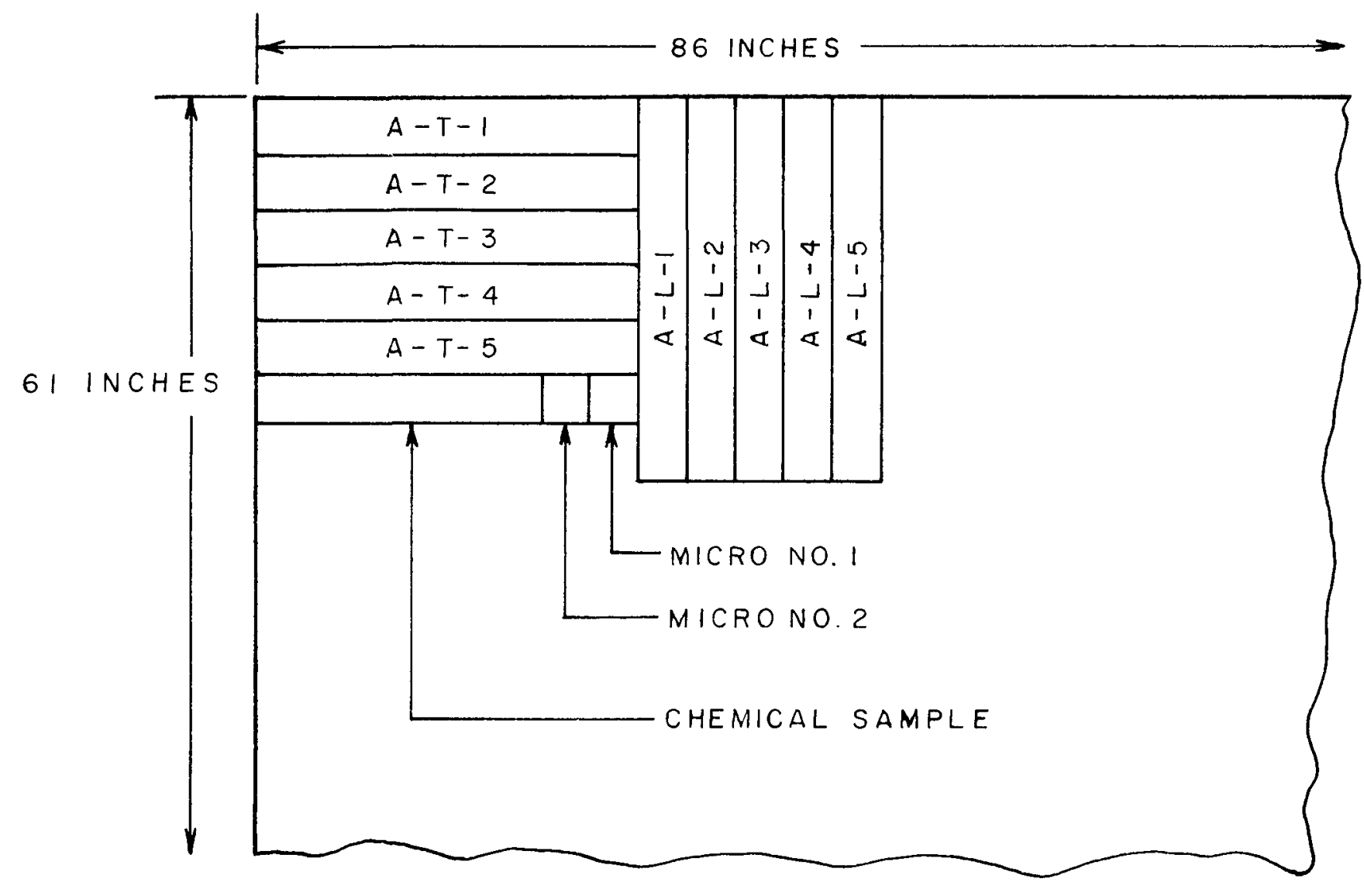

Figure 1. Corner of the 86 inch by 61 inch plate Showing Initial Sampling. 
shown graphically in Figure 2, and is a specimen which is commonly used in the laboratory. This specimen meets all requirements of The American Society for Testing and Materials (ASTM) Test Method E-8, Tensile Testing of Metallic Materials, except for the thickness, which this standard recommends to be less than $1 / 4$ inch. These specimens were $5 / 16$ inch thick, but it is not believed that this fact would influence test results in any manner. Three specimens of each group were tested on a 60,000 pound capacity Tinius-0lsen Hydraulic Testing Machine, Model Super-L, in order to determine tensile strength, percent elongation, and percent reduction in area. The other two were tested on an MTS Closed-Loop Electrohydraulic Testing Machine in order to determine yield strength and modulus of elasticity. Testing on both machines was done at a constant rate of crosshead movement of $0.05 \pm .01$ inches per minute, which is acceptable per ASTM Standard E-8. Strain was measured in the latter two by Micro-Measurements strain gages, type EA-06-250BB-120, cemented to the specimens with Eastman 910 adhesive, certified for strain gage use by Micro-Measurements. Both machines were calibrated prior to usage by standards traceable to the National Bureau of Standards (NBS) .

To further verify the annealed condition of the metal, photomicrographs were made of the aforementioned $1 / 2$ inch square specimen. Typical photographs are shown in Figures 3 and 4 . No large number of twins, slip plane lines or elongated grains are noted from either of these photographs, so that this evidence substantiated the belief that the plate was in the annealed condition.

As a further test of the annealed condition, the specimen as shown 


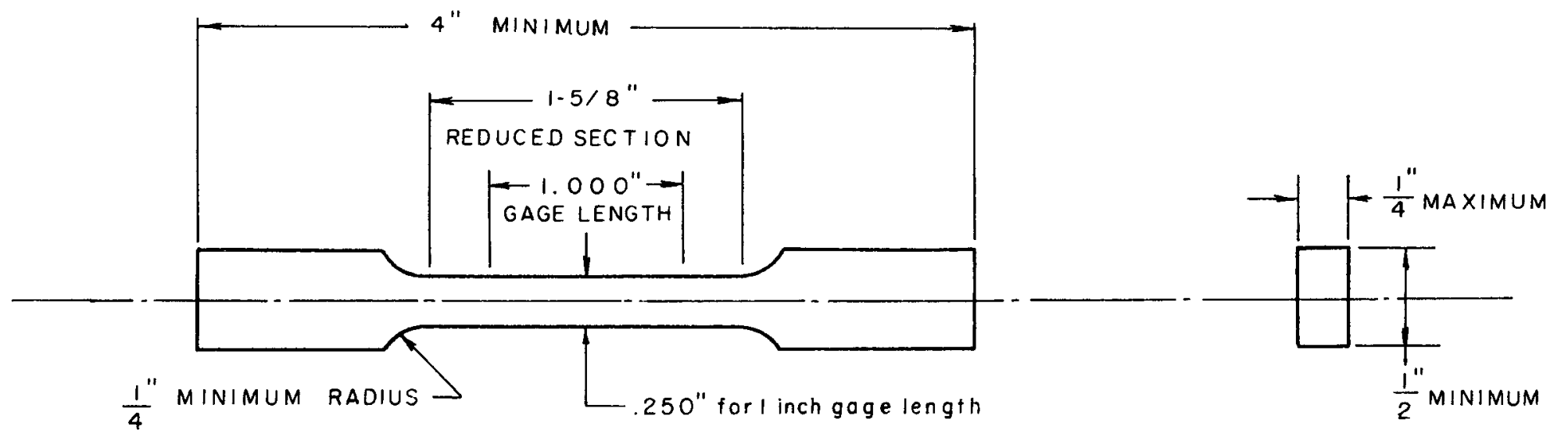

Figure 2. F1at Tensile Specimen Used for the Mechanical Property Tests. 


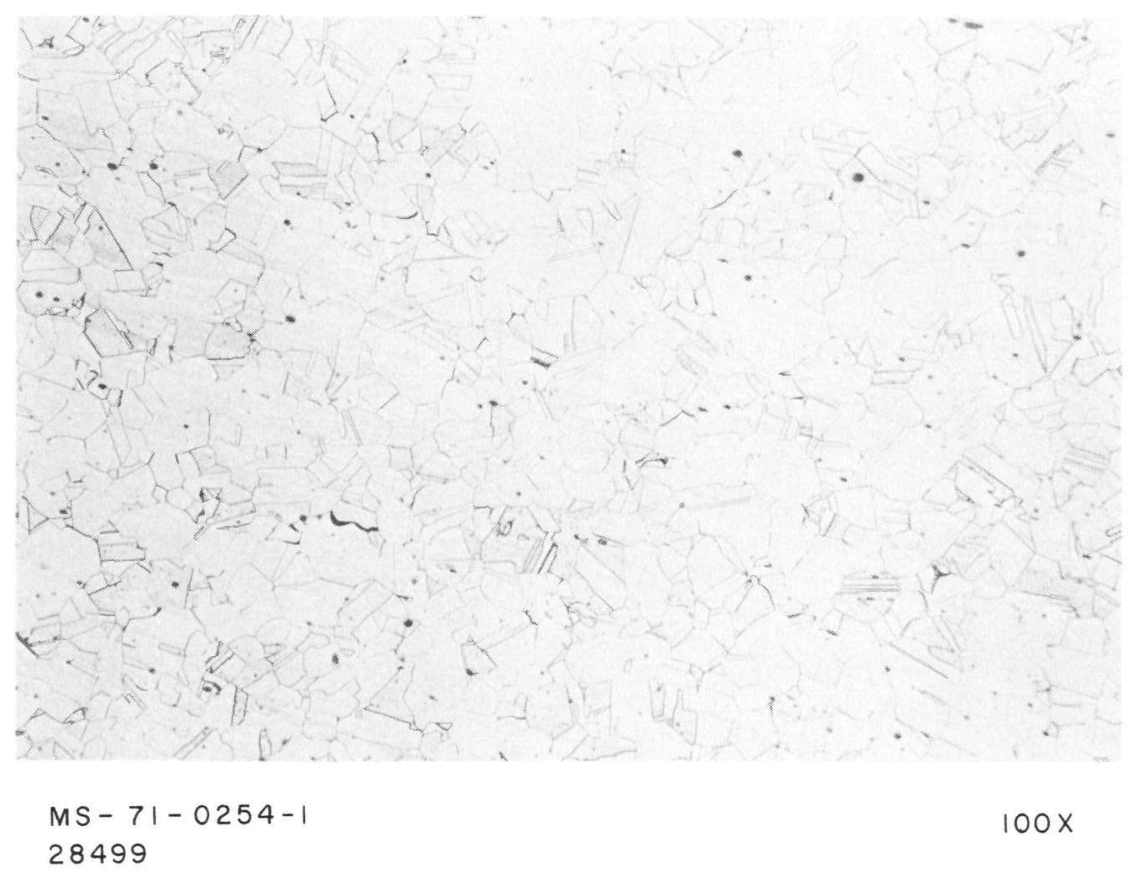

Figure 3. Photomicrograph of a Specimen from the Plate in the Initial (Annealed) Condition. 


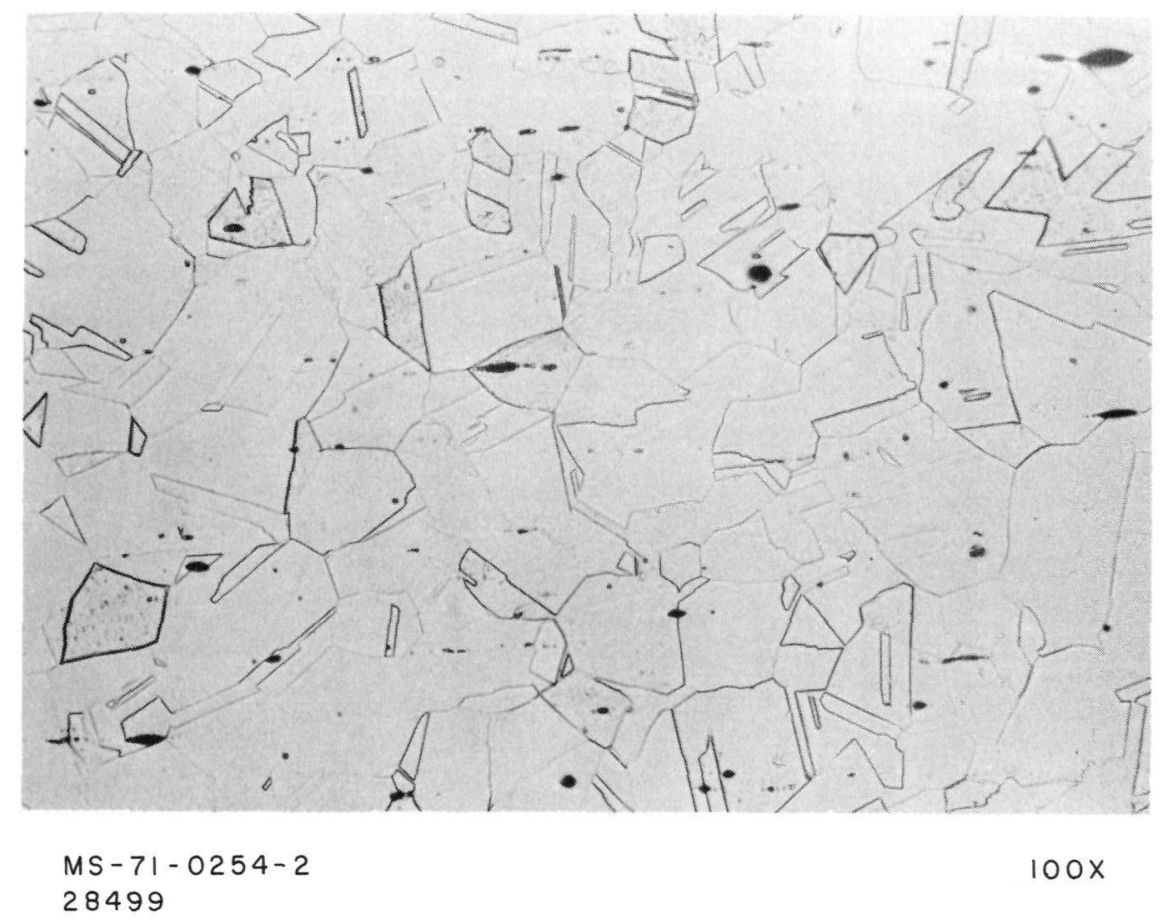

Figure 4. An Enlargement of Figure 3. 
in Figures 3 and 4 was re-annealed for $1 / 2$ hour at $1980^{\circ} \mathrm{F}$. and air cooled rapidly to prevent austenite transformation. This specimen was then repolished and photographed with the result shown in Figure 5. No appreciable difference between this photograph and Figures 3 and 4 is noted, so we may deduce that the plate was in the annealed condition.

\section{Cold Working}

After the annealed condition of the plate had been verified, it was cut up into 14 plates, approximately 12 inches wide by 30 inches long, which were small enough to fit into the rolling machine. The plates were numbered one through fourteen as depicted in Figure 6. Each was marked with an arrow to indicate the direction in which the cold working was to be performed and to assist in retaining the orientation within the plate. Plates one through seven were utilized in this study, the remainder being reserved for future study.

A total of three inches was cut off the end of each plate so as to retain a part of each one for a historical sample. Another photomicrographic specimen was also cut from opposite corners of plate numbers 2, 4 and 6 . Recall that plate number one had the tensile specimens, chemical analysis specimen and original photomicrographic specimens cut from it. The other tirce specimens were analyzed in much the same manner as the first two, and no further evidence of cold working was evident in the plate.

Micro-hardness of these photomicrographic specimens was also measured, and these values are presented in Table V. The extraordinarily 


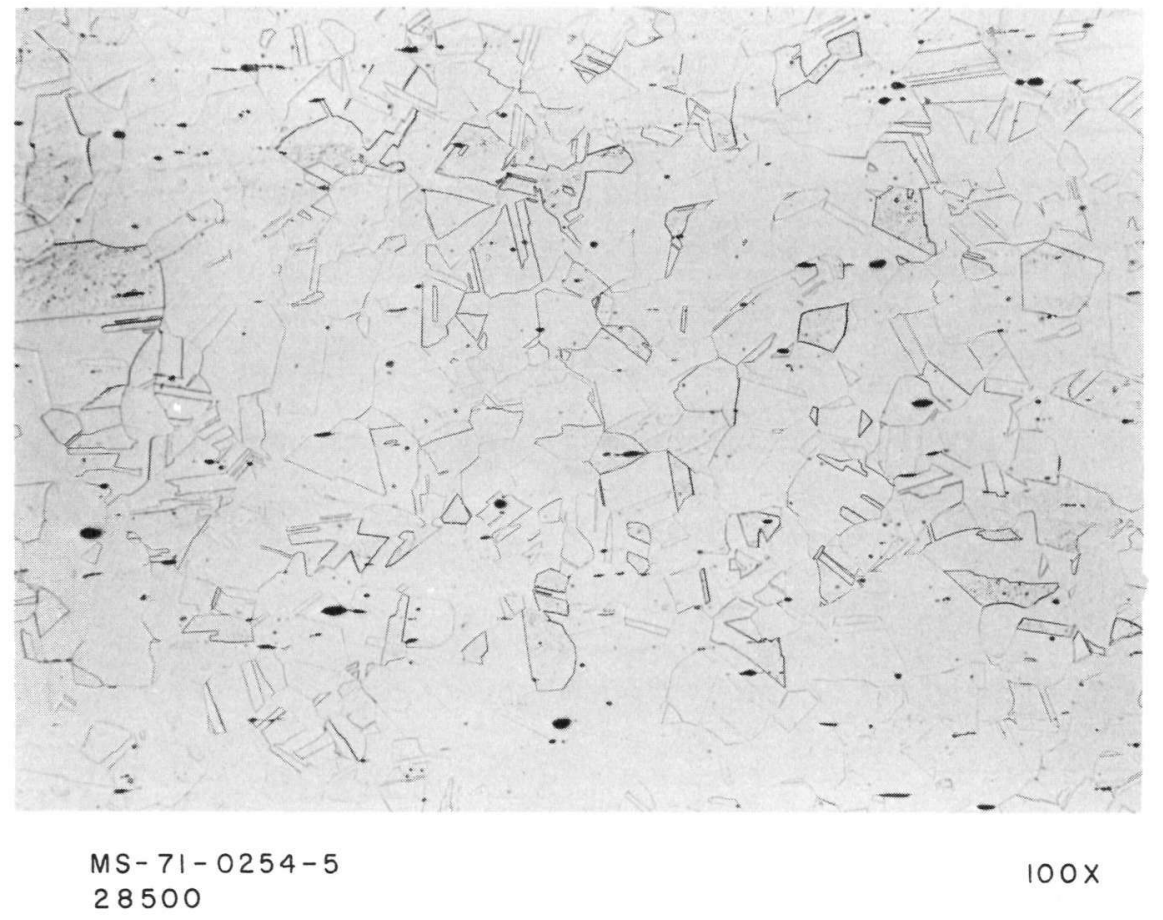

Figure 5. Same Specimen as shown in Figures 3 and 4 , Reannealed. 


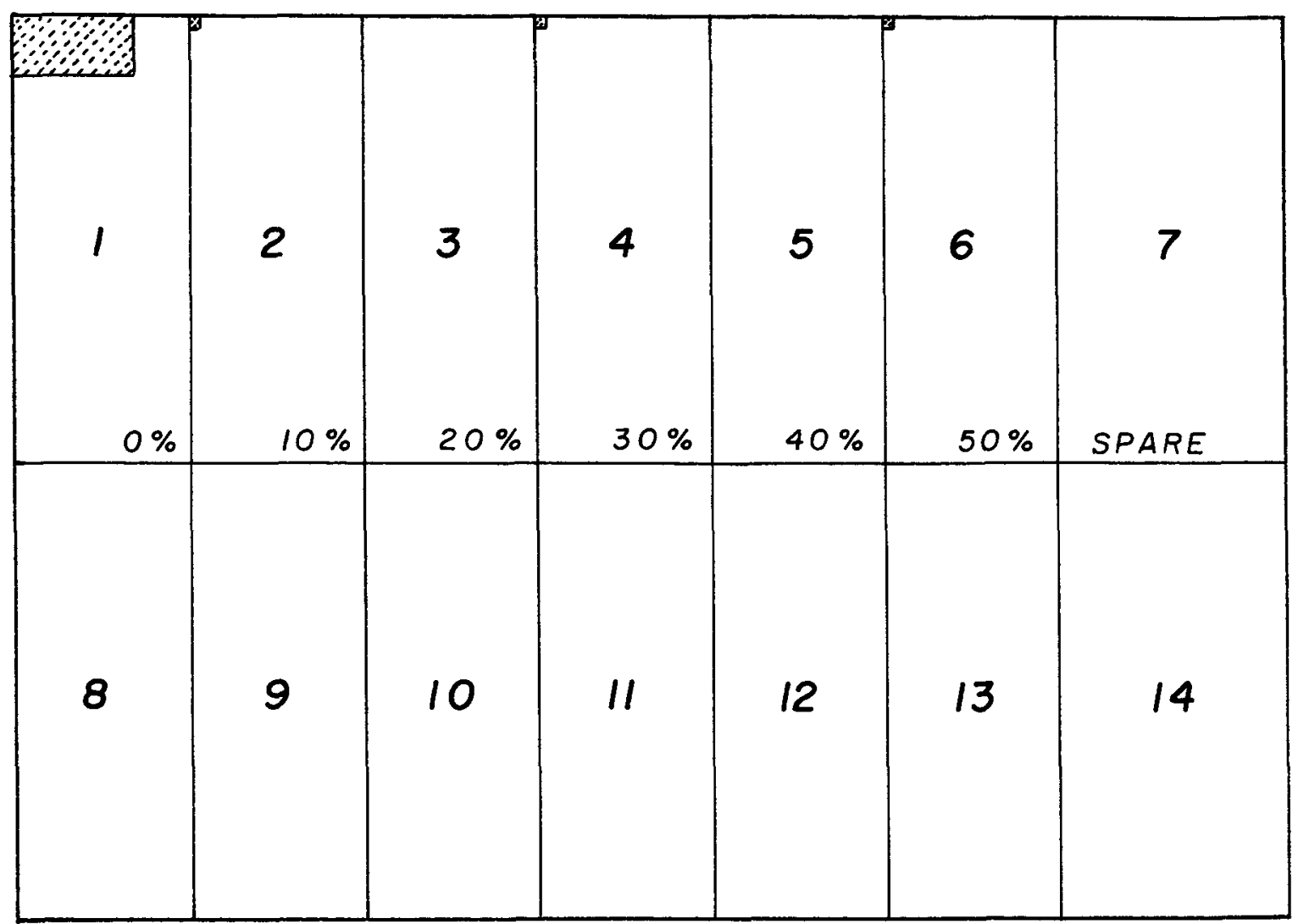

Figure 6. Cutting Schedule for Plates to be Rolled. 
TABLE $V$

MICROHARDNESS OF THE THREE PHOTOMICROGRAPHIC SPECIMENS

\begin{tabular}{ccc}
\hline $\begin{array}{r}\text { Plate } \\
\text { Number }\end{array}$ & $\begin{array}{c}\text { DPH } \\
\text { Hardness } \\
\text { (Average) }\end{array}$ & $\begin{array}{c}\text { Approximate } \\
\text { Rockwel1-B } \\
\text { Hardness }\end{array}$ \\
\hline 2 & 154 & 79 \\
4 & 337 & 107.5 \\
6
\end{tabular}

NOTE: Tests were performed with a diamond pyramid indentor with a $1 \mathrm{Kg}$. load and $20 \mathrm{x}$ objective. 
high value in evidence for plate number four was believed to be due to the specimens being taken from an area of the plate which had been extremely cold worked on the edge where the metal shear had deformed the plate when it was cut. The Rockwell-B hardness of the plate itself was measured over the entire surface of the plate and no such further high hardncss values were measured.

Cold working was performed on a rolling machine in the Development Division of $\mathrm{Y}-12$. Al1 plates were rolled in the direction of the arrow on the plates for the initial rolling, and the direction was rotated $180^{\circ}$ from that for alternate rolling passes. On the plates with higher degrees of cold working, several passes were necessary in order to achieve the desired anount of cold working, and it was necessary to alternate the direction to prevent the plates from curling, though there was some problem with this in the end. Unfortunately, the total number of passes for each plate was not recorded at the time, nor was the amount that the plate thiclness was reduced on each pass. It is not believed that either of tiese omissions would detract from the results of this stlicy. Tho original thickness of cach plate, alon: with the degree of cold working desired, the desired final thickness and the actual final thickness is shown in Table VI. Another factor not recorded at the time of rolling was the temperature of the plates immediately after rolling. As the anount of cold working increased, the plates became quite hot to the touch, though it is not believed that this temperature ever exceeded 250 to $300^{\circ} \mathrm{F}$. Again this factor should not bo of any consequence to this study. Identity of each plate was carefully retained throughout the rolling operation. The amount of cold working 
TABLE VI

PLATE THICKNESS MEASUREMENTS AFTER COLD WORKING

\begin{tabular}{cccccc}
\hline $\begin{array}{c}\text { Plate } \\
\text { Number }\end{array}$ & $\begin{array}{c}\text { Initial } \\
\text { Thickness } \\
(\text { inch })\end{array}$ & $\begin{array}{c}\text { Desired } \\
\text { Degree of } \\
\text { Cold Work } \\
(\%)\end{array}$ & $\begin{array}{c}\text { Final } \\
\text { Desired } \\
\text { Thickness } \\
(\text { inch })\end{array}$ & $\begin{array}{c}\text { Actual } \\
\text { Final } \\
\text { Thickness } \\
\text { (inch) }\end{array}$ & $\begin{array}{c}\text { Actual } \\
\text { Degree of } \\
\text { Cold Work } \\
(\%)\end{array}$ \\
\hline 1 & 0.329 & 0 & 0.329 & 0.329 & 0 \\
2 & 0.332 & 10 & 0.299 & 0.304 & 8.5 \\
3 & 0.337 & 20 & 0.270 & 0.278 & 17.5 \\
5 & 0.342 & 30 & 0.240 & 0.236 & 30.9 \\
6 & 0.341 & 40 & 0.205 & 0.205 & 40.0 \\
7 & 0.336 & 50 & 0.168 & 0.171 & 49.0 \\
\hline
\end{tabular}


performed was also recorded on each plate, but this could always have been verified by thickness measurements.

After cold working was completed, the plates were again sampled for photomicrographic analysis in order to determine some measure and visual indication of the degree of cold work. These photomicrographs are shown in Figure 7 . These photographs show the increase in both the degree of grain elongation or orientation along the direction of rolling and the number of slip plane lines which are evident within these grains. These photomicrographs were taken from specimens which had been etched and polished in the normal manner which is used in the laboratory for such material. In order to make the grain boundaries of the material more visible without showing these slip planes, a chemical etching procedure was developed which would etch the grain boundaries without etching the slip plane lines. The etch utilized was an electrolytic etch with a solution of $80 \%$ concentrated $\mathrm{HNO}_{3}$ and $20 \%$ water. A stainless steel cathode was used and a voltage of one volt was used for one minute. Photomicrographs taken of the specimen after they had been etched in this manner are shown in Figure 8.

As another measure of the degree of cold working which the material had undergone, average length-to-height ratios of the grains were determined from the photographs as depicted in Figure 8 . These measurements were performed on the calculator and digitizer system outlined in Appendix B. A total of twenty grains were measured at random from each photograph. As this length-to-height ratio is a dimensionless quantity, it should be independent of the size of the grain being measured and the magnification of the photograph. The averages of these readings are 
22

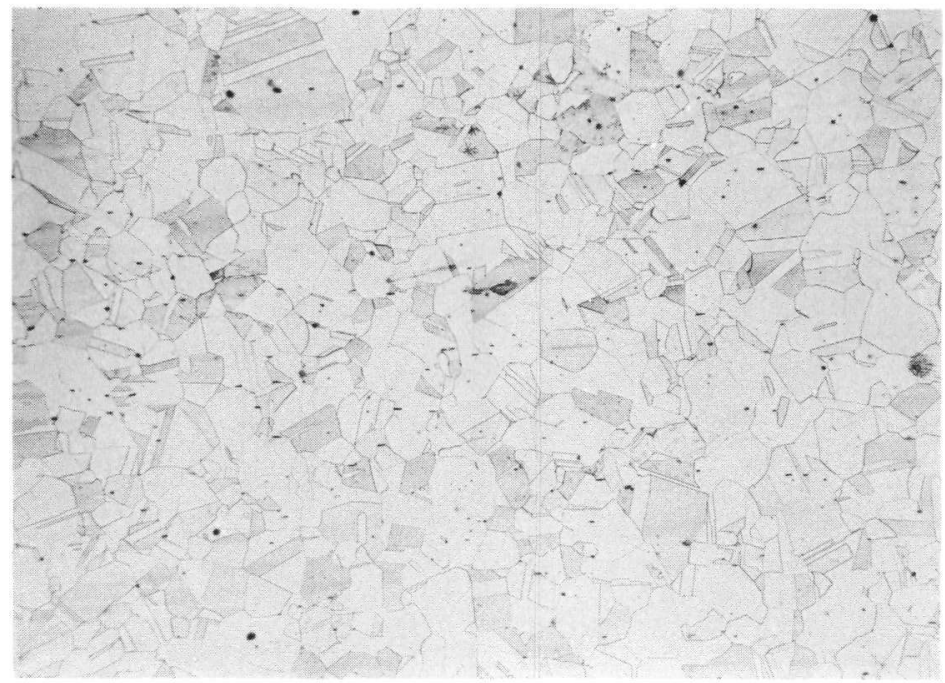

MS- $-71-0568-6$
$100 x$

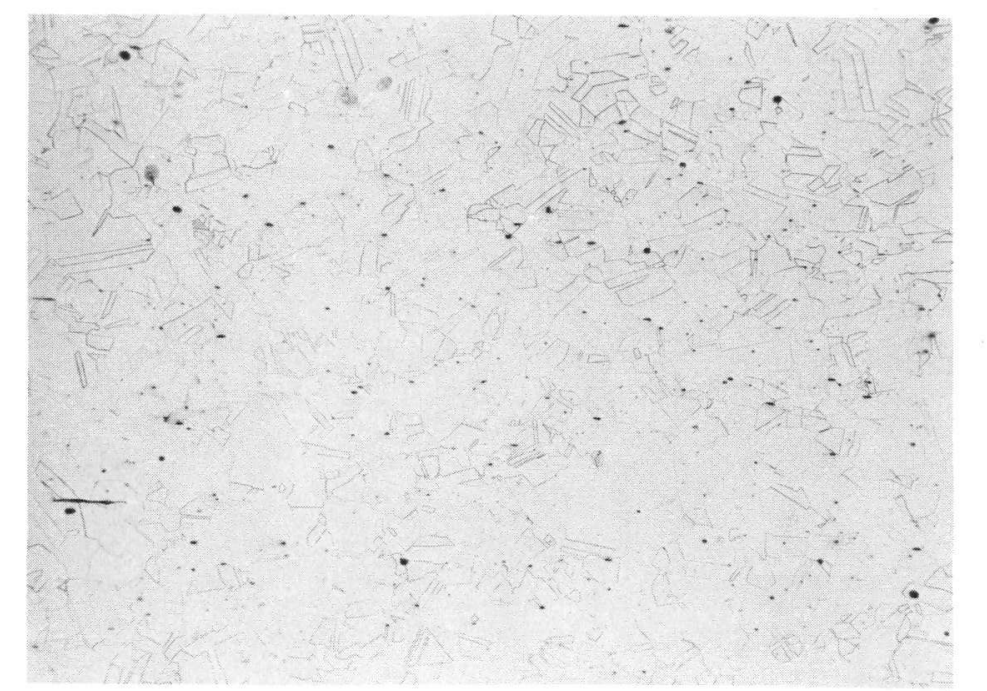

MS-71-0568-1

$100 x$

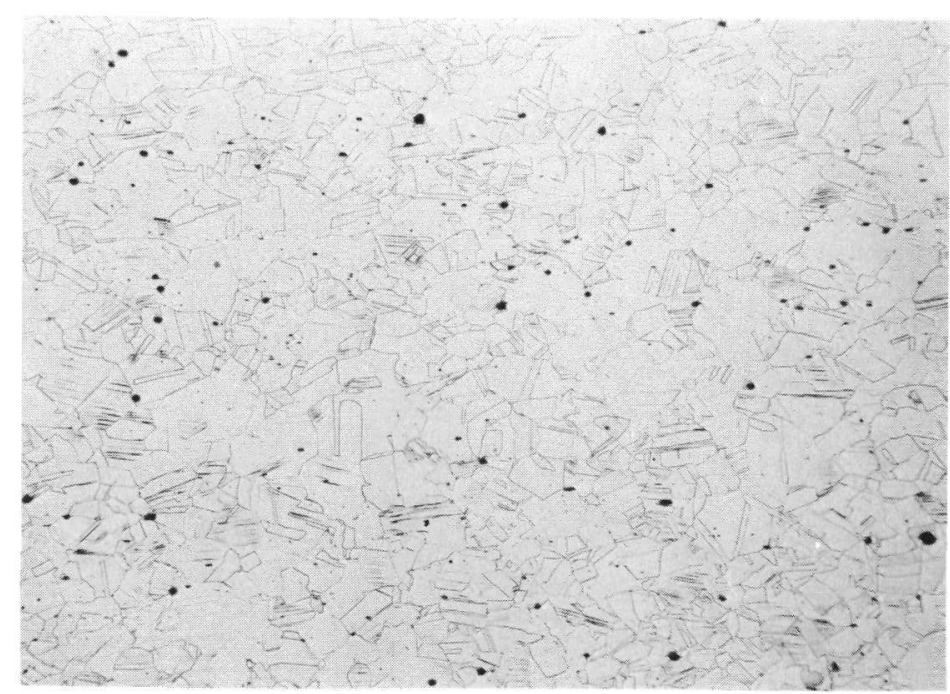

MS- $-71-0568-2$
29126

$100 x$

Plate $3-20 \%$ Cold Work.

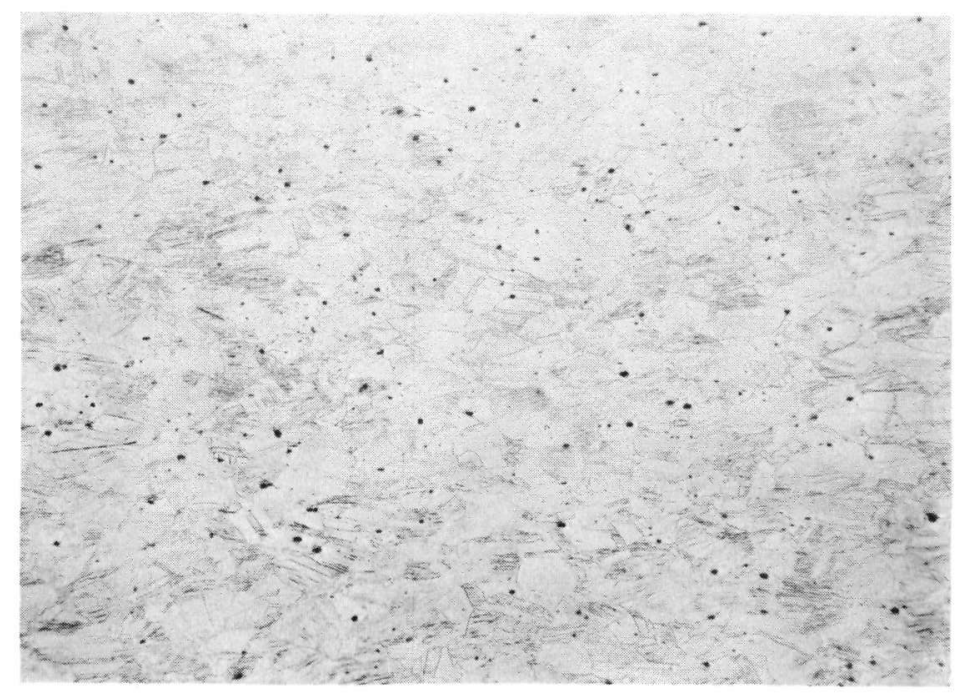

MS- $-71-0568-4$

$100 x$

MS- 71-0568-3

$100 x$

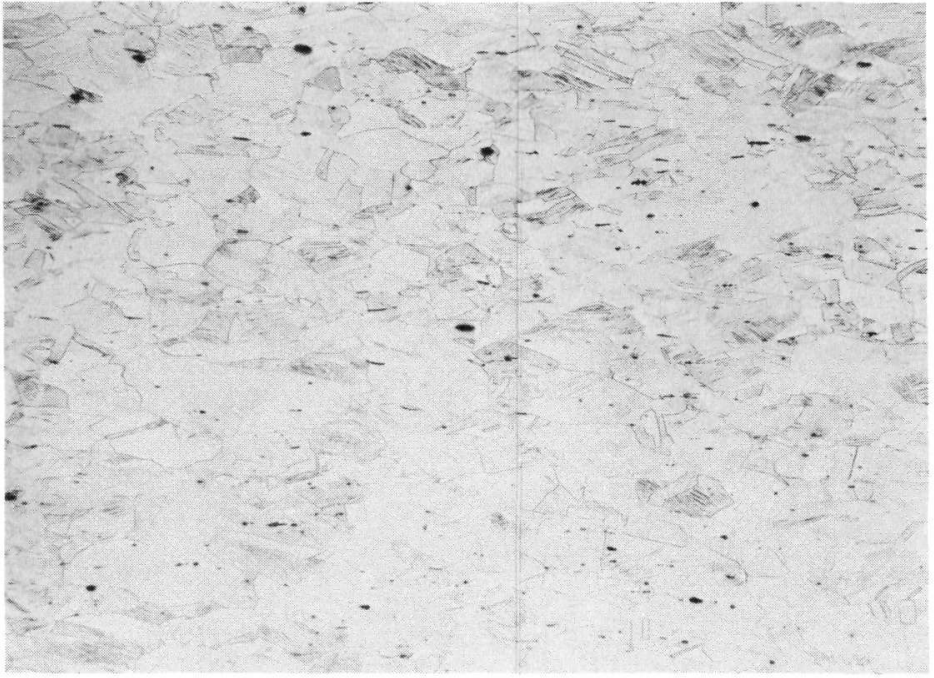

Plate $4-30 \%$ Cold Work.

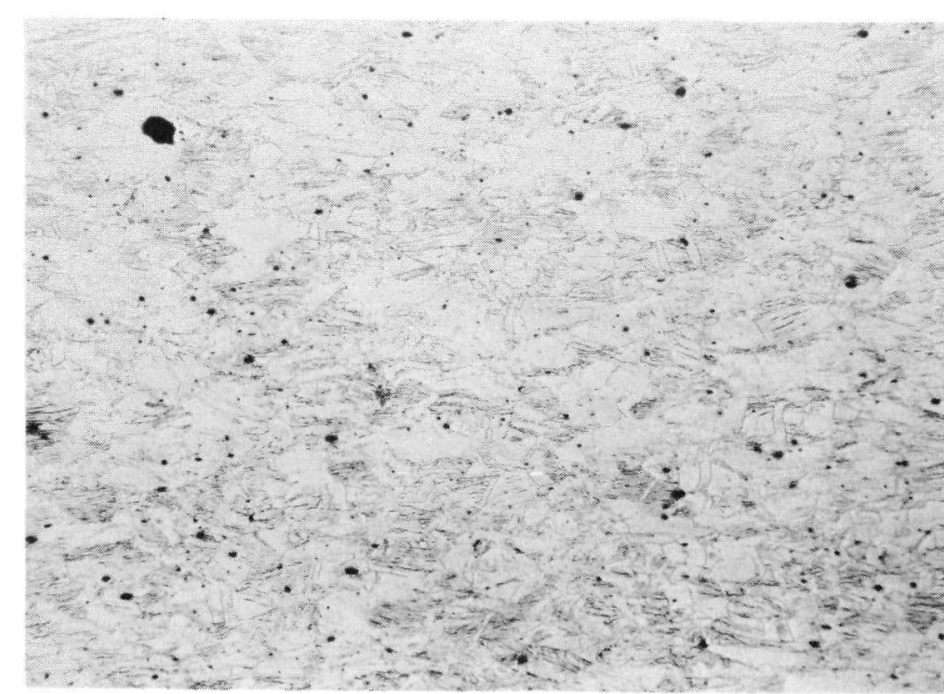

MS-71-0568-5 $100 x$

Plate $6-50 \%$ Cold Work.

Figure 7. Photomicrographs of Specimens from the Cold Worked Plates - Normal Etch. 


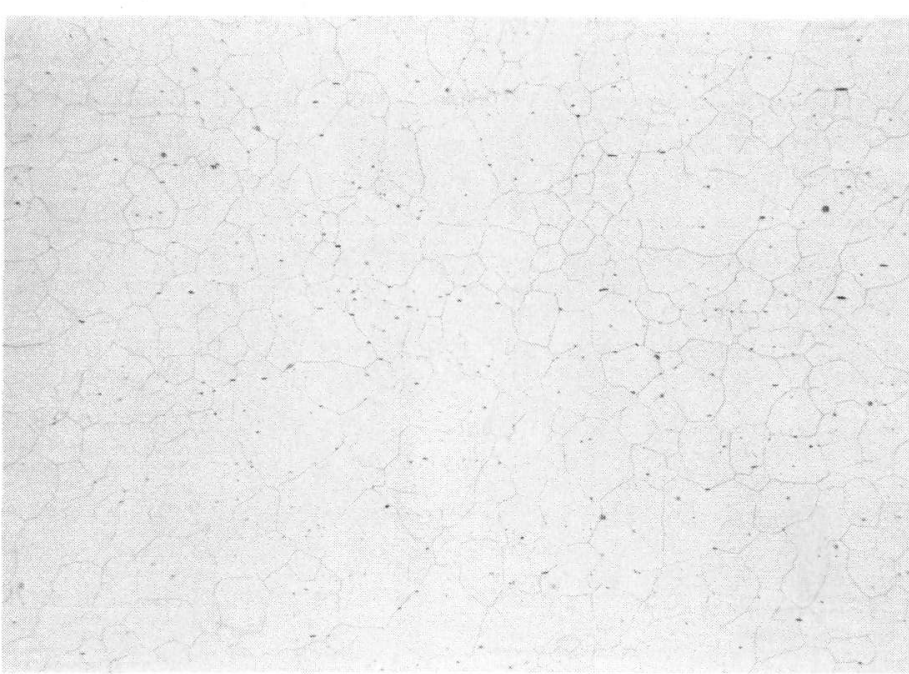

$M S-71-0$
29130

$100 x$

Plate 7 - Annealed.

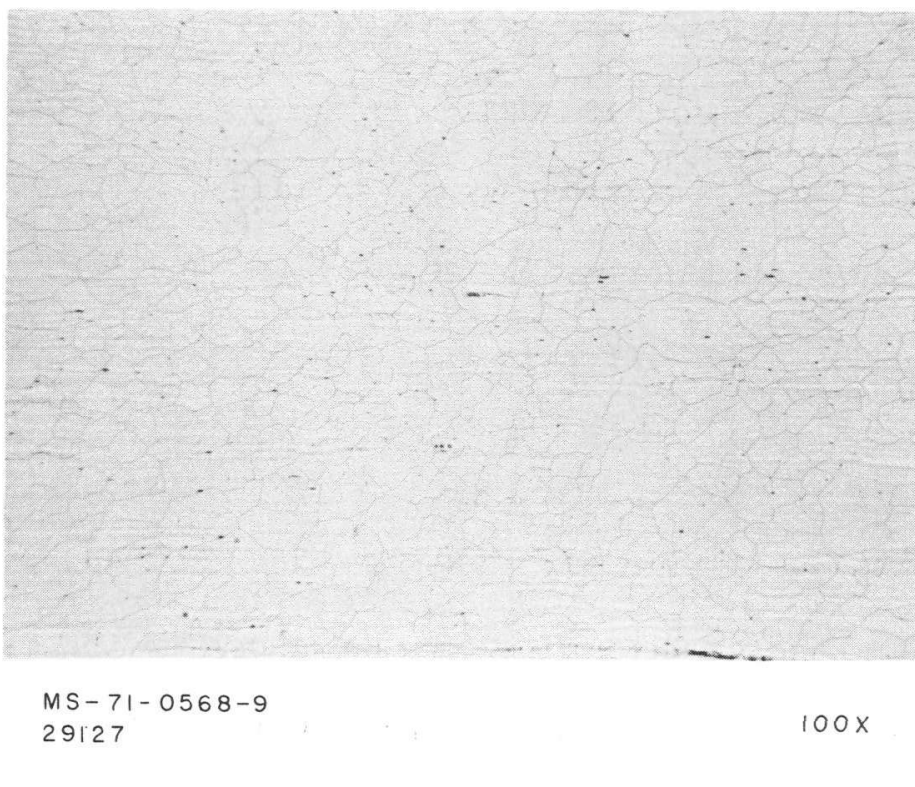

Plate 4-30\% Cold Work.

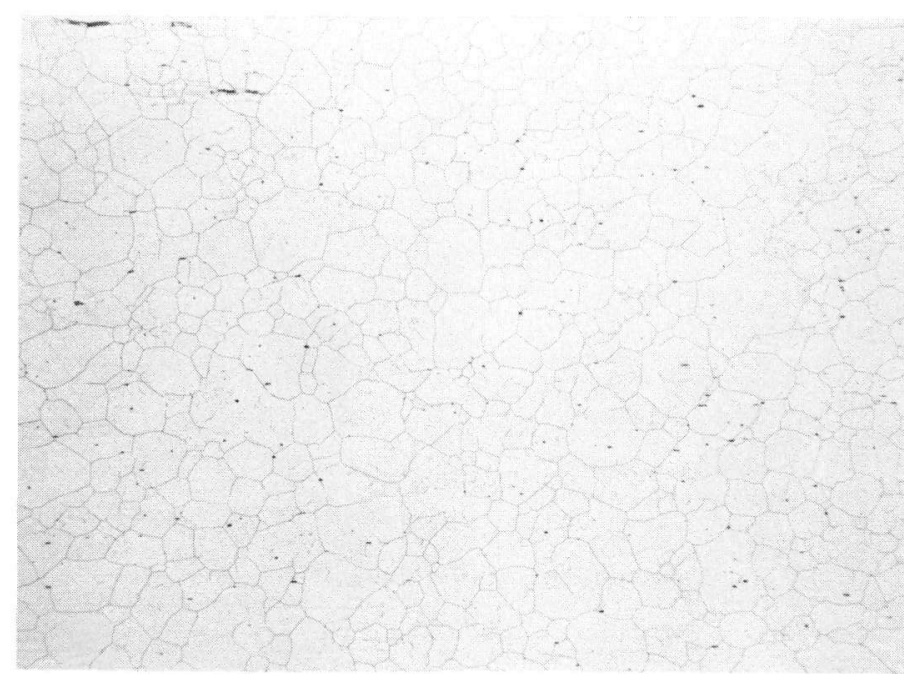

MS - 71- 0568-7
29125

Plate $2-10 \%$ Cold Work.

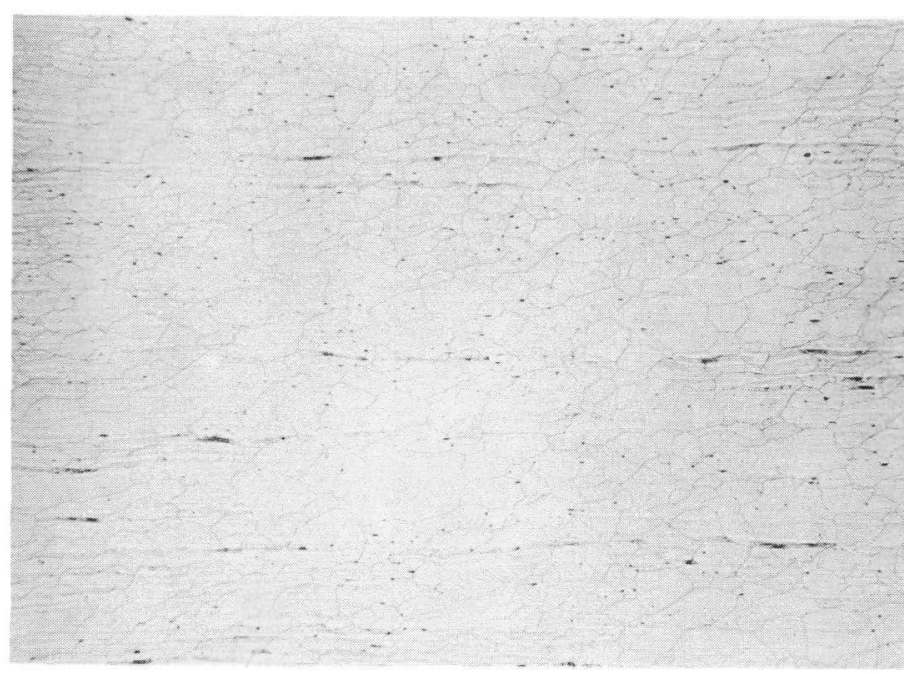

MS - 71- $0568-10$ $100 x$

Plate $5-40 \%$ Cold Work

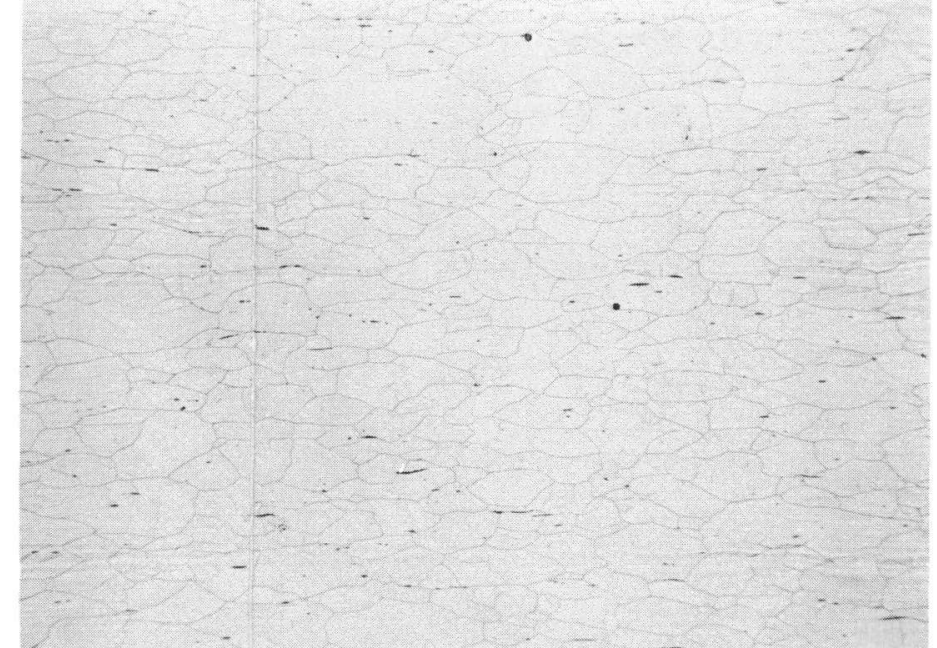

MS- $71-0568-8$
29126

$100 \times$

Plate $3-20 \%$ Cold Work

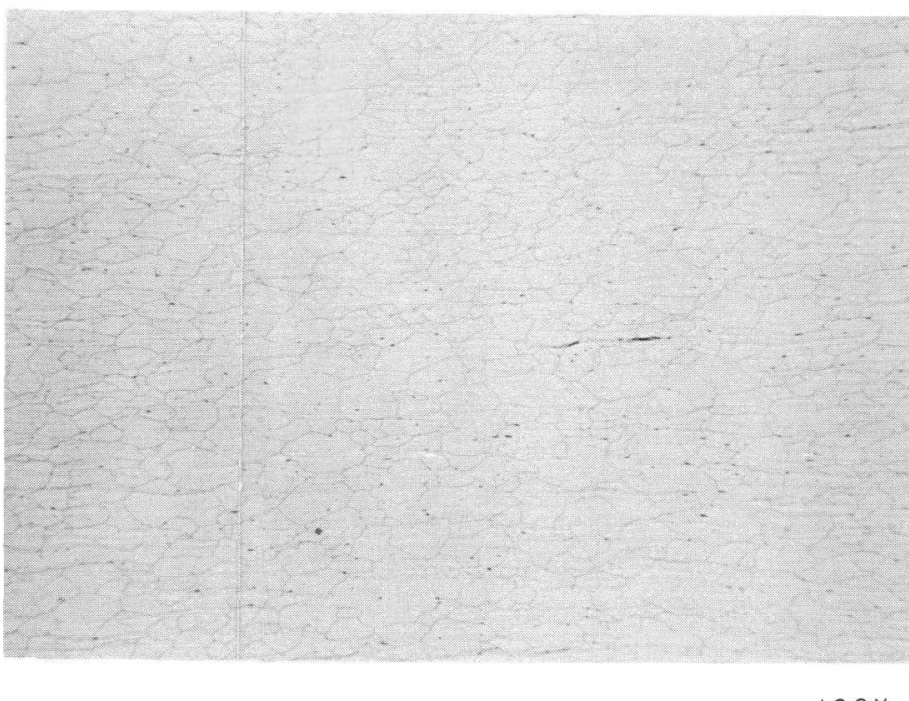

$M S-71-0568-11$
29129

$100 x$

Figure 8. Photomicrographs of Specimens from the Cold Worked Plates-Special Etch. 
given in Table VII, along with the degree of cold working in each plate as determined by thickness measurements which were reported in Table VI, on page 20. A graphical plot of these data is shown in Figure 9. Depicted in the figure are two least squares plots of the data, a straight line and a second order polynomial (parabolic) function, and the functions calculated via these methods are given in Table VIII. Calculations and plotting were performed on the aforementioned calculator.

As can be seen from the figure, and as is also indicated by the correlation coefficient in Table VIII, the straight 1 ine does not fit the data well at all, but the parabola does fit very well.

\section{Plate Sampling for Further Tests}

After all initial sampling of the individually cold worked plates had been completed, each plate was cut up into specimens as depicted in Figure 10. The testing and analyses of data from these specimens will comprise the remainder of this thesis.

The results from the microanalysis specimens have been described previously and the remainder of these specimens and the tests performed on them will be described later in this report.

Microhardness Measurements of the Cold Worked Plates

The specimens as previously shown in Figures 7 and 8 on pages 22 and 23 were also used to determine microhardness of the material in the cold worked condition. These measurements were performed using a diamond pyramid indentor with $1 \mathrm{Kg}$ load and $20 \mathrm{x}$ objective, as were the previous measurements reported in Table $\mathrm{V}$, on page 18. A total of ten readings were taken across each specimen, as depicted in Figure 11, which is a 
TABLE VII

GRAIN LENGTH-TO-HEIGIT RATIOS FOR

VARIOUS DEGREES OF COLD WORKING

\begin{tabular}{cccc}
\hline Number & $\begin{array}{c}\text { Percent } \\
\text { Cold Work }\end{array}$ & $\begin{array}{c}\text { L/H } \\
\text { Ratio }\end{array}$ & $\mathrm{s}^{\mathrm{a}}$ \\
\hline 7 & 0 & 1.21 & .399 \\
2 & 8.5 & 1.26 & .309 \\
3 & 17.6 & 1.47 & .432 \\
4 & 30.9 & 1.83 & .619 \\
5 & 40.1 & 2.13 & .522 \\
6 & 49.0 & 2.44 & .519 \\
\hline
\end{tabular}

a Estimate of the standard deviation. 


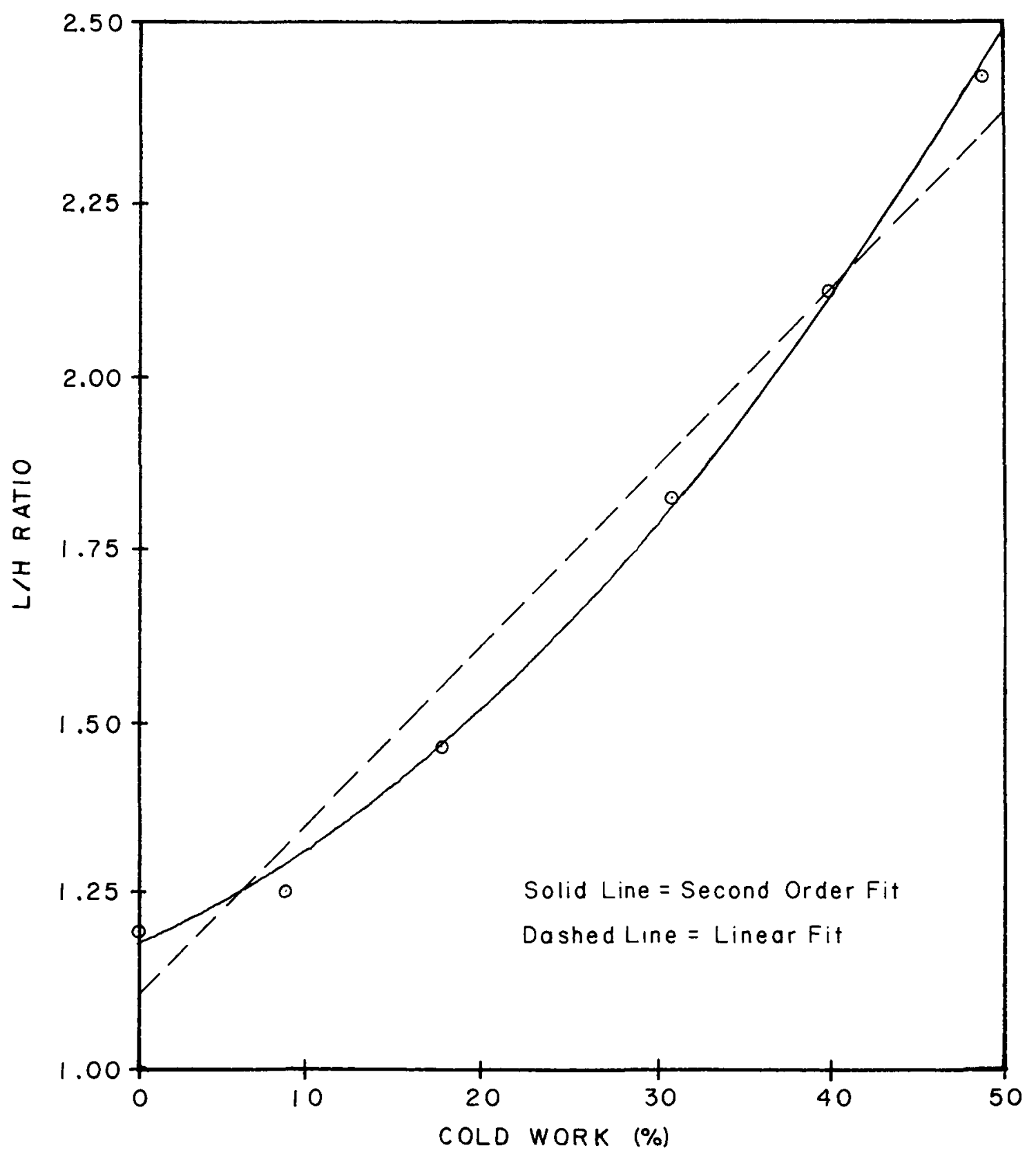

Figure 9. Least Squares Plots of L/H Values versus Percent Cold Working. 
TABLE VIII

LEAST SQUARES FUNCTIONS FOR L/H RATIOS

VERSUS PERCENT COLD WORK

\begin{tabular}{ll}
\hline \multicolumn{1}{c}{ Method } & Function $^{\mathrm{b}}$ \\
\hline Straight Line ${ }^{\mathrm{a}}$ & $\mathrm{Y}=0.02596 \mathrm{X}+1.0904$ \\
Second Order & $Y=1.181+0.01127 \mathrm{X}+0.00030 \mathrm{X}^{2}$ \\
\hline & \\
a $\quad$ Correlation coefficient was $0.987(1.000$ is considered a \\
perfect fit $).$ \\
$\begin{array}{l}X=\text { Percent Cold Work. } \\
Y=\text { L/H Ratio. }\end{array}$
\end{tabular}




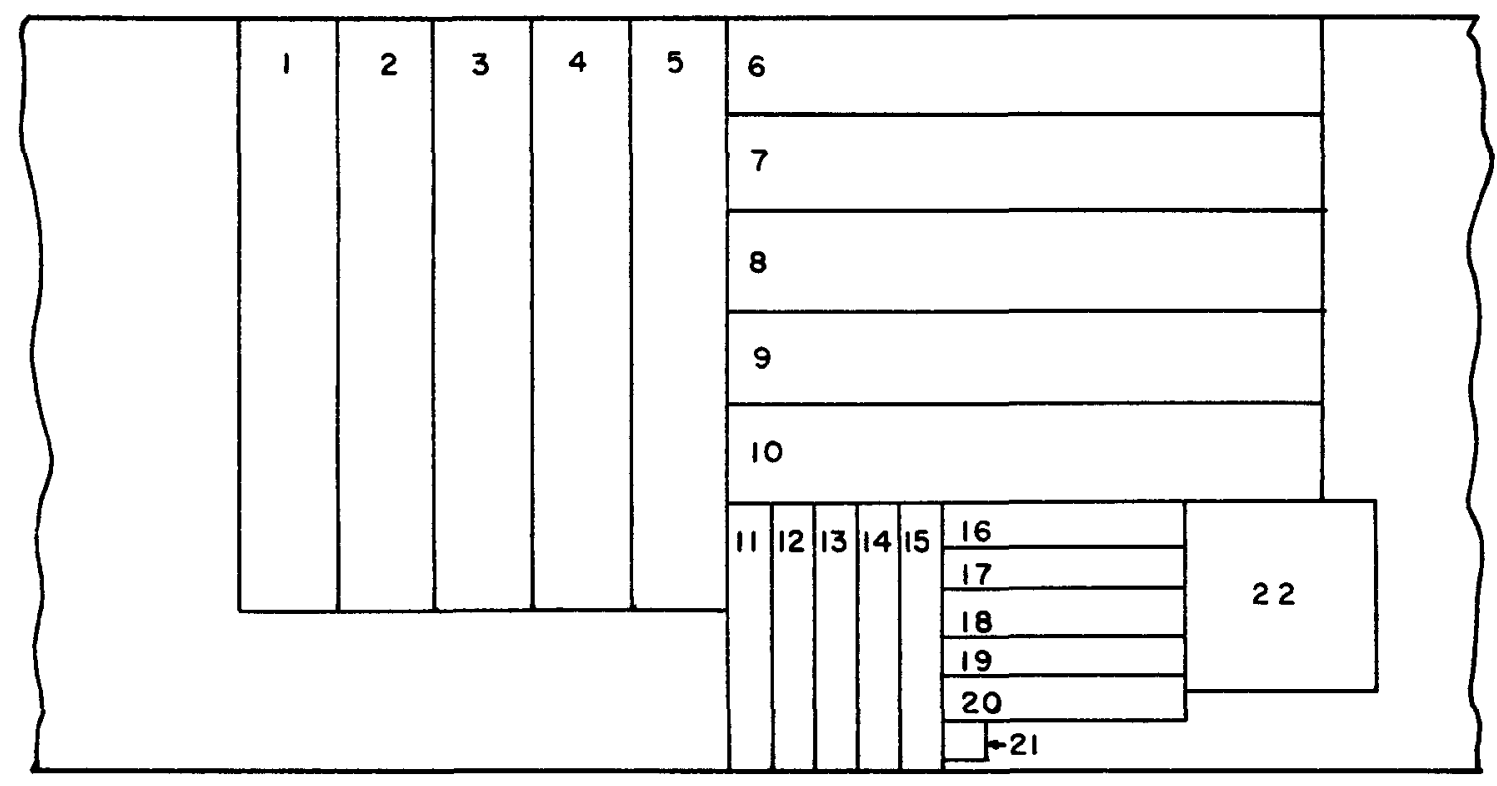

Figure 10. Cutting Schedule for Plates for Further Study.

\section{Legend :}

Specimens 1 through 5: Eddy Current Specimens, Perpendicular to Rolling (not used).

Specimens 6 through 10: Eddy Current Specimens, Parallel to Rolling.

Specimens 11 through 15: Mechanical Properties Specimens, Perpendicular to Rolling.

Specimens 16 through 20: Mechanical Properties Specimens, Parallel to Rolling.

Specimen 21: Netallography Specimen.

Specimen 22: Three inch Square Eddy Current Specimen. 
montage of three $75 \mathrm{X}$ photographs made from the specimen which was cold worked to $50 \%$. Measurements were made in this manner to ascertain if there was any gradient in hardness, and thus degree of cold working, across the thickness of the plates. The right edge is easily visible in the photograph, and the left edge can also be seen, though it is not as obvious. The mark which looks like a hardness reading indentation on this edge was caused by the operator accidentally scraping the diamond indentor across the edge, and is not a hardness indentation.

The averages of these hardness readings along with estimates of the standard deviations are given in Table IX. The desired increase in hardness from the annealed to the highest degree of cold working is obvious. These data are plotted graphically in Figure 12, and the parabolic least squares fit is also shown. The function for this plot is given in Table $X$. The individual hardness readings are given in Table $X I$, and there is no obvious gradient in values on any one of these specimens. From these measurements one would deduce that the cold working was'uniform throughout the specimen thickness, within the accuracy and precision of these measurements. However this was not believed to have been the case, as will be discussed later in Chapter III. 


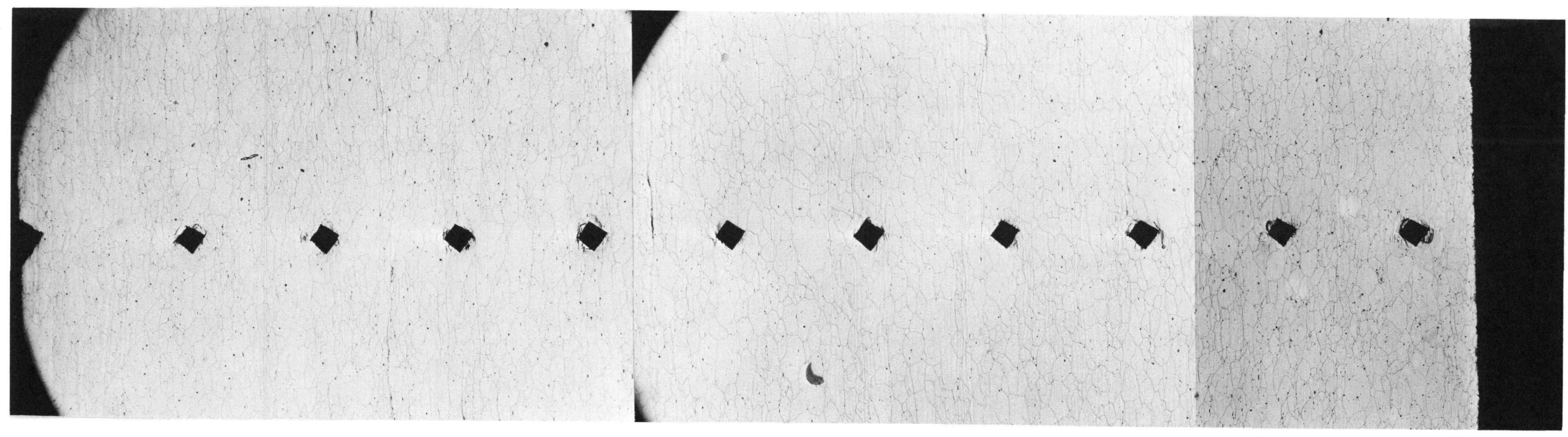

Figure II. A Typical Series of Microhardness Readings Taken on One of the Micro Specimens $(50 \%$ Cold Work). 
TABLE IX

AVERAGES OF MICROHARDNESS READINGS

FROM THE COLD WORKED PLATES

\begin{tabular}{lccc}
\hline $\begin{array}{c}\text { Specimen } \\
\text { Number }\end{array}$ & $\begin{array}{c}\text { Degree of } \\
\text { Cold Work } \\
(\%)\end{array}$ & $\begin{array}{c}\text { DPH } \\
\text { Value } \\
\text { (average) }\end{array}$ & $\mathrm{s}^{\mathrm{a}}$ \\
\hline $07-M-1$ & 0 & 146.4 & 4.58 \\
$02-M-1$ & 8.5 & 216.2 & 11.8 \\
$03-M-1$ & 17.6 & 255.7 & 8.69 \\
$04-M-1$ & 30.9 & 309.6 & 11.2 \\
$05-M-1$ & 40.0 & 317.4 & 17.2 \\
$06-M-1$ & 49.0 & 344.4 & 9.99 \\
\hline
\end{tabular}

a Estimate of the standard deviation. 


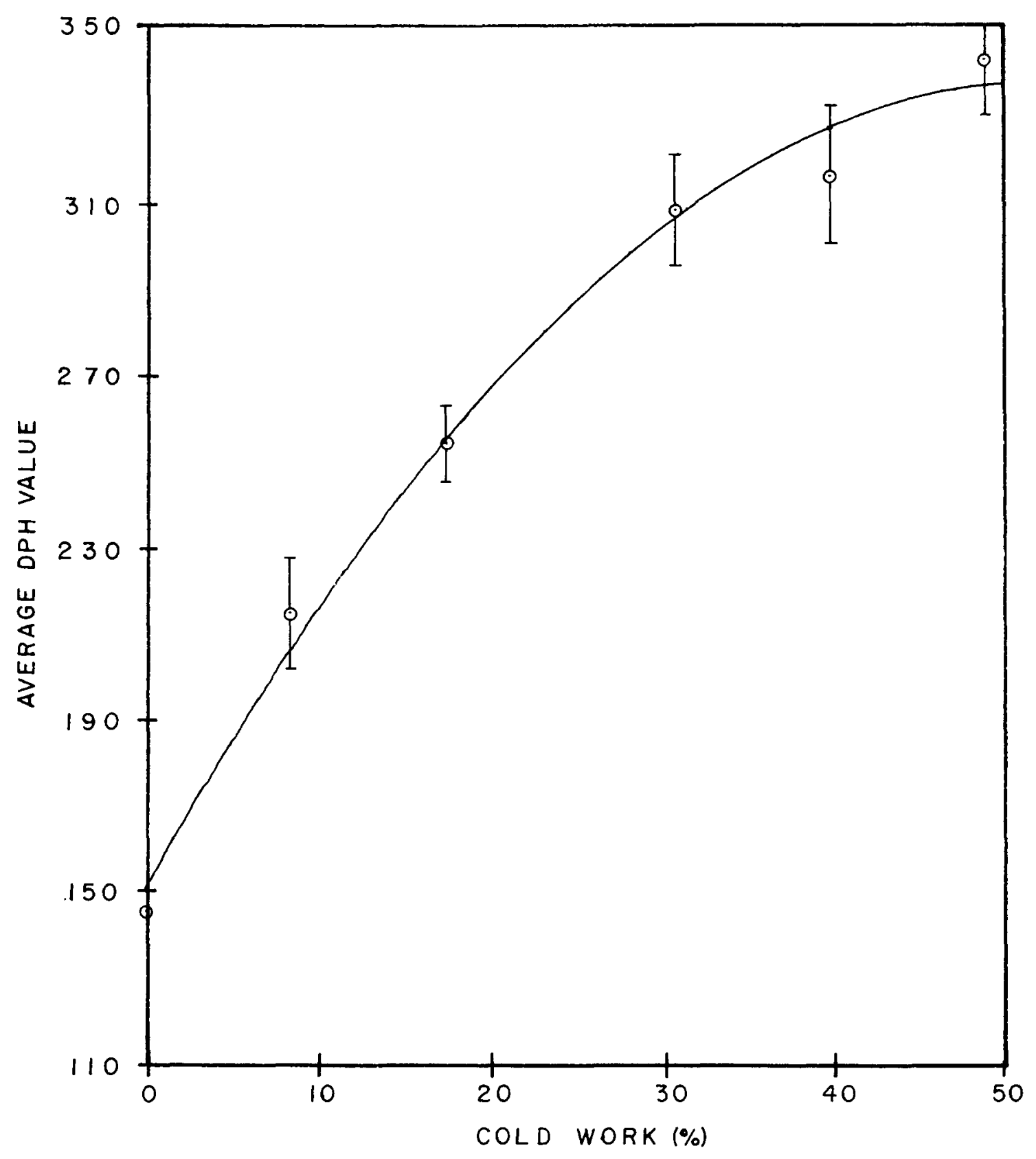

Figure 12. Plot of Average DPH Values versus Percent Cold Work. 
TABLE $X$

THE PARABOLIC FUNCTION FOR FIGURE 12

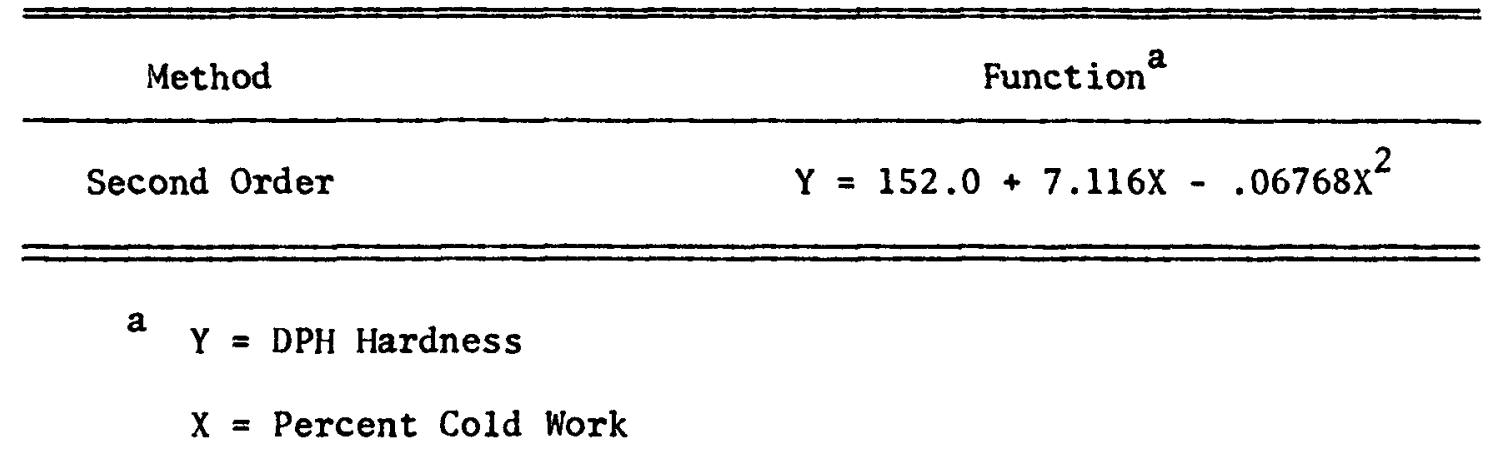


TABLE XI

DPH VALUES MEASURED FROM THE COLD WORKED SPECIMENS

\begin{tabular}{|c|c|c|c|c|c|}
\hline $\begin{array}{l}\text { Specimen } \\
\text { Number }\end{array}$ & $\begin{array}{l}\text { Percent } \\
\text { Cold Work }\end{array}$ & \multicolumn{4}{|c|}{$\begin{array}{c}\text { DPH } \\
\text { Value }\end{array}$} \\
\hline $07-M-1$ & 0 & $\begin{array}{l}148 \\
148 \\
148 \\
144 \\
148\end{array}$ & - edge & $\begin{array}{l}148 \\
138 \\
139 \\
148 \\
154\end{array}$ & - edge \\
\hline $02-M-1$ & 8.5 & $\begin{array}{l}226 \\
215 \\
215 \\
205 \\
201\end{array}$ & - edge & $\begin{array}{l}207 \\
230 \\
219 \\
240 \\
210 \\
210\end{array}$ & - edge \\
\hline $03-M-1$ & 17.6 & $\begin{array}{l}264 \\
244 \\
264 \\
248 \\
262\end{array}$ & - edge & $\begin{array}{l}248 \\
246 \\
253 \\
262 \\
266\end{array}$ & - edge \\
\hline $04-M-1$ & 30.9 & $\begin{array}{l}334 \\
318 \\
344 \\
308 \\
297\end{array}$ & - edge & $\begin{array}{l}309 \\
289 \\
300 \\
283 \\
318 \\
306\end{array}$ & - edge \\
\hline $05-M-1$ & 40.0 & $\begin{array}{l}303 \\
312 \\
289 \\
334 \\
295\end{array}$ & - edge & $\begin{array}{l}334 \\
334 \\
334 \\
318 \\
321\end{array}$ & - edge \\
\hline $06-M-1$ & 49.0 & $\begin{array}{l}341 \\
355 \\
334 \\
348 \\
334\end{array}$ & - edge & $\begin{array}{l}341 \\
337 \\
355 \\
337 \\
362\end{array}$ & - edge \\
\hline
\end{tabular}

NOTE: The readings are given from one edge to the other with the center being the central readings. 
CHAPTER III

\section{D.C. ELECTRICAL RESISTIVITY/CONDUCTIVITY MEASUREMENTS}

\section{Introduction and Theory}

For an isotropic medium, Ohm's Law states that the current density, $j$, in a medium and the electric field intensity, $E$, are related by the equation (Smythe, 1968):

$$
j=\frac{E}{\rho}=\sigma E \text {, }
$$

where $\rho$ is the resistivity and $\sigma$ is the conductivity of the material. Now if we are given an electrical conductor of cross-section, A, carrying an electrical current, $i$, and if $d q$ is the charge passing through this cross-section in time $d t$, then obviously:

$$
i=\frac{d q}{d t}=j A
$$

If there are $n$ free charges per unit volume, each with a charge, $e$, and average speed of progression, $v$, we have:

$$
d q=A n e v d t
$$

Then :

$$
i=\text { Anev, }
$$

and the current density is given by:

$$
j=\frac{i}{A}=\text { nev, }
$$


Now if we apply an external field of intensity, $E$, to this metallic conductor, each free charge within the conductor experiences an acceleration of magnitude $e E / m$, where $m$ is the mass of the charge. The mean free time, $t_{f}$, between successive collisions of a free charge with some atom is thus determined by the structure of the conductor and the temperature, but not $E$.

We may now calculate the electric current, since the mean drift velocity is given by:

$$
v=\frac{1}{2}\left(\frac{e E}{m}\right) t_{f}
$$

Hence from Eq. (4):

$$
j=\left(\frac{n e^{2} t_{f}}{2 m}\right) E \text {, }
$$

From Eq. (1) the quantity in parenthesis must be the electrical conductivity, or the current density produced by a field of unit strength:

$$
\sigma=\frac{n e^{2} t_{f}}{2 m},
$$

Under normal conditions this electrical conductivity is a characteristic of the material and is independent of $j$ or $E$.

The resistivity is the reciprocal of conductivity, or:

$$
\rho=\frac{1}{\sigma}
$$

Using Eqs. (1) and (5):

$$
E=\rho j=\frac{\rho}{A} i
$$

Now for a conductor of length $L, E$ is constant and directed along the 
conductor, and $E \cdot L$ is the electromotive force, $V$, thus:

$$
V=\frac{\rho L}{A} i
$$

The quantity $\rho L / A$ is the resistance of the conductor, and Equation (11) is the familiar Ohm's Law (Page and Adams, 1958).

The normal method utilized to measure the bulk electrical resistivity of a material is to use a long, homogeneous sample with uniform cross section. Current is passed from one end to the other and some method is utilized to measure this current. The potential difference between two points along the specimen, which are reasonably far enough away from the ends to avoid end effects, is then measured. If the contacts are well away from the specimen ends, the current density in the vicinity of the potential contacts should be uniform throughout the cross section and be directed parallel to the sample length, as required by the previous treatment. Then from Eq. (11) the resistivity of this sample is:

$$
\rho=\frac{V A}{i L}
$$

where $L$ is now the distance between potential leads from which $\rho$ is measured. One should be wary of attempting measurements on specimens which are short and thick, for the current density will not be uniform within the potential leads since the current will be spreading as it approaches the center of the specimen. The potential measurenents performed will then be in error due to this unknown potential distribution. Stephens (1971) has treated such cases, and solutions are given for various specimen shapes and contact locations. From this treatment, for the specimens used in this study, the potential leads should have been 
far enough away from the ends to fulfill this requirement.

Taking the divergence of Eq. (1) yields the equation of continuity (Smythe, 1968) for steady current flow (constant charge density):

$$
\nabla \cdot(\sigma \vec{E})=-\nabla(\sigma \nabla V)=\nabla \cdot \bar{j}
$$

and if the medium is homogeneous and isotropic, we may obtain the familiar Laplace Equation:

$$
\nabla^{2} v=0
$$

If the medium is not isotropic, $\sigma$ cannot be factored out; however, if the medium is homogeneous $\sigma$ does not change in any one direction and in this case, for rectangular coordinates, we may write Eq. (13) as:

$$
\sigma_{x} \frac{\delta^{2} V}{\delta x^{2}}+\sigma_{y} \frac{\delta^{2} V}{\delta y^{2}}+\sigma_{z} \frac{\delta^{2} V}{\delta z^{2}}=0
$$

If the conductivity in two directions is the same, and is different in the third, as could be the case for the cold worked plates, this equation may be rewritten in the form:

$$
\sigma_{1}\left(\frac{\delta^{2} V}{\delta x^{2}}+\frac{\delta^{2} V}{\delta y^{2}}\right)+\sigma_{2} \frac{\delta^{2} V}{\delta z^{2}}=0
$$

which can be made a little easier to solve if we transform coordinates via:

$$
u=\left(\frac{\sigma_{1}}{\sigma_{2}}\right)^{\frac{1}{2}}=\alpha z
$$

which transforms the equation to:

$$
\frac{\delta^{2} V}{\delta x^{2}}+\frac{\delta^{2} V}{\delta y^{2}}+\frac{\delta^{2} V}{\delta u^{2}}=0
$$


for which solutions can be found for particular problems, given the necessary boundary conditions.

Page and Adams (1940) have treated the case of an anisotropic material by expressing $\mathrm{Eq} .(1)$ as a tensor equation:

$$
\vec{J}=\vec{\Sigma} \cdot \vec{E}
$$

where now $\vec{\Sigma}$ is the conductivity dyadic. It can be shown that for proper orientation of the axes, $\vec{\Sigma}$ can be written as:

$$
\vec{\Sigma}=\sigma_{x} \vec{i}_{1} \vec{i}_{2}+\sigma_{y} \vec{j}_{1} \vec{j}_{2}+\sigma_{z} \vec{k}_{1} \vec{k}_{2}
$$

In the case of an anisotropic conductor, the electrical field intensity inside the material is not along the direction of $\vec{J}$, though the component in the direction of the current is equal to $E$. Page shows that the measured resistivity, $\rho_{m}$, may be expressed as:

$$
\rho_{m}=\rho_{x} \cos ^{2} \alpha+\rho_{y} \sin ^{2} \alpha
$$

where $\alpha$ is the angle the current makes with the applied electric field.

Eq. (15) has been treated extensively in the development of the four-probe method of resistivity measurement, and solutions have been found for many specimen configurations. Vaughn (1961) has studied resistivity measurements utilizing a four-probe square array on small circular specimens. Zrudsky (1966) has used this method to measure sheet resistivities of evaporated films and disks of bulk materials. The classic use of the method is in the measurement of resistivity of semi-conductors, and Valdes (1952) has treated this method and theory in great detail. He finds a solution of Laplace's Eq. (14) to be: 


$$
V=\frac{\rho i}{2 \pi r}=\frac{\rho i}{2 \pi \sqrt{x^{2}+y^{2}}} \text {, }
$$

for a four-probe linear array of contacts. In a later article, (Valdes, 1964), he treats various boundary conditions as related to this type of measurement.

Hansen (1960) also treats further types of specimen shapes and resultant boundary conditions. Further treatments of such problems are also given by Uhlir (1965) and Smits (1958).

Attempts were made in this study to utilize these vast anounts of developed procedures and theory on the four-probe method for measurements on the cold worked 316 stainless steel, but they were largely unsuccessful. This was due primarily to the low resistivity of the material and resultant instrumentation limitations, and these methods were developed for use on materials with fairly high resistivity, such as semiconductors.

\section{Conductivity/Resistivity Relationships}

Electrical conductivity and electrical resistivity may be related by data from ASTM Test Method B-187, Specifications for Copper Bus Bar Rod and Shapes, from which the data in Table XII were obtained. One can take the conductivity in percent of the International Annealed Copper Standard (\%IACS) versus the resistivity in micro-ohm centimeters for copper and plot it as shown in Figure 13, and determine the relationship or conversion desired. Conversion tables are also given in the NBS Copper Wire Tables, and the formula from this and that from the plot are given below. From the plot we find the least squares straight line: 
TABLE XII

RESISTIVITY RELATIONSHIPS FROM ASTM B187

\begin{tabular}{|c|c|c|c|c|c|}
\hline $\begin{array}{c}\text { Conductivity } \\
\text { @ } 28^{\circ} \mathrm{C}\left(68^{\circ} \mathrm{F}\right)\end{array}$ & 100 & 98.40 & 98.16 & 97.40 & 96.16 \\
\hline$\Omega g / m^{2}$ & 0.15328 & 0.15577 & 0.15614 & 0.15737 & 0.15940 \\
\hline$\Omega 1 b / m i / e^{2}$ & 875.20 & 889.42 & 891.60 & 898.55 & 910.15 \\
\hline$\Omega \mathrm{cmi} 1 / \mathrm{ft}$ & 10.371 & 10.539 & 10.565 & 10.648 & 10.785 \\
\hline$\Omega \mathrm{mm}^{2} / \mathrm{m}$ & 0.017241 & 0.017521 & 0.017564 & 0.017701 & 0.017930 \\
\hline$\mu \Omega$ in & 0.67879 & 0.68981 & 0.69151 & 0.69690 & 0.70590 \\
\hline$\mu \Omega \mathrm{cm}$ & 1.7241 & 1.7521 & 1.7564 & 1.7701 & 1.7930 \\
\hline
\end{tabular}




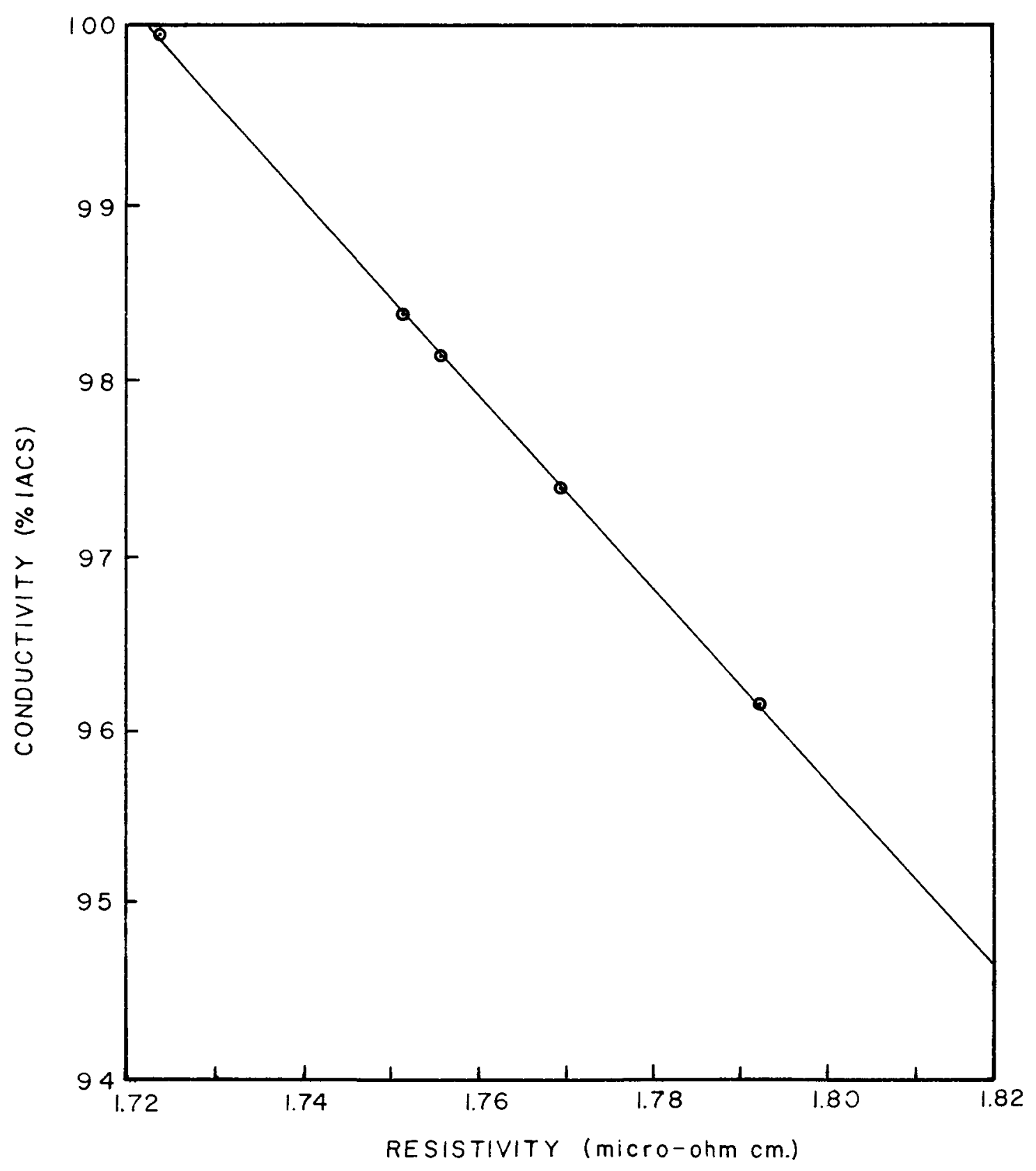

Figure 13. Plot of Conductivity (\%IACS) versus Resistivity $(\mu \Omega-\mathrm{cm})$. 
(23) Conductivity $(\%$ IACS) $=196.0734-55.7371$ X Resistivity (microohm), and from the NBS Handbook we find:

(24) Conductivity $(\%$ IACS $)=\frac{172.41}{\text { Resistivity (microohm-cm) }}$

The latter equation turns out to be easier to use and is more accurate, so it was used for all conversions between resistivity and conductivity.

Metallurgical Mechanisms

When type 316 stainless steel is cold worked, two major mechanisms are at work which cause the conductivity to decrease:

1. New lattice defects, such as vacancies, intersitial atoms or dislocations, are generated (Stanley, 1963), and

2. Some of the austenite or the face-centered cubic form of iron (Gamma phase) is transformed into martensite or the bodycentered tetragonal iron phase (Alpha phase). Austenite contains carbon in interstitial solid solution, and other alloying elements, such as manganese, nickel, chromium, etc., in substitutional solid solution, while martensite has entrapped carbon atoms (Guy, 1959).

It is suspected that the first of these two mechanisms is the primary source of any decrease in conductivity, and that the second should be the source of any increasing permeability of the material as the degree of cold working is increased. However McReynolds (1946) has used measurements of electrical resistivity to measure transformations between austenite and martensite. Fiedler (1955) has reported similar measurements on 18-8 stainless steel. This report lists an almost linear relationship between the quantity of martensite and the degree of cold work. 
If all cold working of the material were to be performed in one direction, one would expect that a preferred grain orientation would result, and that the grains would tend to become longer in the direction of rolling as the degree of cold work is increased. Also Balicki (1945), in a monumental work on the work hardening of iron, reports:

- . A study of the flow of a metal during plastic deformation which causes work-hardening to take place, reveals, when full consideration is given to the mosaic structure of crystals and to the mechanism of plastic flow, that a slightly cold-worked metal cannot be regarded as homogeneously work-hardened. Some groups of atoms, contiguous to the gliding and rotating planes, should be considered as actually work-hardened, whilst the interiors of the crystal blocks remain unchanged and retain fully the properties of the annealed state...

Thus one would suspect that, if this is true, the bulk of the cold worked material for the lower degrees of cold work would lie near the surface, and the amount of cold work would decrease toward the center of the plate.

\section{Asparatus}

Al1 D.C. Electrical Resistivity measurements were performed at room temperature $\left(72^{\circ} \mathrm{F}.\right)$ on a Keithley Model 503 milliohmmeter, as depicted in Figure 14. Visible in the photograph is the milliohmmeter, the electronic readout fabricated for the study, and the fixture used to hold the specimen and voltage and current contacts. The milliohmmeter has ranges of $1000,300,100,30,10,3$ and $1 \mathrm{ohm}$ and 300,100 , $30,10,3$ and $1 \mathrm{milliohm}$. The 1 milliohm range was utilized for all tests in this study, as the specimens exhibited a resistance on the order of $4.0 \times 10^{-4} \mathrm{ohm}$, which meant the readings occurred around midscale of this range. Output of the milliohmmeter is either through the meter on the front panel which reads directly in ohms resistance or 


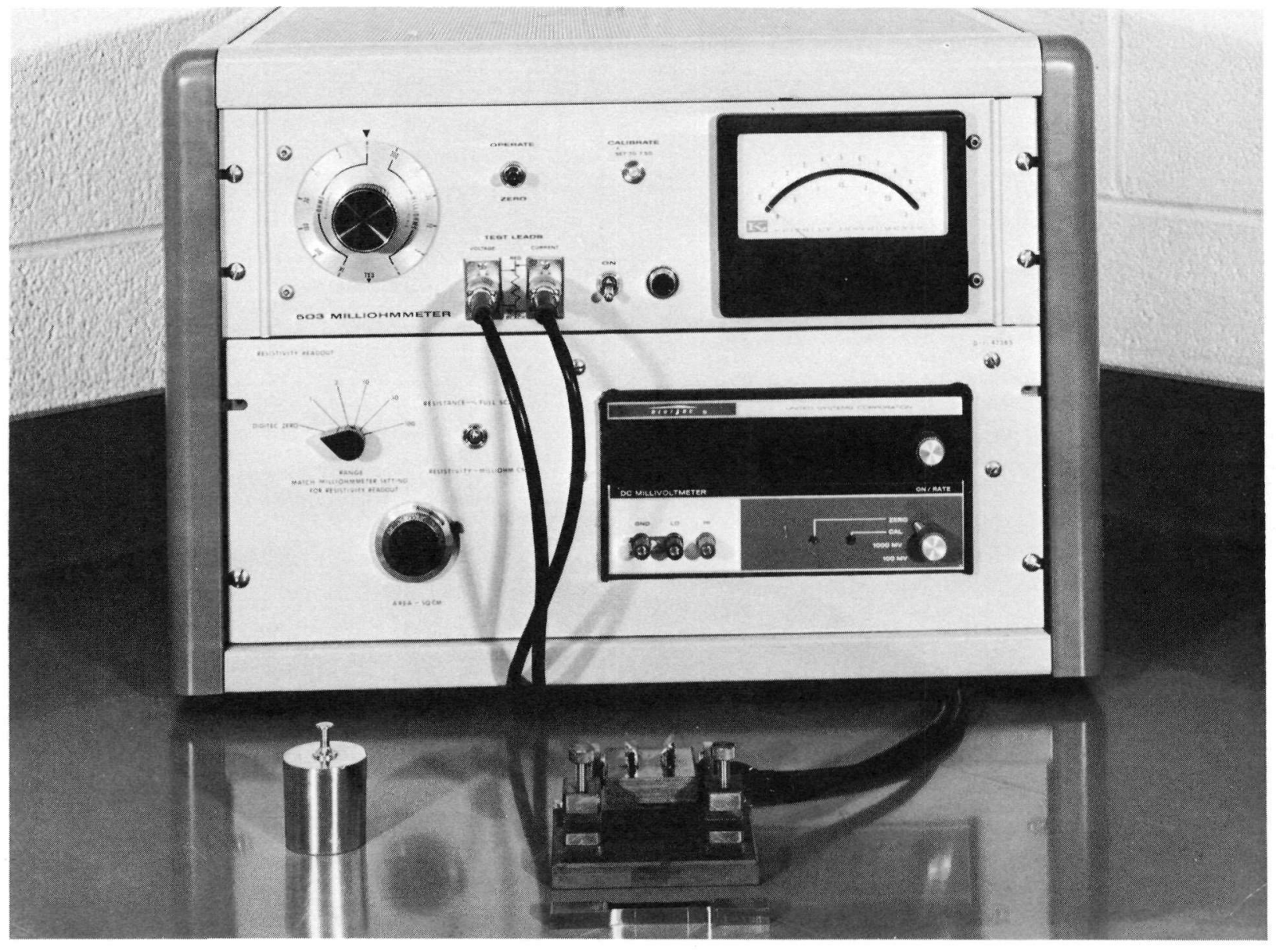

Figure 14. The Apparatus Used to Measure D.C. Resistivity. 
through a 0-100 millivolt (mv) source available for driving recorders or other meters. The latter was utilized with the 0-100 mv digital voltmeter shown in the lower portion of the cabinet so that $0-100 \mathrm{mv}$ represented $0-100 \%$ of full scale. Resolution of the digital voltmeter was 10 microvolts, which yielded a resolution of $1 \times 10^{-7}$ ohm or .1 microohm.

The instrumentation shown is capable of being utilized to display the resistivity of the material directly, but this mode was not utilized in this study due to the desire that the results be as accurate and precise as possible. The digital voltmeter was calibrated before each set of measurements was taken with a voltage standard traceable to NBS. Calibration of the milliohmmeter was performed in like manner utilizing a standard resistor within the instrument which the manufacturer certifitd traceable to NBS to within an accuracy of at least $0.5 \%$. The calibration of the instrument was checked after these measurements had been completed with a Leeds and Northrup Model 4223-B, .001 ohm (1 milliohm) standard resistor, traceable to the NBS, and the accuracy of the instrument, when calibrated in the standard manner, was found to be within $0.5 \%$. This was found in spite of the fact that no great attempts were made to provide low resistance connections to the standard resistor, so that it is felt that all resistance measurements made were accurate to well within $0.5 \%$.

Heretofore we have referred to the test method as a D.C. or direct current method, but in reality only D.C. type methods were used, for the instrument actually is a low frequency A.C. instrument. The well known four terminal technique was used as shown in Figure 15 whereby the current 
is passed through the ends of the specimen and the voltage measured at points a known distance apart on the specimens.

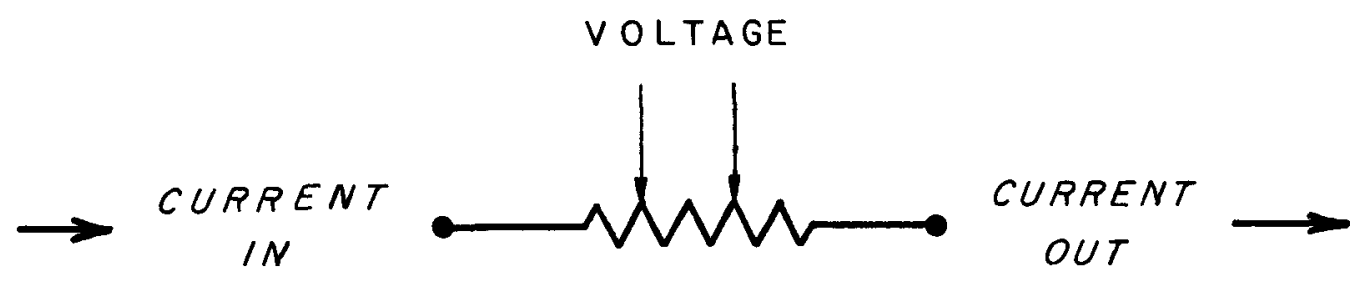

Figure 15. The Four-Terminal Technique.

The current supply within the instrument is a "superregulated" 40 $\mathrm{Hz}$. (Hertz) square wave supply, so that in a sense the test current is D.C. which changes polarity at a $40 \mathrm{~Hz}$. frequency. The advantage of this method is that errors due to thermal effects in the material under measurement as well as other spurious D.C. disturbances are essentially eliminated. A similar technique is used in most pure D.C. measurements, but readings are taken with current flowing both ways through the specimen. The reversal of current in this case is usually done manually, but McElroy (July, 1971) has reported a novel computerized method which should be potentially more accurate and precise than this method. The current measurement used is then the average of the two readings, which is essentially what this instrument does.

The Keithley millohmmeter is essentially, as stated earlier, a very 
stable current source, and in addition a vacuum tube voltmeter which is very similar in most respects to the Keithley electrometer. The net result is that currents on the order of $100 \mathrm{milliamperes}$ and voltages on the order of 100 microvolts are utilized in the instrument on the 1 milliohm range. The meter on the front panel and the 0-100 millivolt output are outputs of the voltmeter section, calibrated to read directly in resistance. This method necessarily assumes, of course, that the current through the specimen is constant and is known for all time. This is perhaps one drawback of this measurement method, but something was necessarily given up for the ease in which the instrument allows measurements to be made. The meter is a synchronous voltmeter so that it is sensitive to the $40 \mathrm{~Hz}$. test frequency only. As the voltmeter section has extremely high input resistance, very little, if any, error should have been introduced by contact and lead resistance in this section of the instrument and specimen junctions due to the negligible current flow in the voltmeter leads.

The test fixture utilized for all measurements is shown in the front of the instrument in Figure 14 on page 45 and again in the closeup in Figure 16. It is shown in the "open" configuration in Figure 14 with a typical specimen shown in the foreground, and in the "closed" position in Figure 16 with this test specimen in the fixture ready for test. Shown in the photographs are the large copper current terminals on either end which also serve to clamp the specimen rigidly via the brass screws on top, and the micarta swivel block which holds the potential knife edges, also of copper. All this was rigidly mounted on a micarta base. Shown in both photographs is a 500 gram mass which 


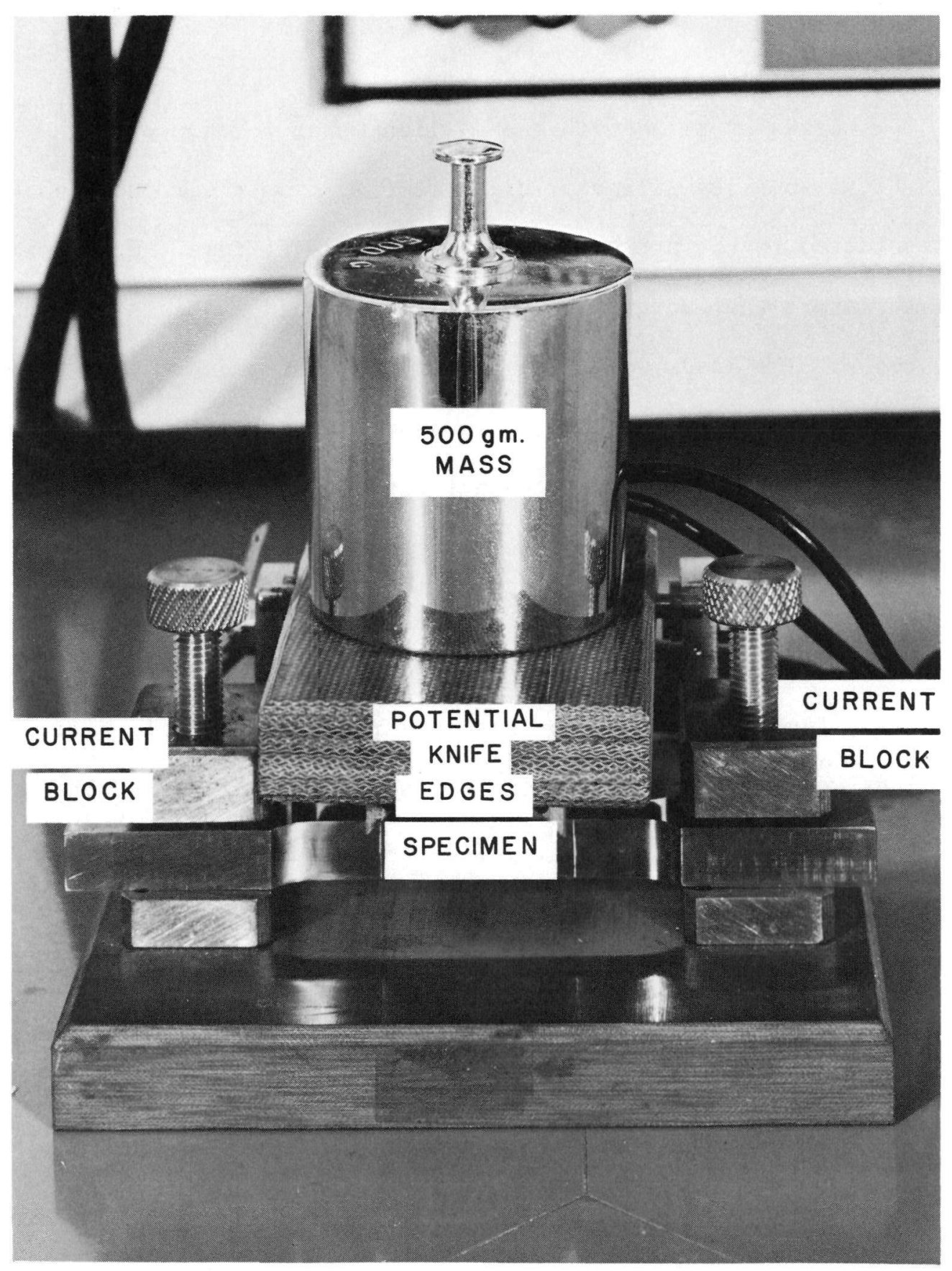

Figure 16. Close-up of the Resistivity Fixture. 
was placed as shown in Figure 16 so as to assist in making low resistance potential contacts on the specimens and also to aid in data precision and repeatability.

Leads supplied with the milliohmmeter were used in the tests with the as-supplied alligator clips removed from their ends, and the leads soldered to the appropriate blocks on the fixture. Great care was taken to assure that adequate, low resistance solder joints were made in all cases. The leads were made of $100 \%$ IACS stranded copper wire of approximately 10 or 12 gauge so as to assure low resistance. As there was some reactive coupling between these leads on the 1 milliohm range, the current and voltage leads were kept separated as far as possible, and the unshielded ends wound together to reduce their enclosed area.

Measurements of the potential knife edge spacings were made with a traveling microscope, and these are reported in Table XIII. Three readings were made at three locations along the edges. A slight taper in the separation is evident, but it was not believed to be a serious problem. These measurements were taken from the third attempt at fabricating an upper pivot block upon which these knife edges were attached, and were the best that were found in these three attempts.

The knife edges were machined so that the radius at the edge was .002 inch maximum, and the separation measurements were made from the center of this radius as determined by careful focusing of the microscope.

The design of this test fixture was based upon a fixture in ASTM Test Method B-63, Resistivity of Metallically Conducting and Contact Materials, and is essentially as shown in that reference with one minor change. The upper pivot block design was changed so as to allow specimens 
TABLE XIII

POTENTIAL KNIFE EDGE SPACING

\begin{tabular}{|c|c|c|c|c|}
\hline \multirow[b]{2}{*}{ Location } & \multicolumn{4}{|c|}{ Spacing (inches) } \\
\hline & $\underset{1}{\text { Reading }}$ & $\begin{array}{l}\text { Reading } \\
\quad 2\end{array}$ & $\begin{array}{c}\text { Reading } \\
3\end{array}$ & Average \\
\hline One end & 1.0012 & 1.0016 & 1.0011 & $\begin{array}{l}1.0013 \\
S=.00022^{a}\end{array}$ \\
\hline Center & 1.0006 & 1.0009 & 1.0009 & $\begin{array}{l}1.0008 \\
S=.00017^{a}\end{array}$ \\
\hline Other end & 1.0002 & 1.0000 & 0.9998 & $\begin{array}{l}1.0000 \\
S=.00020^{a}\end{array}$ \\
\hline Average & --- & --- & -- & $\begin{array}{l}1.00076 \\
S=.00059^{a}\end{array}$ \\
\hline
\end{tabular}

a Estimate of the standard deviation. 
of varying thicknesses to be tested. This was necessary because the test specimens used varied in thickness from $5 / 16$ of an inch to approximately half that amount.

\section{Test Results}

Measurements of the resistivity of the cold worked 316 stainless steel were made on the small tensile specimens, one of which is shown in Figure 14 on page 45 and Figure 16 on page 49 , and was graphically depicted in Figure 2 on page 12. A total of five measurements were made on each specimen, with the specimen remaining in the fixture for these five readings. The procedure used in making all these measurements was the following:

1. The zero and calibration of the DVM was checked.

2. The calibration of the milliohmmeter was checked.

3. At least 5 minutes was allowed for both instruments to stabilize.

4. The specimen was inserted into the fixture, being sure that it made full contact with the back and base of the current contacts.

5. The thumb screws were tightened down finger tight.

6. The pivot block was rotated around so that the voltage contacts made full contact with the specimen, and it was moved back and forth to assist in good, low resistance contacts.

7. The meter was switched to "operate" and at least 30 seconds was allowed for stabilization.

8. The five readings were then taken at random on approximately 30 second time intervals. 
The first two steps were usually done only once before a given measurement series was begun, as both instruments exhibited remarkable stability in both zero and calibration. The instrumentation was left on throughout the study which could account for this stability. As a test of this stability the output was monitored with a specimen installed for a time in excess of 20 hours and it was found to deviate no more than \pm .02 millivolts. Attempts were made to be sure the specimen was centered in the fixture at all times so that measurements were made within the center one inch gage length of the specimen.

Measurements of the cross-sectional area of each specimen were made before resistivity measurements were performed, and these were made with a digital micrometer with a vernier so that measurements were accurate and repeatable to within .0001 inch. These measurements are tabulated in Table XIV, and from these data it should be obvious that there was no need to make these measurements to any greater accuracy due to the deviation in these readings on each specimen. A total of three measurements were taken on each specimen, one on each end of the one inch gage length, and one in the center. Measurement number one was on the numbered end of the specimen. The obvious taper from ends to the center was required for the specimens to be utilized for determination of mechanical properties later in the study, and was not believed to be a great problem here. The area was calculated at each of these three locations and the average is reported along with the estimate of the standard deviation. The scribe marks used to define this measurement region can be easily seen in Figures 14 on page 45 and 16 on page 49 . Because of the rough surface of the specimens in the as-rolled 
TABLE XIV

TENSILE SPECIMEN AREA MEASUREMENTS

(AS-ROLLED)

\begin{tabular}{|c|c|c|c|c|c|c|c|c|}
\hline \multirow[b]{2}{*}{$\begin{array}{l}\text { Specimen } \\
\text { Number }\end{array}$} & \multicolumn{3}{|c|}{ Width (inch) } & \multicolumn{3}{|c|}{ Thickness (inch) } & \multirow{2}{*}{$\begin{array}{c}\text { Average } \\
\text { Area } \\
(\mathrm{Sq} . \mathrm{In} .)\end{array}$} & \multirow[b]{2}{*}{$s^{\mathbf{a}}$} \\
\hline & $\begin{array}{l}\text { Heas. } \\
\# 1\end{array}$ & $\begin{array}{l}\text { Meas. } \\
\# 2\end{array}$ & $\begin{array}{l}\text { Meas. } \\
\# 3\end{array}$ & $\begin{array}{c}\text { Meas. } \\
\# 1\end{array}$ & $\begin{array}{l}\text { Meas. } \\
\# 2\end{array}$ & $\begin{array}{l}\text { Meas. } \\
\# 3\end{array}$ & & \\
\hline $07-S L-1$ & .2523 & .2515 & .2522 & .3290 & .3289 & .3289 & .08289 & .000152 \\
\hline 2 & .2519 & .2510 & .2519 & .3284 & .3285 & .3286 & .08265 & .000173 \\
\hline 3 & .2474 & .2465 & .2472 & .3295 & .3295 & .3297 & .08141 & .000167 \\
\hline 4 & .2518 & .2506 & .2520 & .3307 & .3303 & .3303 & .08305 & .000245 \\
\hline 5 & .2512 & .2501 & .2511 & .3310 & .3311 & .3311 & .08303 & .000194 \\
\hline $07-\mathrm{ST}-1$ & .2531 & .2521 & .2532 & .3339 & .3337 & .3335 & .08436 & .000205 \\
\hline 2 & .2515 & .2503 & .2514 & .3318 & .3320 & .3321 & .08335 & .000214 \\
\hline 3 & .2547 & .2538 & .2546 & .3328 & .3326 & .3327 & .08463 & .000188 \\
\hline 4 & .2554 & .2541 & .2552 & .3318 & .3320 & .3320 & .08461 & .000215 \\
\hline 5 & .2510 & .2500 & .2511 & .3330 & .3327 & .3328 & .08344 & .000231 \\
\hline $02-S L-1$ & .2547 & .2533 & .2544 & .3058 & .3061 & .3063 & .07778 & .000214 \\
\hline 2 & .2575 & .2566 & .2575 & .3061 & .3065 & .3062 & .07877 & .000108 \\
\hline 3 & .2568 & .2558 & .2567 & .3065 & .3065 & .3066 & .07860 & .000176 \\
\hline 4 & .2513 & .2504 & .2515 & .3065 & .3061 & .3057 & .07685 & .000190 \\
\hline 5 & .2515 & .2506 & .2516 & .3051 & .3050 & .3050 & .07664 & .000175 \\
\hline $02-\mathrm{ST}-1$ & .2517 & .2502 & .2518 & .3007 & .3005 & .3005 & .07551 & .000284 \\
\hline 2 & .2548 & .2536 & .2548 & .3015 & .3015 & .3009 & .07665 & .000182 \\
\hline 3 & .2563 & .2550 & .2560 & .3010 & .3009 & .3010 & .07698 & .000219 \\
\hline 4 & .2573 & .2567 & .2576 & .3007 & .3004 & .3009 & .07733 & .000202 \\
\hline 5 & .2510 & .2501 & .2510 & .3015 & .3013 & .3014 & .07556 & .000179 \\
\hline
\end{tabular}


TABLE XIV (continued)

\begin{tabular}{|c|c|c|c|c|c|c|c|c|}
\hline \multirow[b]{2}{*}{$\begin{array}{l}\text { Specimen } \\
\text { Number }\end{array}$} & \multicolumn{3}{|c|}{ Width (inch) } & \multicolumn{3}{|c|}{ Thickness (inch) } & \multicolumn{2}{|l|}{ Average } \\
\hline & $\begin{array}{l}\text { Meas. } \\
\# 1\end{array}$ & $\begin{array}{l}\text { Meas. } \\
\# 2\end{array}$ & $\begin{array}{l}\text { Meas. } \\
\# 3\end{array}$ & $\begin{array}{l}\text { Meas. } \\
\# 1\end{array}$ & $\begin{array}{l}\text { Meas. } \\
\# 2\end{array}$ & $\begin{array}{l}\text { Meas. } \\
\# 3\end{array}$ & $\begin{array}{l}\text { Area } \\
\text { (sq.in.) }\end{array}$ & $s^{a}$ \\
\hline $03-\mathrm{SL}-1$ & .2512 & .2502 & .2514 & .2802 & .2805 & .2805 & .07036 & .000170 \\
\hline 2 & .2575 & .2565 & .2575 & .2807 & .2810 & .2806 & .07220 & .000111 \\
\hline 3 & .2509 & .2497 & .2510 & .2792 & .2792 & .2788 & .06992 & .000176 \\
\hline 4 & .2558 & .2550 & .2562 & .2804 & .2793 & .2800 & .07156 & .000294 \\
\hline 5 & .2520 & .2508 & .2520 & .2775 & .2777 & .2775 & .06984 & .000163 \\
\hline $03-\mathrm{ST}-1$ & .2528 & .2515 & .2531 & .2752 & .2750 & .2750 & .06944 & .000245 \\
\hline 2 & .2515 & .2502 & .2516 & .2574 & .2761 & .2757 & .06924 & .000145 \\
\hline 3 & .2510 & .2499 & .2510 & .2765 & .2769 & .2768 & .06936 & .000145 \\
\hline 4 & .2529 & .2520 & .2530 & .2740 & .2743 & .2747 & .06936 & .000276 \\
\hline 5 & .2518 & .2508 & .2521 & .2758 & .2766 & .2765 & .06951 & .000175 \\
\hline $04-S L-1$ & .2521 & .2509 & .2522 & .2381 & .2378 & .2378 & .05989 & .000195 \\
\hline 2 & .2549 & .2544 & .2540 & .2362 & .2363 & .2364 & .06012 & .000081 \\
\hline 3 & .2528 & .2516 & .2536 & .2373 & .2372 & .2372 & .05994 & .000241 \\
\hline 4 & .2505 & .2503 & .2505 & .2380 & .2380 & .2380 & .05960 & .000027 \\
\hline 5 & .2515 & .2505 & .2516 & .2328 & .2379 & .2330 & .05850 & .000146 \\
\hline $04-\mathrm{ST}-1$ & .2487 & .2480 & .2491 & .2362 & .2361 & .2357 & .05867 & .000102 \\
\hline 2 & .2506 & .2494 & .2507 & .2391 & .2372 & .2374 & .05953 & .000381 \\
\hline 3 & .2549 & .2541 & .2551 & .2361 & .2365 & .2364 & .06019 & .000106 \\
\hline 4 & .2493 & .2480 & .2493 & .2390 & .2380 & .2374 & .05926 & .000288 \\
\hline 5 & .2506 & .2494 & .2508 & .2350 & .2350 & .2354 & .05885 & .000218 \\
\hline
\end{tabular}


TABLE XIV (continued)

\begin{tabular}{|c|c|c|c|c|c|c|c|c|}
\hline \multirow[b]{2}{*}{$\begin{array}{l}\text { Specimen } \\
\text { Number }\end{array}$} & \multicolumn{3}{|c|}{ Width (inch) } & \multicolumn{3}{|c|}{ Thickness (inch) } & \multirow{2}{*}{$\begin{array}{l}\text { Average } \\
\text { Area } \\
\text { (sq.in.) }\end{array}$} & \multirow[b]{2}{*}{$s^{a}$} \\
\hline & $\begin{array}{c}\text { Meas. } \\
\# 1\end{array}$ & $\begin{array}{l}\text { Meas. } \\
\# 2\end{array}$ & $\begin{array}{l}\text { Meas. } \\
\# 3\end{array}$ & $\begin{array}{l}\text { Meas. } \\
\# 1\end{array}$ & $\begin{array}{l}\text { Meas. } \\
\# 2\end{array}$ & $\begin{array}{l}\text { Meas. } \\
\# 3\end{array}$ & & \\
\hline $05-\mathrm{SL}-1$ & .2546 & .2536 & .2542 & .2058 & .2055 & .2053 & .05223 & .000146 \\
\hline 2 & .2517 & .2507 & .2516 & .2054 & .2053 & .2055 & .05162 & .000134 \\
\hline 3 & .2518 & .2506 & .2517 & .2048 & .2052 & .2050 & .05153 & .000094 \\
\hline 4 & .2515 & .2505 & .2515 & .2056 & .2066 & .2057 & .05173 & .000023 \\
\hline 5 & .2590 & .2578 & .2591 & .2020 & .2016 & .2017 & .05218 & .000185 \\
\hline $05-\mathrm{ST}-1$ & .2588 & .2580 & .2590 & .2031 & .2022 & .2021 & .05236 & .000198 \\
\hline 2 & .2616 & .2606 & .2615 & .2031 & .2030 & .2031 & .05305 & .000127 \\
\hline 3 & .2518 & .2497 & .2514 & .2048 & .2042 & .2043 & .05131 & .000294 \\
\hline 4 & .2523 & .2508 & .2521 & .2048 & .2052 & .2044 & .05156 & .000106 \\
\hline 5 & .2565 & .2553 & .2566 & .2041 & .2042 & .2049 & .05235 & .000223 \\
\hline $06-S L-1$ & .2578 & .2569 & .2578 & .1732 & .1732 & .1732 & .04460 & .00009 \\
\hline 2 & .2569 & .2560 & .2574 & .1725 & .1723 & .1723 & .04420 & .00013 \\
\hline 3 & .2518 & .2507 & .2516 & .1724 & .1725 & .1726 & .04336 & .00010 \\
\hline 4 & .2518 & .2507 & .2518 & .1725 & .1726 & .1726 & .04339 & .00010 \\
\hline 5 & .2520 & .2506 & .2516 & .1716 & .1715 & .1722 & .04318 & .00018 \\
\hline $06-S T-1$ & .2518 & .2505 & .2515 & .1700 & .1699 & .1694 & .04266 & .00013 \\
\hline 2 & .2539 & .2527 & .2537 & .1699 & .1699 & .1695 & .04302 & .00010 \\
\hline 3 & .2543 & .2530 & .2540 & .1702 & .1697 & .1691 & .04306 & .00020 \\
\hline 4 & .2520 & .2510 & .2521 & .1697 & .1695 & .1691 & .04265 & .00011 \\
\hline 5 & .2518 & .2506 & .2516 & .1697 & .1694 & .1692 & .04258 & .00014 \\
\hline
\end{tabular}

a Estimate of the standard deviation. 
condition, two series of measurements were made on the specimens, one in the as-rolled and one with the surfaces finished with 400 grit emery paper on a metallographic polishing wheel. This was done in order to attempt to lower variance in test data, and to attempt to improve measurement accuracy. Figure 17 shows one of these in the as-rolled condition, and the polished surface is shown in Figure 18. Measurements on the specimens cut from the annealed plate (Plate 7) were made on polished surfaces only.

Average values of the resistivity/conductivity as measured from the specimens in the as-rolled condition are reported in Table XV, along with the estimate of the standard deviation in each case. This average is the average of five readings on five specimens from each plate in each direction, so that the deviation includes specimen-to-specimen deviation as well as deviation within a given specimen. Each average reported in Table $X V$ would then be an average of twenty-five measurements for a given condition of cold work and direction with respect to the rolling direction. The resistivity was calculated per formula (12) of the theory, and the conductivity was calculated from the resistivity per the note in the theory. Reported also in this table is the $t$ statistic between the different rolling directions to ascertain if there was a difference in resistivity with rolling direction. There is no statistically significant difference noted from these data, but there does seem to be a general trend toward significance as the degree of cold working is increased. However, it is significant that in the last four of the six degrees of cold work the resistivity perpendicular to rolling is lower than that parallel to rolling. 


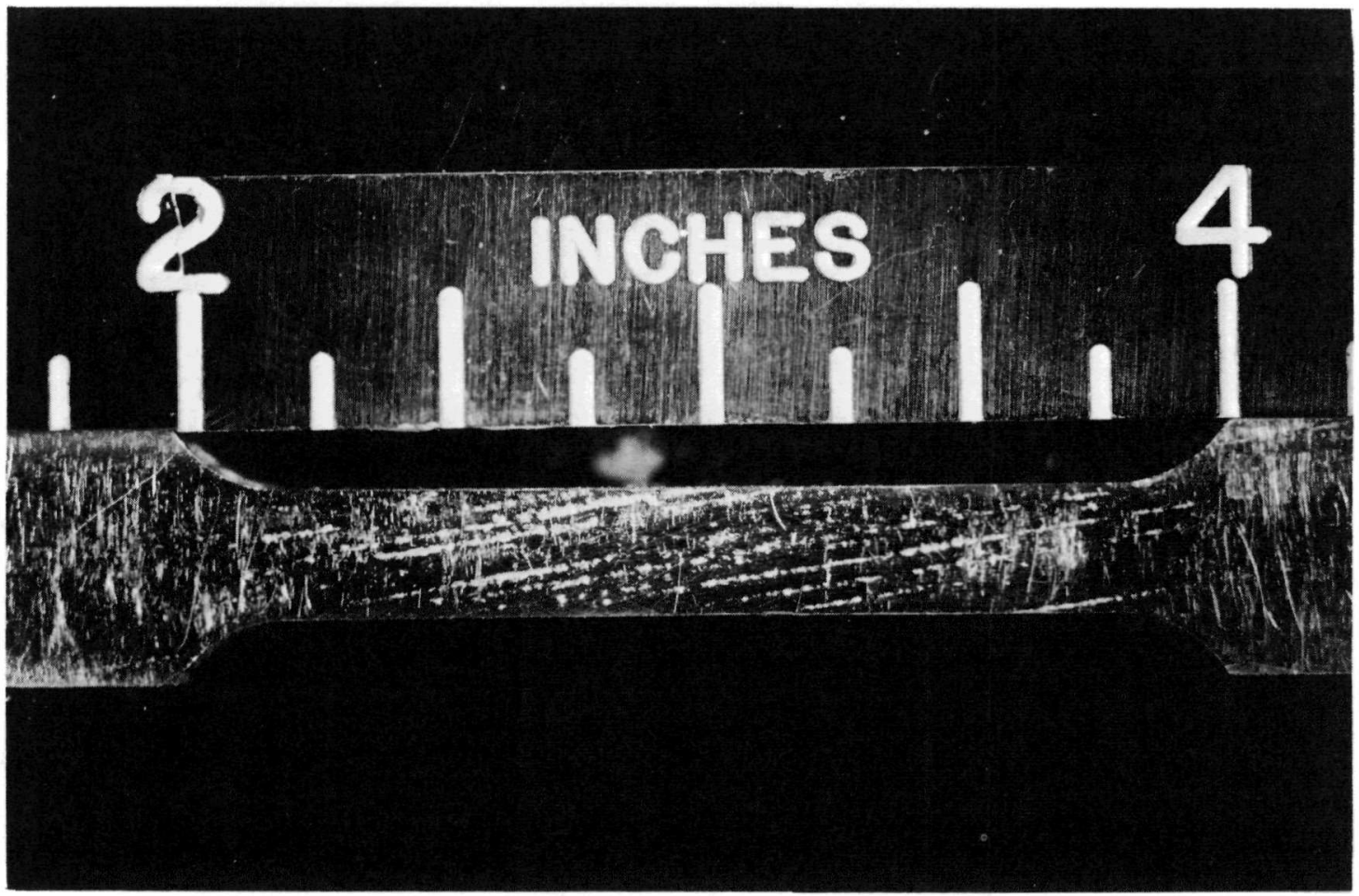

Figure 17. A Tensile Specimen in the As-Rolled Condition. 


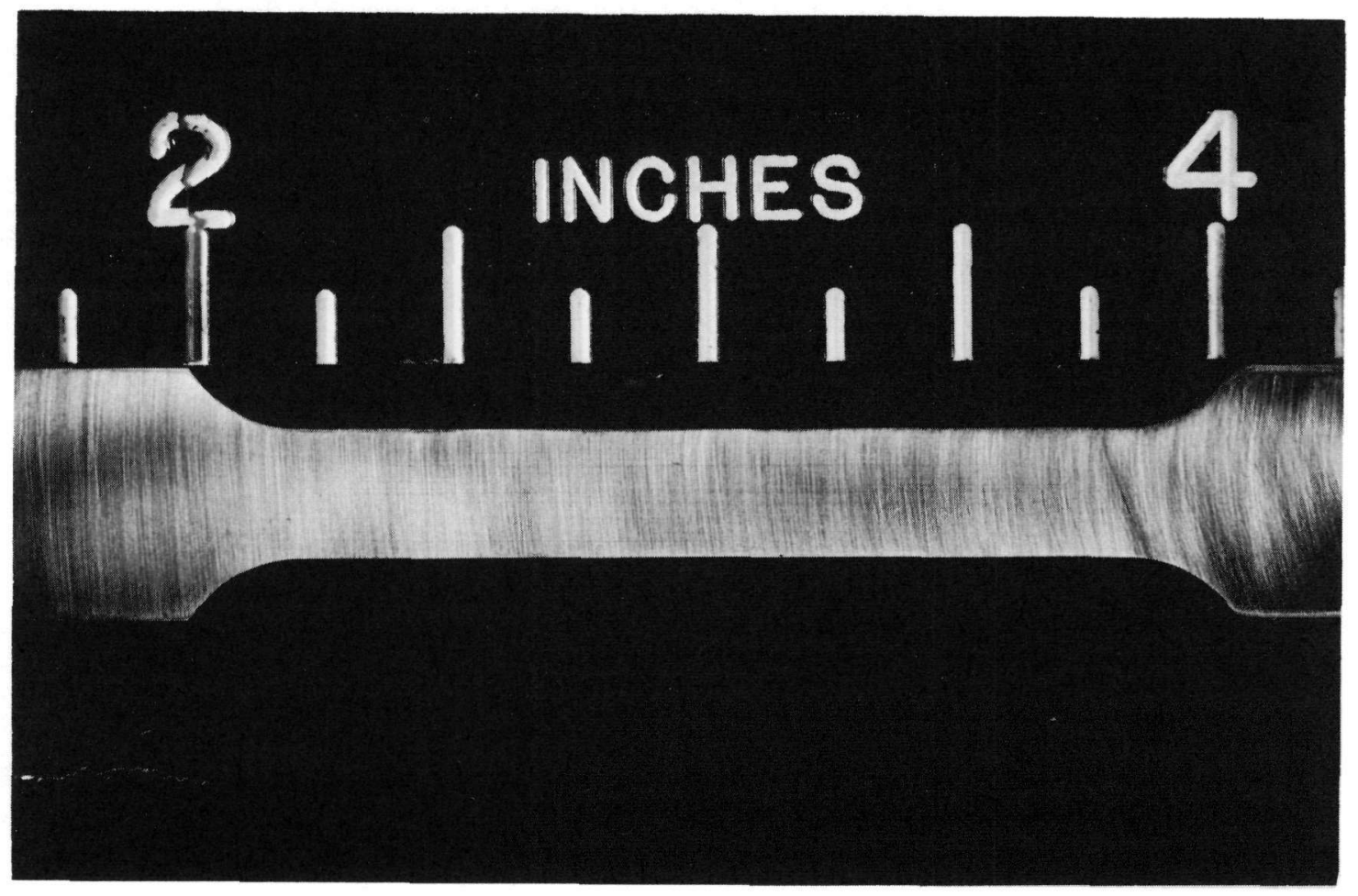

Figure 18. A Tensile Specimen After Polishing. 
TABLE XV

AVERAGE ELECTRICAL RESISTIVITY/CONDUCTIVITY

MEASURED FROM THE AS-ROLLED SPECIMENS

\begin{tabular}{|c|c|c|c|c|c|}
\hline $\begin{array}{l}\text { Specimen } \\
\text { Series }\end{array}$ & $\begin{array}{l}\text { Percent } \\
\text { Cold Work }\end{array}$ & $\begin{array}{c}\text { Average } \\
\text { Resistivity } \\
(\mu \text { ohm }-\mathrm{cm})\end{array}$ & $\begin{array}{c}\text { Average } \\
\text { Conductivity } \\
(\% \text { IACS })\end{array}$ & $s^{b}$ & $t^{c}$ \\
\hline $\begin{array}{l}07-S L \\
07-S T\end{array}$ & $\begin{array}{l}0 \\
0\end{array}$ & $\begin{array}{l}76.25 \\
76.43\end{array}$ & $\begin{array}{l}2.261 \\
2.256\end{array}$ & $\begin{array}{l}.482 \\
.550\end{array}$ & .333 \\
\hline $\begin{array}{l}02-S L \\
02-S T\end{array}$ & $\begin{array}{l}8.5 \\
8.5\end{array}$ & $\begin{array}{l}77.11 \\
77.16\end{array}$ & $\begin{array}{l}2.236 \\
2.234\end{array}$ & $\begin{array}{l}.331 \\
.174\end{array}$ & .304 \\
\hline $\begin{array}{l}\text { O3-SL } \\
03-S T\end{array}$ & $\begin{array}{l}17.6 \\
17.6\end{array}$ & $\begin{array}{l}77.54 \\
77.37\end{array}$ & $\begin{array}{l}2.224 \\
2.228\end{array}$ & $\begin{array}{l}.283 \\
.110\end{array}$ & 1.238 \\
\hline $\begin{array}{l}04-S L \\
04-S T\end{array}$ & $\begin{array}{l}30.9 \\
30.9\end{array}$ & $\begin{array}{l}78.13 \\
78.04\end{array}$ & $\begin{array}{l}2.207 \\
2.209\end{array}$ & $\begin{array}{l}.158 \\
.203\end{array}$ & .761 \\
\hline $\begin{array}{l}05-S L \\
05-S T\end{array}$ & $\begin{array}{l}40.1 \\
40.1\end{array}$ & $\begin{array}{l}78.38 \\
78.22\end{array}$ & $\begin{array}{l}2.200 \\
2.204\end{array}$ & $\begin{array}{l}.491 \\
.180\end{array}$ & .680 \\
\hline $\begin{array}{l}06-S L \\
06-S T\end{array}$ & $\begin{array}{l}49.0 \\
49.0\end{array}$ & $\begin{array}{l}78.33 \\
78.18\end{array}$ & $\begin{array}{l}2.201 \\
2.205\end{array}$ & $\begin{array}{l}.133 \\
.189\end{array}$ & 1.431 \\
\hline
\end{tabular}

a

$\mathrm{SL}=$ parallel to rolling ST $=$ perpendicular to rolling

b Estimate of standard deviation

c "T" statistic; significant $t$ is 2.036 
Plotted in Figure 19 are the data as presented in Table XV, which lists the resistivity/conductivity versus degree of cold work in each direction. The one sigma or one $s$ error bars are shown for the specimens taken parallel to rolling. The second order polynomial best fit is also given, and it is apparent that these data fit the parabola quite well, which has been the case for other data in this study. The individual averages of the resistivity for each specimen are given in Table XVI.

This entire series of measurements was then repeated for the specimens after they had been polished. Area measurements are given in Table XVII, average resistivities/conductivites are given in Table XVIII, the resulting plot in Figure 20, and the individual data in Table XIX.

Upon comparison of Figures 19 and 20, one marked difference does become immediately evident, and that is the lowering of the relative change in resistivity from the annealed condition to $50 \%$ cold work, seemingly due to polishing. Very little change after polishing is noted as one nears $50 \%$ cold work, the major change being at the lower degrees of cold work. This is to be expected if the major conductivity/resistivity change that is due to cold working lies near or at the surface of the specimen. In effect it would seem that most of the affected material was polished away on the lower degree of cold worked specimens, which would tend to add substance to the premise that most of the cold worked material lay near to the surface. This is surprising since only .002.006 of an inch was removed from the overall thickness of the specimens. Also, the desired effect of reducing data variance was not achieved, thus any future usage of these data will utilize the results from the unpolished specimens unless otherwise noted, due to this fact. It is 


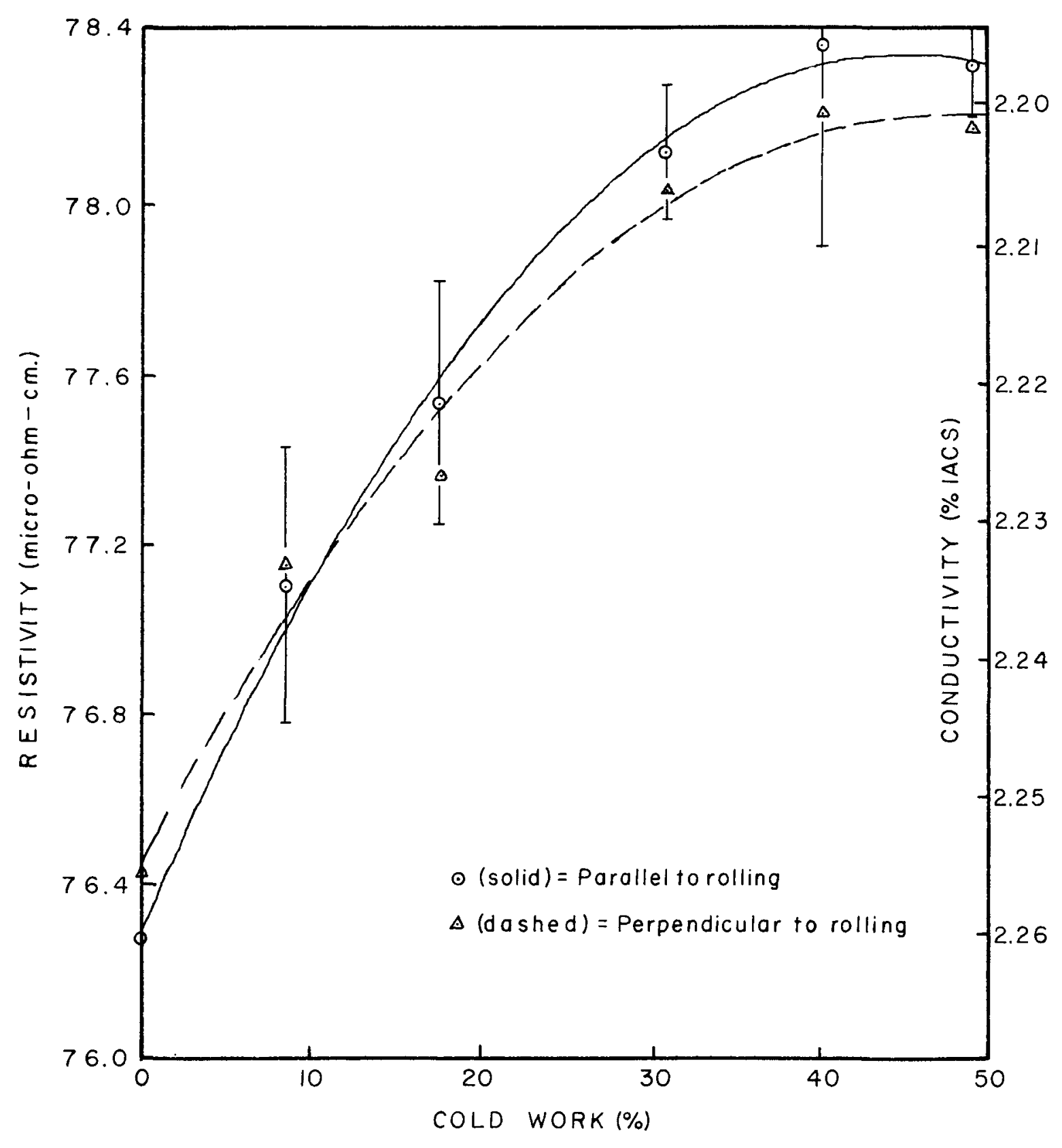

Figure 19. Plot of Average Resistivity/Conductivity versus Percent Cold Work for the As-Rolled Specimens. 
TABLE XVI

INDIVIDUAL SPECIIIEN DATA FOR THE ELECTRICAL

RESISTIVITY/CONDUCTIVITY MEASURED

FRON TIIE AS-ROLLED SPECIMEIS

\begin{tabular}{|c|c|c|c|c|c|c|c|}
\hline $\begin{array}{l}\text { Specimen } \\
\text { Number }\end{array}$ & $\begin{array}{l}\text { Resistivity } \\
\text { (microohm-cm) }\end{array}$ & $\begin{array}{l}\text { Conductivity } \\
\text { (\%IACS })\end{array}$ & $s^{b}$ & $\begin{array}{l}\text { Specimen } \\
\text { Number }\end{array}$ & $\begin{array}{l}\text { Resistivity } \\
\text { (microohm-cm) }\end{array}$ & $\begin{array}{c}\text { Conductivity } \\
(\% \text { IACS })\end{array}$ & $s^{b}$ \\
\hline 07-SL-1 & 76.46 & 2.255 & .027 & $07-\mathrm{ST}-1$ & 75.54 & 2.282 & .018 \\
\hline 2 & 76.46 & 2.255 & .018 & 2 & 76.25 & 2.261 & .018 \\
\hline 3 & 76.40 & 2.257 & .035 & 3 & 76.90 & 2.242 & .018 \\
\hline 4 & 75.40 & 2.257 & .015 & 4 & 76.67 & 2.249 & .024 \\
\hline 5 & 76.55 & 2.252 & .024 & 5 & 76.76 & 2.246 & .018 \\
\hline $02-S L-1$ & 77.46 & 2.226 & .011 & $02-S T-1$ & 77.46 & 2.226 & .016 \\
\hline 2 & 77.19 & 2.234 & .017 & 2 & 77.07 & 2.237 & .021 \\
\hline 3 & 77.38 & 2.228 & .014 & 3 & 77.03 & 2.238 & .009 \\
\hline 4 & 76.81 & 2.245 & .016 & 4 & 77.18 & 2.234 & .018 \\
\hline 5 & 76.72 & 2.247 & .009 & 5 & 77.07 & 2.237 & .016 \\
\hline 03-SL-1 & 77.17 & 2.234 & .020 & $03-S T-1$ & 77.40 & 2.228 & .015 \\
\hline 2 & 77.72 & 2.218 & .015 & 2 & 77.33 & 2.230 & .020 \\
\hline 3 & 77.47 & 2.226 & .016 & 3 & 77.55 & 2.223 & .015 \\
\hline 4 & 77.91 & 2.213 & .010 & 4 & 77.30 & 2.230 & .015 \\
\hline 5 & 77.42 & 2.227 & .015 & 5 & 77.28 & 2.231 & .015 \\
\hline $04-S L-1$ & 78.06 & 2.209 & .014 & $04-S T-1$ & 77.89 & 2.214 & .012 \\
\hline 2 & 78.25 & 2.203 & .011 & 2 & 77.95 & 2.212 & .015 \\
\hline 3 & 78.28 & 2.202 & .007 & 3 & 78.02 & 2.210 & .008 \\
\hline 4 & 77.89 & 2.214 & .013 & 4 & 77.94 & 2.212 & .013 \\
\hline 5 & 78.14 & 2.206 & .015 & 5 & 78.39 & 2.199 & .015 \\
\hline
\end{tabular}


TABLE XVI (continued)

\begin{tabular}{|c|c|c|c|c|c|c|c|}
\hline $\begin{array}{l}\text { Specimen } \\
\text { Number }\end{array}$ & $\begin{array}{l}\text { Resistivity } \\
(\text { microohm- } \mathrm{cm})\end{array}$ & $\begin{array}{c}\text { Conductivity } \\
\text { (\%IACS) }\end{array}$ & $s^{b}$ & $\begin{array}{l}\text { Specimen } \\
\text { Number }\end{array}$ & $\begin{array}{l}\text { Resistivity } \\
\text { (microohm- } \mathrm{cm} \text { ) }\end{array}$ & $\begin{array}{c}\text { Conductivity } \\
(\% \text { IACS })\end{array}$ & $s^{b}$ \\
\hline $05-S L-1$ & 78.39 & 2.199 & .015 & $05-S T-1$ & 78.43 & 2.198 & .015 \\
\hline 2 & 78.05 & 2.209 & .007 & 2 & 78.30 & 2.202 & .011 \\
\hline 3 & 77.96 & 2.212 & .007 & 3 & 78.16 & 2.206 & .020 \\
\hline 4 & 78.20 & 2.205 & .009 & 4 & 77.95 & 2.212 & .022 \\
\hline 5 & 78.31 & 2.202 & .013 & 5 & 78.28 & 2.202 & .012 \\
\hline $06-S L-1$ & 78.21 & 2.204 & .009 & $06-\mathrm{ST}-1$ & 78.24 & 2.204 & .012 \\
\hline 2 & 78.53 & 2.195 & .008 & 2 & 78.44 & 2.198 & .010 \\
\hline 3 & 78.36 & 2.200 & .013 & 3 & 78.17 & 2.206 & .008 \\
\hline 4 & 78.32 & 2.201 & .012 & 4 & 78.14 & 2.206 & .005 \\
\hline 5 & 78.22 & 2.204 & .008 & 5 & 77.91 & 2.213 & .014 \\
\hline
\end{tabular}

a Conductivity $(\%$ IACS $)=\frac{172.41}{\text { Resistivity }}$

b Estimate of the standard deviation of the Resistivity 
TABLE XVII

TENSILE SPECIMEN AREA MEASUREMENTS

(POLISIIED)

\begin{tabular}{|c|c|c|c|c|c|c|c|c|}
\hline \multirow[b]{2}{*}{$\begin{array}{l}\text { Specimen } \\
\text { Number }\end{array}$} & \multicolumn{3}{|c|}{ Width (inch) } & \multicolumn{3}{|c|}{ Thickness (inch) } & \multirow{2}{*}{$\begin{array}{c}\text { Average } \\
\text { Area } \\
\text { (sq.in.) }\end{array}$} & \multirow[b]{2}{*}{$s^{a}$} \\
\hline & $\begin{array}{l}\text { Meas. } \\
\# 1\end{array}$ & $\begin{array}{l}\text { Meas. } \\
\# 2\end{array}$ & $\begin{array}{l}\text { Meas. } \\
\# 3\end{array}$ & $\begin{array}{l}\text { Meas. } \\
\# 1\end{array}$ & $\begin{array}{l}\text { 'Jeas. } \\
\# 2\end{array}$ & $\begin{array}{l}\text { Meas. } \\
\# 3\end{array}$ & & \\
\hline $07-S L-1$ & .2522 & .2510 & .2522 & .3268 & .3269 & .3269 & .08230 & .00023 \\
\hline 2 & .2519 & .2510 & .2520 & .3265 & .3266 & .3267 & .08218 & .00018 \\
\hline 3 & .2473 & .2466 & .2473 & .3274 & .3274 & .3275 & .08090 & .00014 \\
\hline 4 & .2517 & .2507 & .2519 & .3281 & .3281 & .3283 & .08251 & .00023 \\
\hline 5 & .2511 & .2500 & .2512 & .3240 & .3238 & .3237 & .08188 & .00046 \\
\hline 07-ST-1 & .2531 & .2522 & .2532 & .3309 & .3307 & .3306 & .08362 & .00019 \\
\hline 2 & .2515 & .2505 & .2515 & .3281 & .3283 & .3284 & .08245 & .00019 \\
\hline 3 & .2546 & .2535 & .2549 & .3313 & .3310 & .3310 & .08421 & .00026 \\
\hline 4 & .2553 & .2547 & .2555 & .3300 & .3301 & .3304 & .08425 & .00017 \\
\hline 5 & .2510 & .2499 & .2508 & .3314 & .3313 & .3313 & .08302 & .00020 \\
\hline $02-S L-1$ & .2547 & .2534 & .2543 & .3011 & .3011 & .3016 & .07656 & .00023 \\
\hline 2 & .2576 & .2565 & .2573 & .3020 & .3020 & .3020 & .07765 & .00017 \\
\hline 3 & .2566 & .2556 & .2565 & .3030 & .3028 & .3028 & .07760 & .00018 \\
\hline 4 & .2514 & .2504 & .2513 & .3026 & .3022 & .3026 & .07593 & .00022 \\
\hline 5 & .2516 & .2506 & .2514 & .3004 & .2998 & .2998 & .07536 & .00023 \\
\hline $02-S T-1$ & .2516 & .2502 & .2517 & .2965 & .2960 & .2957 & .07436 & .00028 \\
\hline 2 & .2549 & .2537 & .2547 & .2983 & .2980 & .2978 & .07583 & .00022 \\
\hline 3 & .2562 & .2550 & .2559 & .2974 & .2971 & .2969 & .07598 & .00022 \\
\hline 4 & .2574 & .2567 & .2575 & .2968 & .2964 & .2964 & .07627 & .00016 \\
\hline 5 & .2511 & .2501 & .2509 & .2988 & .2937 & .2986 & .07488 & .00016 \\
\hline
\end{tabular}


TABLE XVII (continued)

\begin{tabular}{|c|c|c|c|c|c|c|c|c|}
\hline \multirow[b]{2}{*}{$\begin{array}{l}\text { Specimen } \\
\text { Number }\end{array}$} & \multicolumn{3}{|c|}{ Width (inch) } & \multicolumn{3}{|c|}{ Thickness (inch) } & \multirow{2}{*}{$\begin{array}{c}\text { Average } \\
\text { Area } \\
\text { (sq.in.) }\end{array}$} & \multirow[b]{2}{*}{$\mathrm{s}^{\mathrm{a}}$} \\
\hline & $\begin{array}{c}\text { Meas. } \\
\# 1\end{array}$ & $\begin{array}{l}\text { Meas. } \\
\# 2\end{array}$ & $\begin{array}{l}\text { Meas. } \\
\# 3\end{array}$ & $\begin{array}{l}\text { lleas. } \\
\# 1\end{array}$ & $\begin{array}{l}\text { Meas. } \\
\# 2\end{array}$ & $\begin{array}{l}\text { Meas. } \\
\# 3\end{array}$ & & \\
\hline $03-S L-1$ & .2513 & .2502 & .2515 & .2763 & .2767 & .2771 & .06945 & .00023 \\
\hline 2 & .2574 & .2565 & .2575 & .2770 & .2768 & .2768 & .07119 & .00017 \\
\hline 3 & .2511 & .2500 & .2510 & .2745 & .2743 & .2743 & .06878 & .00018 \\
\hline 4 & .2561 & .2552 & .2562 & .2747 & .2752 & .2754 & .07038 & .00016 \\
\hline 5 & .2521 & .2507 & .2521 & .2738 & .2733 & .2728 & .06877 & .00025 \\
\hline $03-S T-1$ & .2528 & .2518 & .2529 & .2721 & .2719 & .2719 & .06867 & .00018 \\
\hline 2 & .2514 & .2503 & .2516 & .2728 & .2728 & .2729 & .06851 & .00020 \\
\hline 3 & .2509 & .2500 & .2510 & .2730 & .2730 & .2733 & .06845 & .00018 \\
\hline 4 & .2529 & .2519 & .2528 & .2705 & .2708 & .2711 & .06839 & .00016 \\
\hline 5 & .2518 & .2508 & .2520 & .2737 & .2738 & .2739 & .06887 & .00018 \\
\hline $04-S L-1$ & .2520 & .2508 & .2521 & .2358 & .2349 & .2346 & .05916 & .00025 \\
\hline 2 & .2549 & .2535 & .2541 & .2345 & .2349 & .2350 & .05968 & .00012 \\
\hline 3 & .2532 & .2517 & .2535 & .2361 & .2358 & .2357 & .05963 & .00024 \\
\hline 4 & .2505 & .2496 & .2505 & .2371 & .2373 & .2375 & .05937 & .00013 \\
\hline 5 & .2515 & .2501 & .2512 & .2311 & .2308 & .2305 & .05792 & .00020 \\
\hline $04-S T-1$ & .2489 & .2476 & .2487 & .2343 & .2340 & .2339 & .05814 & .00019 \\
\hline 2 & .2505 & .2493 & .2506 & .2359 & .2357 & .2359 & .05900 & .00020 \\
\hline 3 & .2548 & .2539 & .2550 & .2345 & .2345 & .2346 & .05970 & .00015 \\
\hline 4 & .2494 & .2479 & .2492 & .2356 & .2355 & .2355 & .05861 & .00020 \\
\hline 5 & .2508 & .2496 & .2509 & .2329 & .2332 & .2334 & .05839 & .00018 \\
\hline
\end{tabular}


TABLE XVII (continued)

\begin{tabular}{|c|c|c|c|c|c|c|c|c|}
\hline \multirow[b]{2}{*}{$\begin{array}{l}\text { Specimen } \\
\text { Number }\end{array}$} & \multicolumn{3}{|c|}{ Width (inch) } & \multicolumn{3}{|c|}{ Thickness (inch) } & \multirow{2}{*}{$\begin{array}{c}\text { Average } \\
\text { Area } \\
\text { (sq.in.) }\end{array}$} & \multirow[b]{2}{*}{$\mathrm{s}^{\mathrm{a}}$} \\
\hline & $\begin{array}{l}\text { Meas. } \\
\# 1\end{array}$ & $\begin{array}{l}\text { Meas. } \\
\# 2\end{array}$ & $\begin{array}{l}\text { Meas. } \\
\# 3\end{array}$ & $\begin{array}{c}\text { Meas. } \\
\# 1\end{array}$ & $\begin{array}{l}\text { Meas. } \\
\# 2\end{array}$ & $\begin{array}{l}\text { Meas. } \\
\# 3\end{array}$ & & \\
\hline $05-S L-1$ & .2543 & .2535 & .2529 & .2016 & .2014 & .2014 & .05108 & .00017 \\
\hline 2 & .2519 & .2506 & .2513 & .2010 & .2008 & .2011 & .05050 & .00016 \\
\hline 3 & .2518 & .2506 & .2514 & .2006 & .2005 & .2008 & .05041 & .00015 \\
\hline 4 & .2517 & .2506 & .2515 & .2015 & .2008 & .2014 & .05052 & .00028 \\
\hline 5 & .2590 & .2578 & .2589 & .1992 & .1992 & .1998 & .05156 & .00019 \\
\hline $05-\mathrm{ST}-1$ & .2586 & .2580 & .2586 & .2009 & .2002 & .1996 & .05174 & .00018 \\
\hline 2 & .2617 & .2607 & .2614 & .2003 & .1997 & .1998 & .05224 & .00018 \\
\hline 3 & .2518 & .2499 & .2511 & .2020 & .2016 & .2016 & .05062 & .00024 \\
\hline 4 & .2510 & .2510 & .2527 & .2024 & .2020 & .2017 & .05090 & .00017 \\
\hline 5 & .2565 & .2554 & .2562 & .2024 & .2024 & .2027 & .05185 & .00013 \\
\hline $06-S L-1$ & .2578 & .2568 & .2579 & .1699 & .1693 & .1707 & .04377 & .00028 \\
\hline 2 & .2569 & .2559 & .2570 & .1692 & .1667 & .1671 & .04302 & .00041 \\
\hline 3 & .2518 & .2506 & .2517 & .1681 & .1677 & .1686 & .04226 & .00021 \\
\hline 4 & .2520 & .2508 & .2517 & .1690 & .1680 & .1695 & .04246 & .00029 \\
\hline 5 & .2518 & .2508 & .2516 & .1688 & .1673 & .1686 & .04229 & .00029 \\
\hline $06-\mathrm{ST}-1$ & .2518 & .2505 & .2515 & .1687 & .1671 & .1675 & .04224 & .00021 \\
\hline 2 & .2537 & .2526 & .2537 & .1675 & .1670 & .1666 & .04232 & .00016 \\
\hline 3 & .2540 & .2531 & .2540 & .1688 & .1683 & .1677 & .04269 & .00016 \\
\hline 4 & .2523 & .2509 & .2522 & .1687 & .1680 & .1673 & .04230 & .00023 \\
\hline 5 & .2519 & .2507 & .2517 & .1668 & .1664 & .1660 & .04184 & .00016 \\
\hline
\end{tabular}


TABLE XVIII

AVERAGE ELECTRICAL RESISTIVITY/CONDUCTIVITY

MEASURED FROM THE POLISHED SPECIMENS

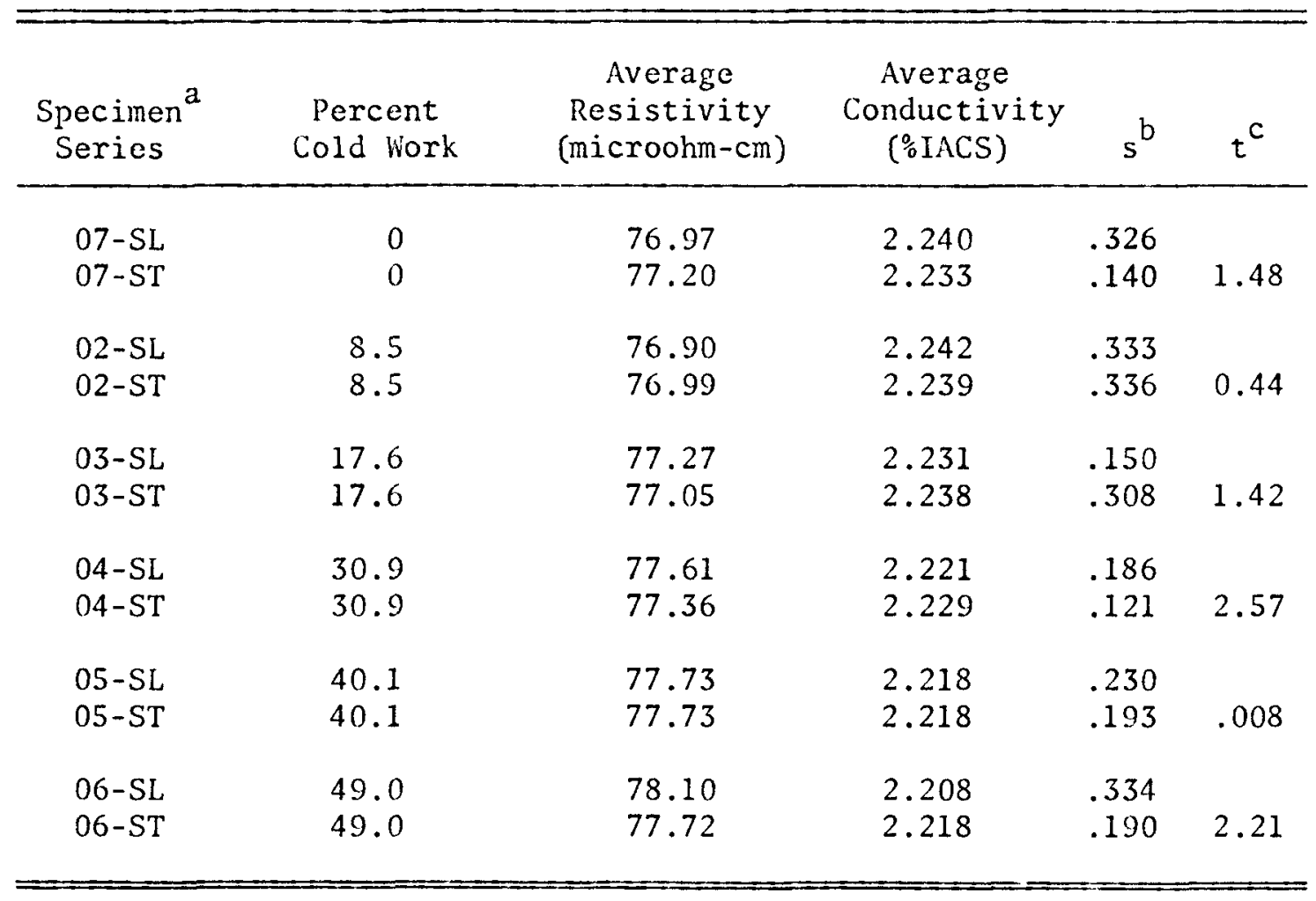

a

$\mathrm{SL}=$ parallel to rolling

ST $=$ perpendicular to rolling

b Estimate of standard deviation

c $t$ statistic 


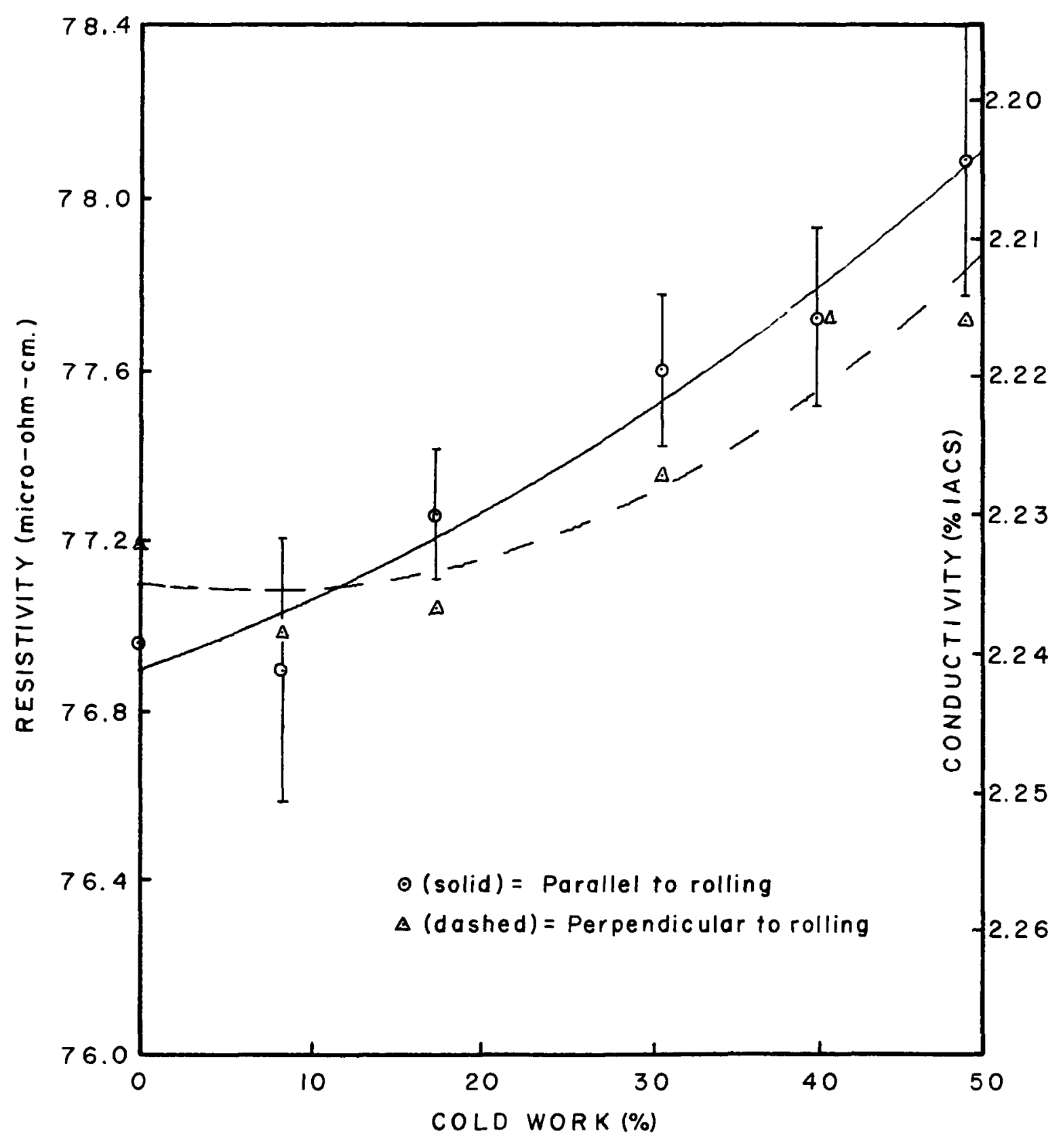

Figure 20. Plot of Average Resistivity/Conductivity versus Percent Cold Work for the Polished Specimens. 
TABLE XIX

INUIVIDUAL SPECIMEN DATA FOR THE LLECTRICAL

RESISTIVITY/CONDUCTIVITY MEASURED

FROM THE POLISHED SPECIMENS

\begin{tabular}{|c|c|c|c|c|c|c|c|}
\hline $\begin{array}{l}\text { Specimen } \\
\text { Number }\end{array}$ & $\begin{array}{l}\text { Resistivity } \\
\text { (microohm-cm) }\end{array}$ & $\begin{array}{c}\text { Conductivity } \\
(\% \text { IACS })\end{array}$ & $s^{b}$ & $\begin{array}{l}\text { Specimen } \\
\text { Number }\end{array}$ & $\begin{array}{l}\text { Resistivity } \\
(\mathrm{microohm}-\mathrm{cm})\end{array}$ & $\begin{array}{c}\text { Conductivity } \\
(\% \text { IACS })\end{array}$ & $s^{b}$ \\
\hline $07-S L-1$ & 76.64 & 2.250 & .017 & $07-S T-1$ & 77.39 & 2.228 & .012 \\
\hline 2 & 77.03 & 2.238 & .017 & 2 & 77.21 & 2.233 & .011 \\
\hline 3 & 77.04 & 2.240 & .017 & 3 & 77.15 & 2.235 & .012 \\
\hline 4 & 77.45 & 2.226 & .018 & 4 & 77.26 & 2.232 & .018 \\
\hline 5 & 76.69 & 2.248 & .011 & 5 & 77.01 & 2.239 & .009 \\
\hline $02-S L-1$ & 77.26 & 2.232 & .016 & $02-S T-1$ & 77.24 & 2.232 & .008 \\
\hline 2 & 76.98 & 2.240 & .016 & 2 & 77.19 & 2.234 & .017 \\
\hline 3 & 76.74 & 2.247 & .016 & 3 & 77.13 & 2.235 & .011 \\
\hline 4 & 77.09 & 2.236 & .016 & 4 & 76.42 & 2.256 & .011 \\
\hline 5 & 76.41 & 2.256 & .016 & 5 & 76.97 & 2.240 & .008 \\
\hline $03-S L-1$ & 77.39 & 2.228 & .010 & $03-\mathrm{ST}-1$ & 77.12 & 2.236 & .012 \\
\hline 2 & 77.11 & 2.236 & .010 & 2 & 76.53 & 2.253 & .012 \\
\hline 3 & 77.17 & 2.234 & .010 & 3 & 77.14 & 2.235 & .016 \\
\hline 4 & 77.23 & 2.232 & .010 & 4 & 77.14 & 2.235 & .012 \\
\hline 5 & 77.46 & 2.226 & .012 & 5 & 77.34 & 2.229 & .010 \\
\hline $04-S L-1$ & 77.58 & 2.222 & .011 & $04-S \Gamma-1$ & 77.21 & 2.233 & .013 \\
\hline 2 & 77.84 & 2.215 & .013 & 2 & 77.30 & 2.230 & .013 \\
\hline 3 & 77.74 & 2.218 & .013 & 3 & 77.52 & 2.224 & .011 \\
\hline 4 & 77.53 & 2.224 & .007 & 4 & 77.32 & 2.230 & .011 \\
\hline 5 & 77.37 & 2.228 & .015 & 5 & 77.44 & 2.226 & .008 \\
\hline
\end{tabular}


TABLE XIX (continued)

\begin{tabular}{|c|c|c|c|c|c|c|c|}
\hline $\begin{array}{l}\text { Specimen } \\
\text { Number }\end{array}$ & $\begin{array}{c}\text { Resistivity } \\
\text { (microohm-cm) }\end{array}$ & $\begin{array}{c}\text { Conductivity } \\
(\% \text { I } \Lambda \text { CS })\end{array}$ & $s^{b}$ & $\begin{array}{l}\text { Specimen } \\
\text { Number }\end{array}$ & $\begin{array}{l}\text { Resistivity } \\
\text { (microohm-cm) }\end{array}$ & $\begin{array}{c}\text { Conductivity } \\
(\% \text { IACS })\end{array}$ & $s^{b}$ \\
\hline $05-S L-1$ & 77.87 & 2.214 & .007 & $05-S T-1$ & 78.04 & 2.209 & .007 \\
\hline 2 & 77.47 & 2.226 & .011 & 2 & 77.52 & 2.224 & .009 \\
\hline 3 & 77.52 & 2.224 & .009 & 3 & 77.69 & 2.219 & .009 \\
\hline 4 & 77.76 & 2.217 & .007 & 4 & 77.74 & 2.218 & .009 \\
\hline 5 & 78.01 & 2.210 & .007 & 5 & 77.63 & 2.221 & .009 \\
\hline $06-$ SL-1 & 77.64 & 2.221 & .009 & $06-\mathrm{ST}-1$ & 77.84 & 2.215 & .006 \\
\hline 2 & 78.49 & 2.196 & .009 & 2 & 77.90 & 2.213 & .006 \\
\hline 3 & 78.25 & 2.203 & .005 & 3 & 77.69 & 2.219 & .006 \\
\hline 4 & 78.22 & 2.204 & .006 & 4 & 77.76 & 2.217 & .009 \\
\hline 5 & 77.89 & 2.214 & .010 & 5 & 77.41 & 2.227 & .009 \\
\hline
\end{tabular}

a Conductivity $(\% \mathrm{I} \Lambda \mathrm{CS})=\frac{172.41}{\text { Resistivity }(\mu \Omega-\mathrm{cm})}$

b Estimate of the standard deviation of the Resistivity 
notable that the resistivity in the direction perpendicular to rolling continues to be pre. ominately lower than that parallel to rolling as was the case for the data presented for the as-rolled specimens, though the differences continue to be statistically nonsignificant. Second order polynomial (parabolic) least squares fits to both sets of data were calculated, and these are reported in Table XX. These were determined on the calculator system described in Appendix $B$. 


\section{TABLE XX}

LEAST SQUARES PARABOLIC FUNCTIONS FOR THE RESISTIVITY VERSUS PERCENT COLD WORK PLOTS

\begin{tabular}{lll}
$\begin{array}{c}\text { Surface } \\
\text { Condition }\end{array}$ & $\begin{array}{c}\text { Direction } \\
\text { With Respect } \\
\text { to Rolling }\end{array}$ & $Y=76.294+\left(9.237 \times 10^{-3}\right) \times-\left(1.033 \times 10^{-4}\right) x^{2}$ \\
\hline As-rolled & Parallel & Function \\
As-rolled & Perpendicular & $Y=76.462+\left(7.38 \times 10^{-3}\right) \times-\left(7.77 \times 10^{-5}\right) x^{2}$ \\
Polished & Parallel & $Y=76.905+\left(1.3965 \times 10^{-3}\right) \times+\left(2.07 \times 10^{-5}\right) x^{2}$ \\
Polished & Perpendicular & $Y=77.108-\left(6.024 \times 10^{-4}\right) \times+\left(4.26 \times 10^{-5}\right) x^{2}$ \\
\hline
\end{tabular}

a $Y=$ Resistivity in microohm centimeters

$X=$ Percent cold work 
CHAPTER IV

MECHANICAL PROPERTY TEST RESULTS

\section{Introduction}

In order to characterize the material in each of the degrees of cold working, mechanical property tests were performed on the tensile specimens described previously in Chapter III. These tests were performed on the polished specimens since this was the condition in which they were left after the D.C. resistivity/conductivity measurements had been completed. The following information was initially desired in order to fully characterize the properties of the materials:

1. Tensile Strength.

2. Yield Strength.

3. Modulus of Elasticity (Young's Modulus).

4. Total Energy absorbed by the specimen to some strain level. Since the Y-12 Mechanical Properties Laboratory had just completed installation of a new computerized tensile machine system, it was desired that these properties be determined by utilization of this system, which is described in further detail in Appendix $C$. Thus the results as reported herein are perhaps much more accurate and precise than any heretofore available. Since the computer controlled the test from start to finish, calculated all results, and did both of these in the same manner from one test to another, practically all variance in data due to the operator should have been removed from the test series. The machine utilized for these tests was calibrated before the tests were begun with standards directly traceable to the NBS. 


\section{5}

An example of a typical load versus strain plot which might be obtained from one of these tests is shown in Figure 21 , and on this figure are shown the quantities which were listed earlicr that we wish to determine from this plot. The following definitions may be listed from this figure:

1. Tensile Strength (psi): The maximum load in pounds reached in the test divided by the original cross-sectional area of the specimen in square inches.

2. Yield Strength at $0.2 \%$ Offset (psi): The load at the intersection of the record with a line drawn parallel to the elastic modulus tangent line, offset by a total of 0.002 inch per inch of strain, divided by the original crosssectional area of the specimen in square inches.

3. Yield Strength at $1.0 \%$ Extension (psi): The load at a strain level of 0.010 inch/inch divided by the original crosssectional area.

4. Modulus of Elasticity or Young's Modulus (psi): The slope, in psi per inch/inch or psi, of the line drawn tangent to the initial linear portion of the load versus strain record, with the load being divided by the original cross-sectional area to obtain the modulus.

5. Energy to $1 \%$ Strain $\left(i n-1 b / i n^{3}\right)$ : The area under the load versus strain record in inch-pounds/inch divided by the original crosssectional area. The units iof this quantity are actually those of energy density, but these are the commonly used units for this quantity. This area is shaded in Figure 21. 


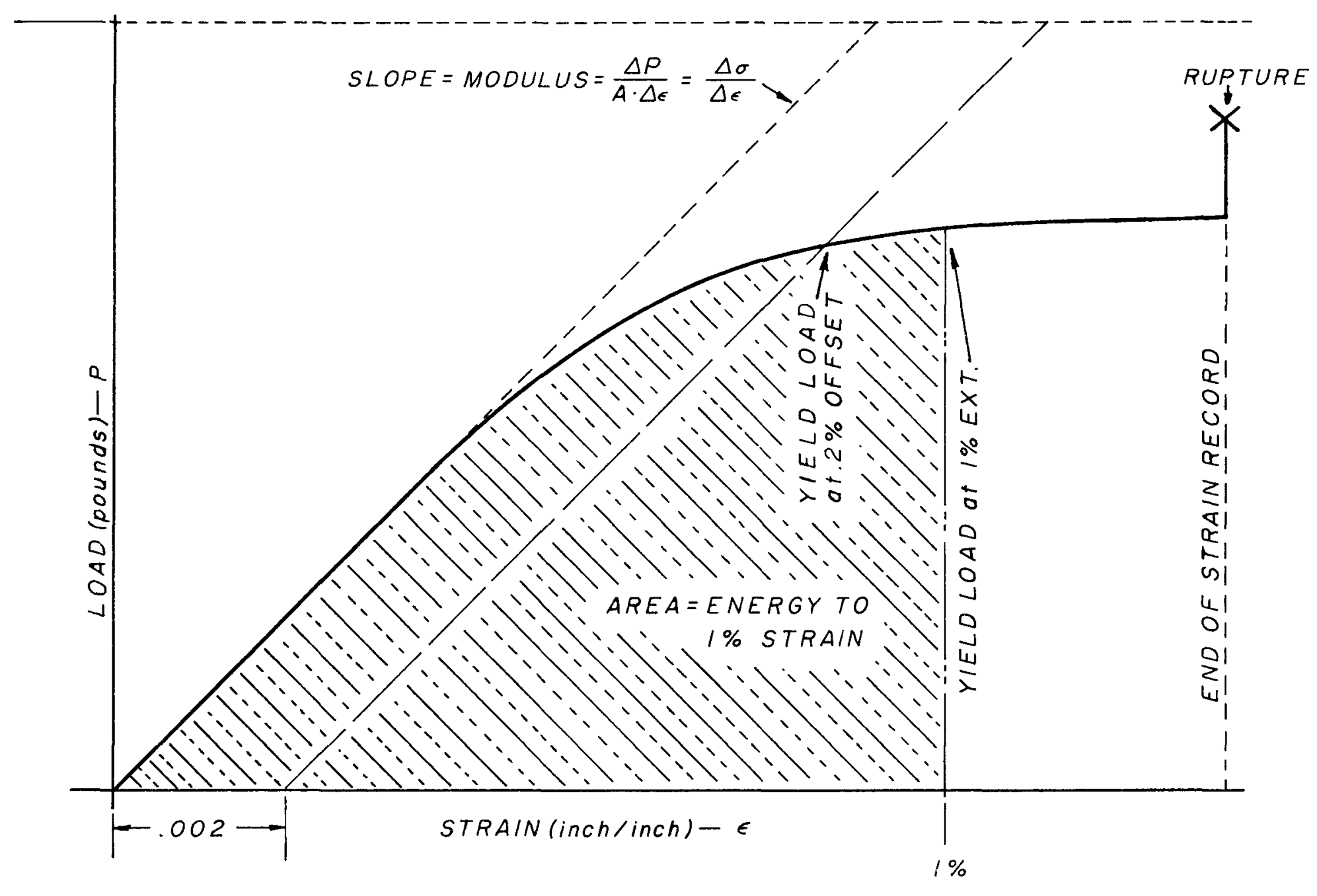

Figure 21. A Typical Load versus Strain Plot with Resulting Measured Quantities. 
The first three of these quantities were measured and calculated for these tests by the computer unless stated otherwise in the data. The energy calculation was not a portion of the computer software and was calculated from the load versus strain plot resulting from the test in a manner to be described later in this chapter.

\section{Test Method}

Five specimens were taken from each plate, both parallel and perpendicular to the direction of rolling. This means that a total of ten specimens were taken from each plate, or that sixty specimens in all were tested. In order to measure strain in the specimen in the most accurate and precise manner available, strain gages were cemented to each specimen, two per specimen, 180 degrees opposed. These were then wired in series and represented one $1 \mathrm{eg}$ of a four-arm Wheatstone Bridge so as to avoid measuring any strain in the specimen due to bending. Thus if any bending moment were exerted on the specimen, the strain gages would only measure the pure axial component of that strain, which is required in order to calculate true tensile properties (Perry, 1962).

Micro-Measurements strain gages number EA-09-250BG-120 or EP-08250BG-120 were utilized for these tests. Both had a nominal gage resistance of $120 \mathrm{ohms} \pm 0.15 \%$, a gage length of $0.250 \mathrm{inch}$, an overall length of 0.375 inch, a grid width of 0.125 inch and an overall width of 0.125 inch. The overall matrix size was 0.52 inch long by 0.22 inch wide. The EA gages had an upper strain limit on the order of $5 \%$, and the upper limit of the EP gages was approximately $20 \%$. The EP gages were used wherever possible due to a premature gage failure problem to be discussed later. Both gages were self temperature compensating, with the EA-09 
gages having a coefficient of thermil expansion of approximately $9 \mathrm{PPM} /{ }^{\circ} \mathrm{F}$, and the EP-08 gages having a coeffi-ient of $8 \mathrm{PPM} /{ }^{\circ} \mathrm{F}$. The 316 stainless has a coefficient of $8.9 \mathrm{PPM} /{ }^{\circ} \mathrm{F}$ (Taylor, 1961), so that either of these gages matched the material adequately for this study. This is only a problem in tests where the temperature changes drastically during the test, and as these were all short term tests, it was not believed to be a problem.

Figure 22 shows two of the tensile specimens, one without gages and one with gages mounted. It is difficult to see the gage due to the darkness of the photograph, but the lead wires and stress-relief. loops are easily visible. The gages were cemented to the specimens with E-: $\operatorname{man} 910$ methyl-two-cyanoacrylate adhesive especially selected by Micro-Measurements for strain gage usage, using a well established procedure of application. Care was taken to roughen up the polished surface with 180 grit emery paper, being sure to run the abrasive markings at approximately $45^{\circ}$ angles with the axis of the specimen so that a criss-cr issed pattern was evident when completed. This was necessary to obtain adequate bonds so that it was possible to measure the maximum degree of strain. Some experimentation in method was usea at the start of the test series, but this was the one which gave most consistent results with little or no premature gage bond failure. As the Eastman 910 adhesive is somewhat hygroscopic, the gages were coated with a suitable gage coating after installation, and the specimens were tested as soon as was possible after gage installation.

The electrical circuit utilized for the excitation and monitoring of the output of the strain gages is shown in Figure 23, and is a commonly 


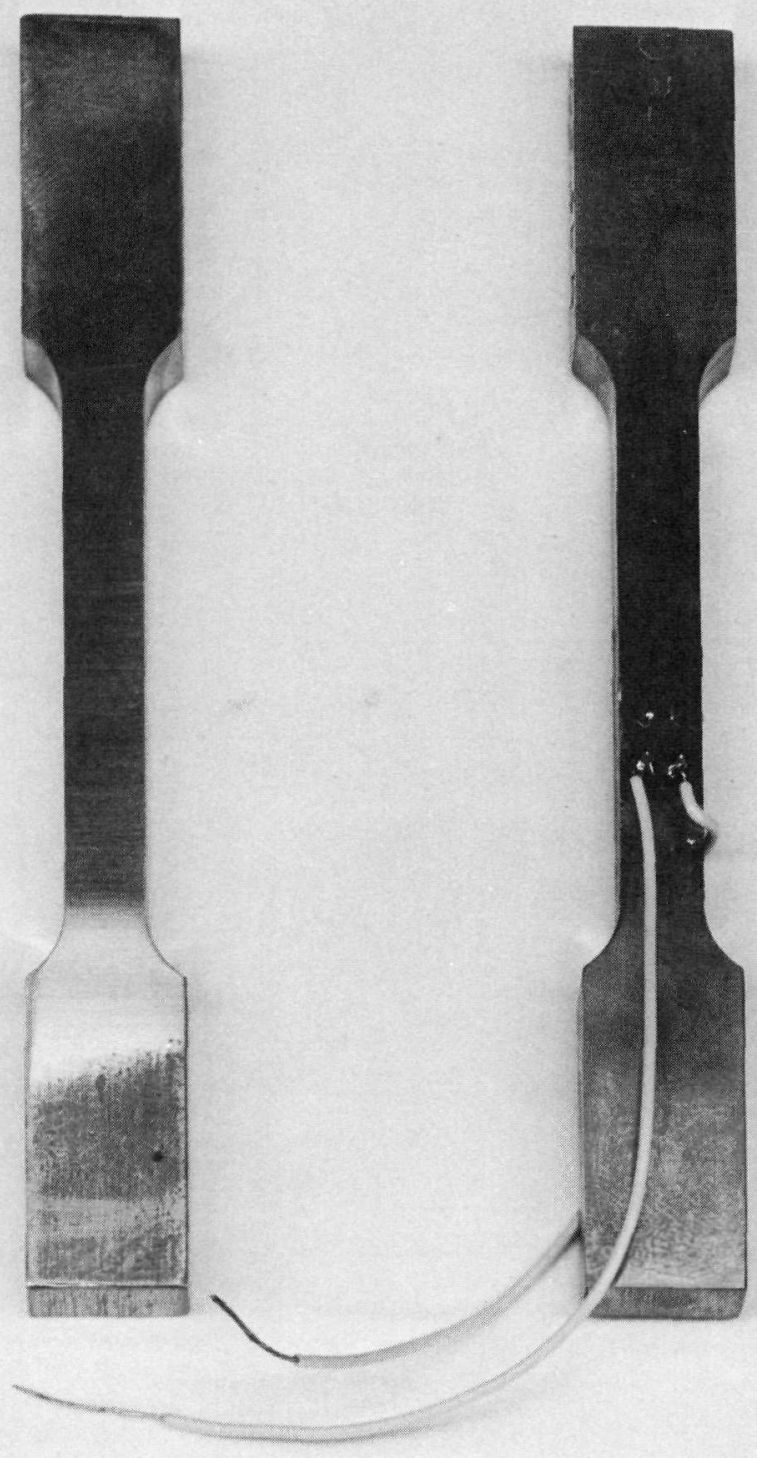

Figure 22. Tensile Specimens - Gaged and Ungaged. 


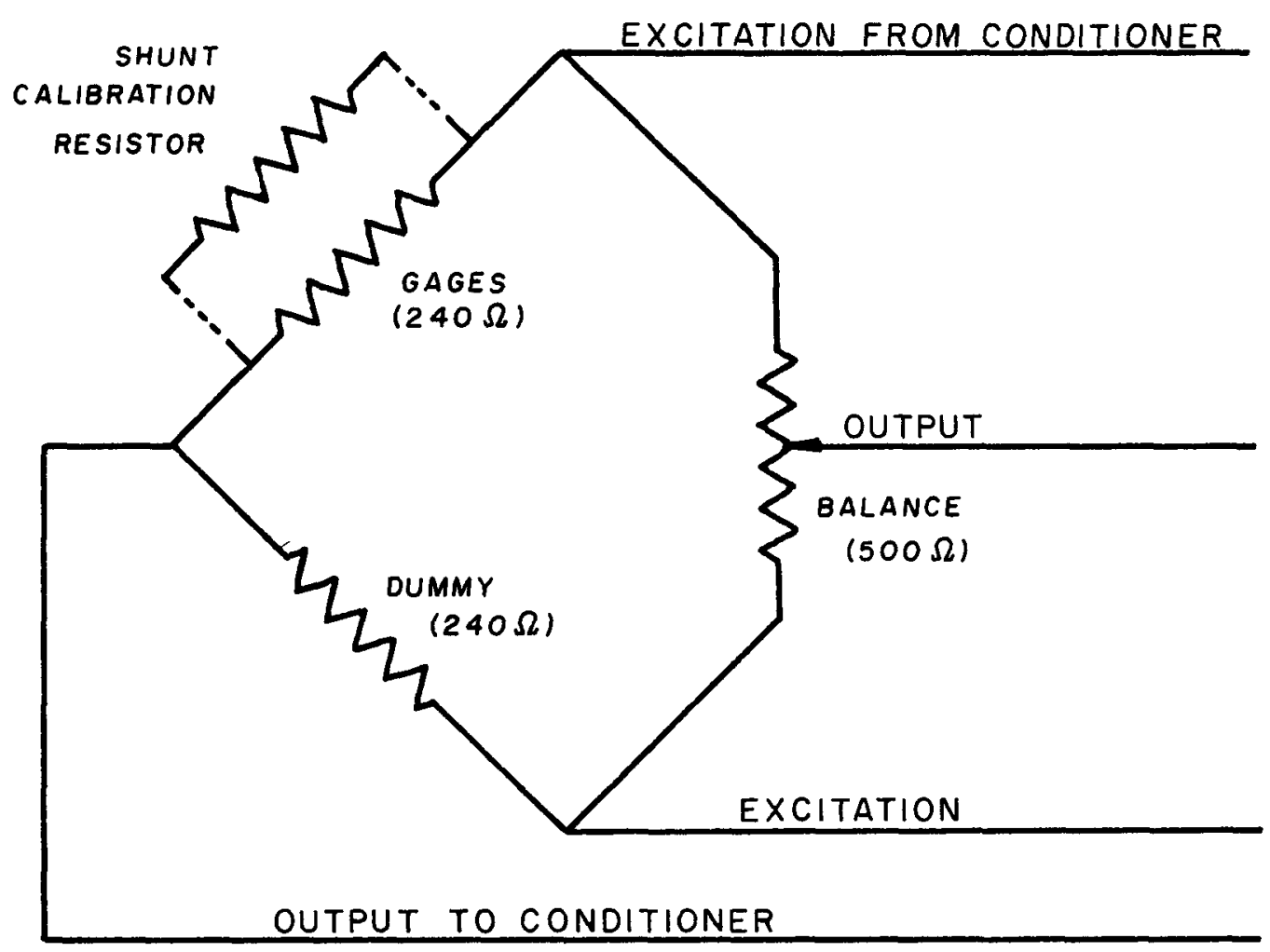

Figure 23. The Wheatstone Bridge. 
used Wheatstone Bridge circuit. No temperature compensation was used on any of the tests, because it was not believed that temperature variations were a problem. Balance of the bridge was accomplished with both the $500 \mathrm{~K}$ ohm balance potentiometer (coarse adjustment) and the zero potentiometer on the strain gage conditioner on the testing machine (fine adjustment). Calibration of the bridge was achieved by shunting a standard resistor, in the form of a resistance decade box, across the gage to simulate a change in resistance due to an equivalent amount of strain. This was calculated from the following equation (Perry, 1962):

$$
R_{c}=\frac{R_{g}(I-F \epsilon)}{F \epsilon}
$$

Depending on the gage factor of the gage $(F)$, a resistance $\left(R_{c}\right)$ on the order of 5700 ohns was used for most of the tests for a strain range of 20,000 micro-inches/inch $(\epsilon)$.

Shown in Figure 24 is the testing machine used for all of the mechanical property tests. A typical test specimen is shown in the gripping devices, which were standard wedge action "V" grips used for flat specimens. From left to right in the photograph are the following components:

1. Load Frame, with the following items:

a. Grips,

b. Specimen with strain gages attached,

c. Bridge completion box, and

d. Resistance Decade Box for bridge calibration.

2. Teletype which was the source of communication with the computer, and 


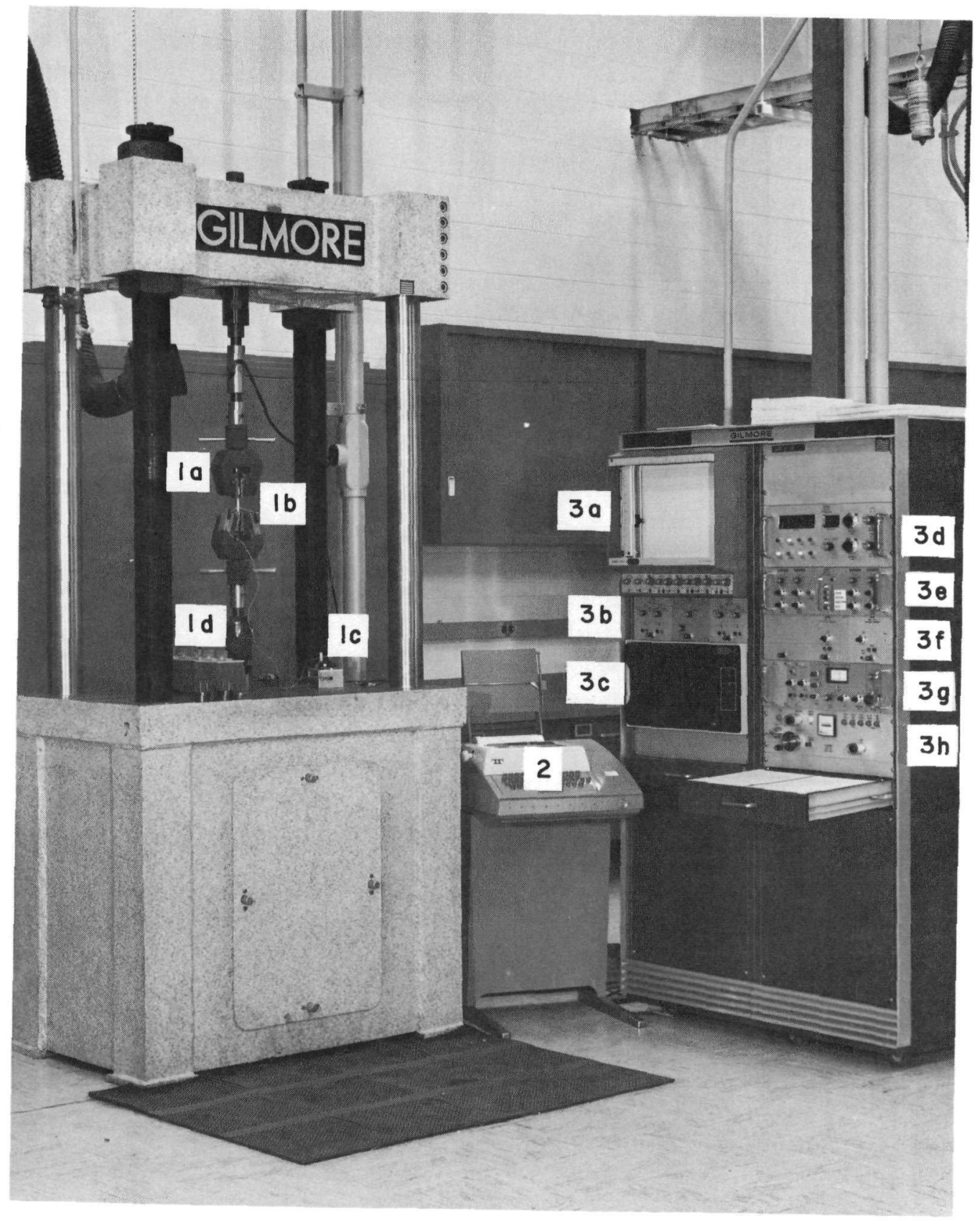

Figure 24. The Testing Machine used for the Mechanical Property Tests. 
3. The control console, composed of the following components from the left top to the right bottom:

a. $X-Y-Y^{\prime}$ recorder on which the load versus strain plots were made,

b. Interface panels for the recorder and computer,

c. High speed paper tape punch,

d. Ramp generator (not used),

e. ilode transfer module,

f. Strain conditioners,

g. Servo controllers with conditioners, and

h. Control panel for hydraulic power supply.

These items are discussed in greater detail in Appendix $C$, as is the computer program used for all tests.

A further enlargement of the test specimen in the grips can be seen in Figure 25, which also shows one of the strain gages in greater detail than was shown in Figure 22 on page 79. The lead wires are visible also, along with the alligator clips to the bridge completion box. Care was taken to ensure that the specimen was placed in the grips so that no extraneous bending moments were placed on it. A universal joint, visible in Figure 24, was used in the load train to also assist in this problem. Efforts were made to install one below the lower grip, but the lack of adequate vertical test space in the machine prevented this. These precautions should have been adequate to ensure axial alignment so that the specimens experienced almost pure tension when under test.

$\Lambda 11$ tests were performed so that the portion of the test depicted in Figure 21 on page 76 was obtained under a condition of uniform rate of 


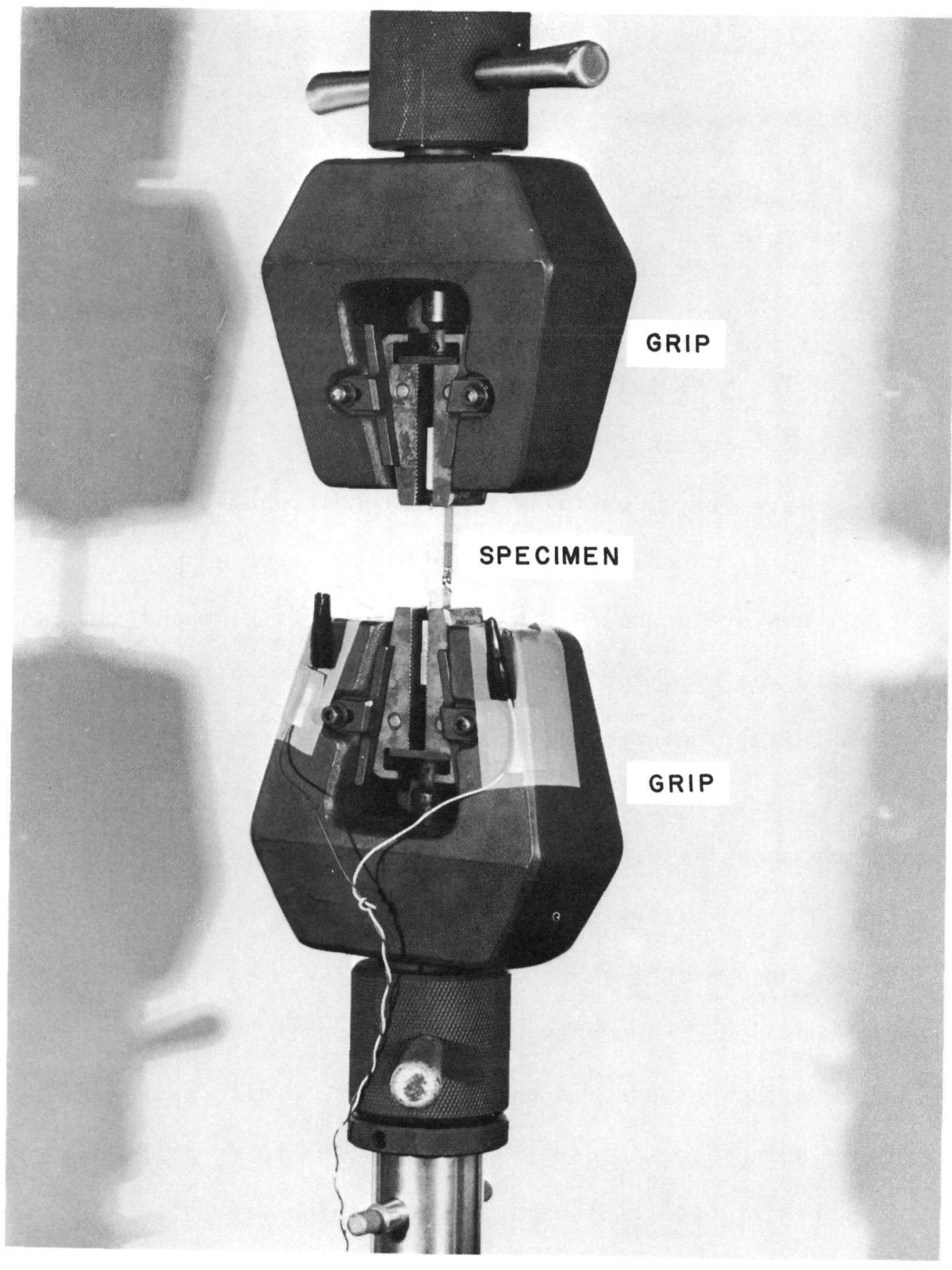

Figure 25. Close-up of the Tensile Specimen and Grips. 
straining. This was accomplished by using the output from the strain gages to control the ram position of the machine so that the machine operated in true strain control. Tests such as these are normally performed at a uniform rate of straining in the laboratory, and it is believed that this method yields the most reliable test results. A strain rate of 0.005 inch/inch per minute was used for these tests, which is also the same rate as is routinely used in the laboratory. Since some of the gages were only capable of monitoring $3-5 \%$ of strain, the machine automatically transferred out of strain control at $1.5 \%$ strain, after the portion of the record as depicted in Figure 21 on page 76 was made. Transfer was made to ram position control and the test was completed at a uniform rate of ram movement of either 0.15 or 0.30 inch/minute until the specimen ruptured. The procedure utilized is described in greater detail in Appendix C.

After the specimen had ruptured, the computer calculated the test results, and these were printed out on the teletype, which again is described in Appendix C. The energy calculation was not performed by the computer, but was calculated from the load versus strain plots. The calculator system, as described in Appendix B, was utilized in this calculation. The areas involved were calculated using the digitizer in a manner described in Appendix B.

\section{Test Results}

The summary of the averages of all mechanical property test results is given in Tables XXI through XXV, along with the estimates of the standard deviation for each value and the associated $95 \%$ confidence limits on these averages. The resulting plots of these averages versus 
TABLE XXI

MECHANICAL PROPERTY TEST RESULTS

TENSILE STRENGTH

\begin{tabular}{|c|c|c|c|c|c|}
\hline $\begin{array}{l}\text { Specimen } \\
\text { Series }\end{array}$ & $\begin{array}{l}\text { Percent } \\
\text { Cold Work }\end{array}$ & $\begin{array}{l}\text { Average } \\
\text { Tensile } \\
\text { Strength } \\
\text { (psi) }\end{array}$ & $s^{a}$ & $\begin{array}{c}95 \% \\
\text { Confidence } \\
\text { Limits } \\
\text { (psi) }\end{array}$ & $\begin{array}{l}\text { Number } \\
\text { of Results } \\
\text { Used for } \\
\text { Average }\end{array}$ \\
\hline $07-S L$ & 0 & 84,470 & 1258 & 3126 & 3 \\
\hline 07-ST & 0 & 85,820 & 56 & 503 & 2 \\
\hline $02-\mathrm{SL}$ & 8.5 & 95,270 & 246 & 391 & 4 \\
\hline $02-\mathrm{ST}$ & 8.5 & 96,090 & 581 & 721 & 5 \\
\hline 03-SL & 17.6 & 108,600 & 552 & 685 & 5 \\
\hline 03-ST & 17.6 & 111,250 & 1603 & 2550 & 4 \\
\hline 04-SL & 30.9 & 137,600 & 575 & 714 & 5 \\
\hline $04-S T$ & 30.9 & 139,300 & 899 & 1116 & 5 \\
\hline $05-S L$ & 40.1 & 148,500 & 1545 & 2458 & 4 \\
\hline $05-S T$ & 40.1 & 156,200 & 1057 & 1312 & 5 \\
\hline 06-SL & 49.0 & 158,800 & 1567 & 2493 & 4 \\
\hline 06-ST & 49.0 & 170,700 & 1183 & 2939 & 3 \\
\hline
\end{tabular}

a

Estimate of the standard deviation.

b See Table XXVII for the reasons for not using five test results for each group. 
TABLE XXII

MECHANICAL PROPERTY TEST RESULTS

YIELD STRENGTH AT $0.2 \%$ OFFSET

\begin{tabular}{|c|c|c|c|c|c|}
\hline $\begin{array}{l}\text { Specimen } \\
\text { Number }\end{array}$ & $\begin{array}{l}\text { Percent } \\
\text { Cọld Work }\end{array}$ & $\begin{array}{l}\text { Average } \\
\text { Yield } \\
\text { Strength } \\
\text { (psi) }\end{array}$ & $s^{a}$ & $\begin{array}{c}95 \% \\
\text { Confidence } \\
\text { Limits } \\
\text { (psi) }\end{array}$ & $\begin{array}{l}\text { Number } \\
\text { of Results } \\
\text { Used for } \\
\text { Average }\end{array}$ \\
\hline $07-S L$ & 0 & 35,020 & 848 & 1053 & 3 \\
\hline $07-S T$ & 0 & 35,700 & 69 & 86 & 5 \\
\hline $02-S L$ & 8.5 & 70,100 & 390 & 480 & 5 \\
\hline $02-S T$ & 8.5 & 73,300 & 1146 & 1423 & 5 \\
\hline 03-SL & 17.6 & 96,280 & 1079 & 1717 & 4 \\
\hline 03-ST & 17.6 & 94,560 & 1430 & 1775 & 5 \\
\hline $04-S L$ & 30.9 & 124,400 & 647 & 803 & 5 \\
\hline $04-S T$ & 30.9 & 115,300 & 827 & 1027 & 5 \\
\hline $05-S L$ & 40.1 & 135,300 & 1237 & 1536 & 5 \\
\hline $05-S T$ & 40.1 & 128,200 & 620 & 770 & 5 \\
\hline $06-S L$ & 49.0 & 144,100 & 1814 & 2252 & 5 \\
\hline 06-ST & 49.0 & 139,400 & 541 & 861 & 5 \\
\hline
\end{tabular}

a Estimate of the standard deviation.

b See Table XXVII for the reasons for not using five test results for each group. 
TABLE XXIII

MECHANICAL PROPERTY TEST RESULTS

YIELD STRENGTH AT $1.0 \%$ EXTENSION

\begin{tabular}{|c|c|c|c|c|c|}
\hline $\begin{array}{l}\text { Specimen } \\
\text { Number }\end{array}$ & $\begin{array}{l}\text { Percent } \\
\text { Cold Work }\end{array}$ & $\begin{array}{l}\text { Average } \\
\text { Yield } \\
\text { Strength } \\
\text { (psi) }\end{array}$ & $\mathbf{s}^{\mathrm{a}}$ & $\begin{array}{c}95 \% \\
\text { Confidence } \\
\text { Limits } \\
\text { (psi) }\end{array}$ & $\begin{array}{l}\text { Number } \\
\text { of Results } \\
\text { Used for } \\
\text { Average }\end{array}$ \\
\hline $\begin{array}{l}07-S L \\
07-S T\end{array}$ & $\begin{array}{l}0 \\
0\end{array}$ & $\begin{array}{l}38,830 \\
39,950\end{array}$ & $\begin{array}{l}983 \\
403\end{array}$ & $\begin{array}{r}1220 \\
500\end{array}$ & $\begin{array}{l}5 \\
5\end{array}$ \\
\hline $\begin{array}{l}\text { 02-SL } \\
02-S T\end{array}$ & $\begin{array}{l}8.5 \\
8.5\end{array}$ & $\begin{array}{l}75,280 \\
78,450\end{array}$ & $\begin{array}{r}509 \\
1198\end{array}$ & $\begin{array}{r}632 \\
1487\end{array}$ & $\begin{array}{l}5 \\
5\end{array}$ \\
\hline $\begin{array}{l}03-S L \\
03-S T\end{array}$ & $\begin{array}{l}17.6 \\
17.6\end{array}$ & $\begin{array}{l}100,100 \\
102,100\end{array}$ & $\begin{array}{r}963 \\
1610\end{array}$ & $\begin{array}{l}1196 \\
1999\end{array}$ & $\begin{array}{l}5 \\
5\end{array}$ \\
\hline $\begin{array}{l}04-S L \\
04-S T\end{array}$ & $\begin{array}{l}30.9 \\
30.9\end{array}$ & $\begin{array}{l}129,000 \\
128,400\end{array}$ & $\begin{array}{l}608 \\
956\end{array}$ & $\begin{array}{r}755 \\
1187\end{array}$ & $\begin{array}{l}5 \\
5\end{array}$ \\
\hline $\begin{array}{l}05-\mathrm{SL} \\
05-\mathrm{ST}\end{array}$ & $\begin{array}{l}40.1 \\
40.1\end{array}$ & $\begin{array}{l}140,000 \\
143,000\end{array}$ & $\begin{array}{r}1340 \\
800\end{array}$ & $\begin{array}{r}1664 \\
993\end{array}$ & $\begin{array}{l}5 \\
5\end{array}$ \\
\hline $\begin{array}{l}06-S L \\
06-S T\end{array}$ & $\begin{array}{l}49.0 \\
49.0\end{array}$ & $\begin{array}{l}149,800 \\
155,500\end{array}$ & $\begin{array}{r}1628 \\
923\end{array}$ & $\begin{array}{l}2021 \\
1146\end{array}$ & $\begin{array}{l}5 \\
5\end{array}$ \\
\hline
\end{tabular}

a Estimate of the standard deviation. 
TABLE XXIV

MECIUNICAL PROPERTY TEST RESULTS MODULUS OF ELASTICITY

\begin{tabular}{|c|c|c|c|c|c|c|c|c|c|}
\hline $\begin{array}{l}\text { Specimen } \\
\text { Number }\end{array}$ & $\begin{array}{l}\text { Percent } \\
\text { Cold Work }\end{array}$ & $\begin{array}{l}\text { Average } \\
\text { Computer } \\
\text { Modulus of } \\
\text { Elasticity } \\
\text { (X10 psi) }\end{array}$ & $s^{a}$ & $\begin{array}{l}\text { Number } \\
\text { of Results } \\
\text { Used for } \\
\text { Average }\end{array}$ & $\begin{array}{l}\text { Average } \\
\text { Calculator } \\
\text { Nodulus of } \\
\text { Elasticity } \\
\text { (X10 psi) }\end{array}$ & $s^{a}$ & $\begin{array}{l}95 \% \\
\text { Conf. } \\
\text { Limits }\end{array}$ & $\begin{array}{l}\text { Number } \\
\text { of } \\
\text { Results }\end{array}$ & $R^{C}$ \\
\hline $\begin{array}{l}07-S L \\
07-S T\end{array}$ & $\begin{array}{l}0 \\
0\end{array}$ & $\begin{array}{l}26.67 \\
27.24\end{array}$ & $\begin{array}{l}.379 \\
.699\end{array}$ & $\begin{array}{l}4 \\
5\end{array}$ & $\begin{array}{l}27.67 \\
27.85\end{array}$ & $\begin{array}{l}.320 \\
.547\end{array}$ & $\begin{array}{l}2.88 \\
1.36\end{array}$ & $\begin{array}{l}2 \\
3\end{array}$ & $\begin{array}{l}.9991 \\
.9997\end{array}$ \\
\hline $\begin{array}{l}02-S L \\
02-S T\end{array}$ & $\begin{array}{l}8.5 \\
8.5\end{array}$ & $\begin{array}{l}25.72 \\
27.11\end{array}$ & $\begin{array}{r}1.489 \\
.803\end{array}$ & $\begin{array}{l}5 \\
5\end{array}$ & $\begin{array}{l}27.45 \\
28.42\end{array}$ & $\begin{array}{l}.839 \\
.360\end{array}$ & $\begin{array}{l}2.08 \\
0.89\end{array}$ & $\begin{array}{l}3 \\
3\end{array}$ & $\begin{array}{l}.9999 \\
.9999\end{array}$ \\
\hline $\begin{array}{l}03-S L \\
03-S T\end{array}$ & $\begin{array}{l}17.6 \\
17.6\end{array}$ & $\begin{array}{l}25.39 \\
27.68\end{array}$ & $\begin{array}{l}.100 \\
.462\end{array}$ & $\begin{array}{l}3 \\
5\end{array}$ & $\begin{array}{l}27.70 \\
27.84\end{array}$ & $\begin{array}{l}.456 \\
.927\end{array}$ & $\begin{array}{l}1.13 \\
2.30\end{array}$ & $\begin{array}{l}3 \\
3\end{array}$ & $\begin{array}{l}.9999 \\
.9999\end{array}$ \\
\hline $\begin{array}{l}04-S L \\
04-S T\end{array}$ & $\begin{array}{l}30.9 \\
30.9\end{array}$ & $\begin{array}{l}24.86 \\
27.98\end{array}$ & $\begin{array}{l}.650 \\
.566\end{array}$ & $\begin{array}{l}5 \\
5\end{array}$ & $\begin{array}{l}27.30 \\
27.98\end{array}$ & $\begin{array}{l}.147 \\
.566\end{array}$ & $\begin{array}{l}1.32 \\
5.08\end{array}$ & $\begin{array}{l}2 \\
2\end{array}$ & $\begin{array}{l}.9999 \\
.9993\end{array}$ \\
\hline $\begin{array}{l}05-S L \\
05-S T\end{array}$ & $\begin{array}{l}40.1 \\
40.1\end{array}$ & $\begin{array}{l}24.26 \\
28.25\end{array}$ & $\begin{array}{l}.575 \\
.649\end{array}$ & $\begin{array}{l}5 \\
5\end{array}$ & $\begin{array}{l}26.15 \\
29.89\end{array}$ & $\begin{array}{l}1.37 \\
.268\end{array}$ & $\begin{array}{r}12.31 \\
2.41\end{array}$ & $\begin{array}{l}2 \\
2\end{array}$ & $\begin{array}{r}.9995 \\
1.0000\end{array}$ \\
\hline $\begin{array}{l}06-S L \\
06-S T\end{array}$ & $\begin{array}{l}49.0 \\
49.0\end{array}$ & $\begin{array}{l}23.78 \\
27.93\end{array}$ & $\begin{array}{l}.952 \\
.406\end{array}$ & $\begin{array}{l}5 \\
5\end{array}$ & $\begin{array}{l}25.39 \\
28.19\end{array}$ & $\begin{array}{l}.572 \\
1.44\end{array}$ & $\begin{array}{l}0.71 \\
1.79\end{array}$ & $\begin{array}{l}5 \\
5\end{array}$ & $\begin{array}{l}.9999 \\
.9998\end{array}$ \\
\hline
\end{tabular}


TABLE XXIV (continued)

a Estimate of the standard deviation.

b See Table XXVII for the reasons for not using five results from each group.

c Correlation coefficient ( 1.0000 is a perfect fit to a straight line). 
TABLE XXV

MECIIANICAL PROPERTY TEST RESULTS

ENERGY TO $1.0 \%$ STRAIN

\begin{tabular}{|c|c|c|c|c|c|}
\hline $\begin{array}{l}\text { Specimen } \\
\text { Number }\end{array}$ & $\begin{array}{l}\text { Percent } \\
\text { Cold Hork }\end{array}$ & $\begin{array}{c}\text { Average } \\
\text { Energy } \\
\text { to } 1 \% \\
\text { Strain } \\
\left(\text { in-1b/in }^{3}\right)\end{array}$ & $s^{a}$ & $\begin{array}{c}95 \% \\
\text { Confidence } \\
\text { Limits } 3 \\
(\text { in-1b/in })\end{array}$ & $\begin{array}{l}\text { Number } \\
\text { of Results } \\
\text { Used for } \\
\text { Average }\end{array}$ \\
\hline 07-SL & 0 & 335.6 & 4.06 & 5.04 & 5 \\
\hline 07-ST & 0 & 338.3 & 2.67 & 3.32 & 5 \\
\hline $\begin{array}{l}02-S L \\
02-S T\end{array}$ & $\begin{array}{l}8.5 \\
8.5\end{array}$ & $\begin{array}{l}603.3 \\
631.6\end{array}$ & $\begin{array}{r}5.96 \\
10.55\end{array}$ & $\begin{array}{r}7.40 \\
13.10\end{array}$ & $\begin{array}{l}5 \\
5\end{array}$ \\
\hline $\begin{array}{l}03-S L \\
03-S T\end{array}$ & $\begin{array}{l}17.6 \\
17.6\end{array}$ & $\begin{array}{l}768.2 \\
779.7\end{array}$ & $\begin{array}{l}9.68 \\
9.48\end{array}$ & $\begin{array}{l}12.02 \\
11.77\end{array}$ & $\begin{array}{l}5 \\
5\end{array}$ \\
\hline $\begin{array}{l}\text { 04-SL } \\
04-S T\end{array}$ & $\begin{array}{l}30.9 \\
30.9\end{array}$ & $\begin{array}{l}909.6 \\
900.0\end{array}$ & $\begin{array}{r}6.09 \\
14.21\end{array}$ & $\begin{array}{r}7.56 \\
17.64\end{array}$ & $\begin{array}{l}5 \\
5\end{array}$ \\
\hline $\begin{array}{l}05-S L \\
05-S T\end{array}$ & $\begin{array}{l}40.1 \\
40.1\end{array}$ & $\begin{array}{l}969.0 \\
972.8\end{array}$ & $\begin{array}{l}7.06 \\
7.11\end{array}$ & $\begin{array}{l}8.76 \\
8.83\end{array}$ & $\begin{array}{l}5 \\
5\end{array}$ \\
\hline $\begin{array}{l}06-S L \\
06-S T\end{array}$ & $\begin{array}{l}49.0 \\
49.0\end{array}$ & $\begin{array}{r}975.4 \\
1015.5\end{array}$ & $\begin{array}{l}7.04 \\
2.89\end{array}$ & $\begin{array}{l}8.74 \\
3.59\end{array}$ & $\begin{array}{l}5 \\
5\end{array}$ \\
\hline
\end{tabular}

a Fstimate of the standard deviation. 
percent cold work are shown in Figures 26 through 30 . Confidence limits or estimates of the standard deviations are not plotted in these figures, for in most cases they are smaller than the circles or triangles surrounding the data points. The familiar second order polynomial least squares fits are also shown in these figures. The resulting functions are given in Table XXVI.

As can be seen from Table XXIII, two Modulus of Elasticity values are reported, one of which was calculated by the computer, in the manner described in Appendix B. The other was calculated from what punched paper tapes were available (not all test results were punched on tape), from the first 15-20 stress versus strain data points punched on the tape. This modulus would correspond to an initial tangent modulus, and it is probably the more representative of the two modulus values. The only reason for reporting the computer result at all is to illustrate the decrease in modulus with degree of cold work in the direction parallel to rolling. This decrease was largely due to the shape of the stress versus strain curve and the resultant data points used by the computer to calculate the modulus values. Thus these modulus values do illustrate this change in curve shape with degree of cold work. The value of the energy to $1 \%$ strain will also give some insight into this changing curve shape. However, the modulus values as found by the calculator also show this marked decrease, though it is not as drastic as that from the computer calculations. Correlation coefficients for the modulus data points as fitted to the least squares straight line are given for the calculator values, and all are very near 1.000 , indicating an excellent fit to this line. The slope of this line is the modulus of elasticity desired. 


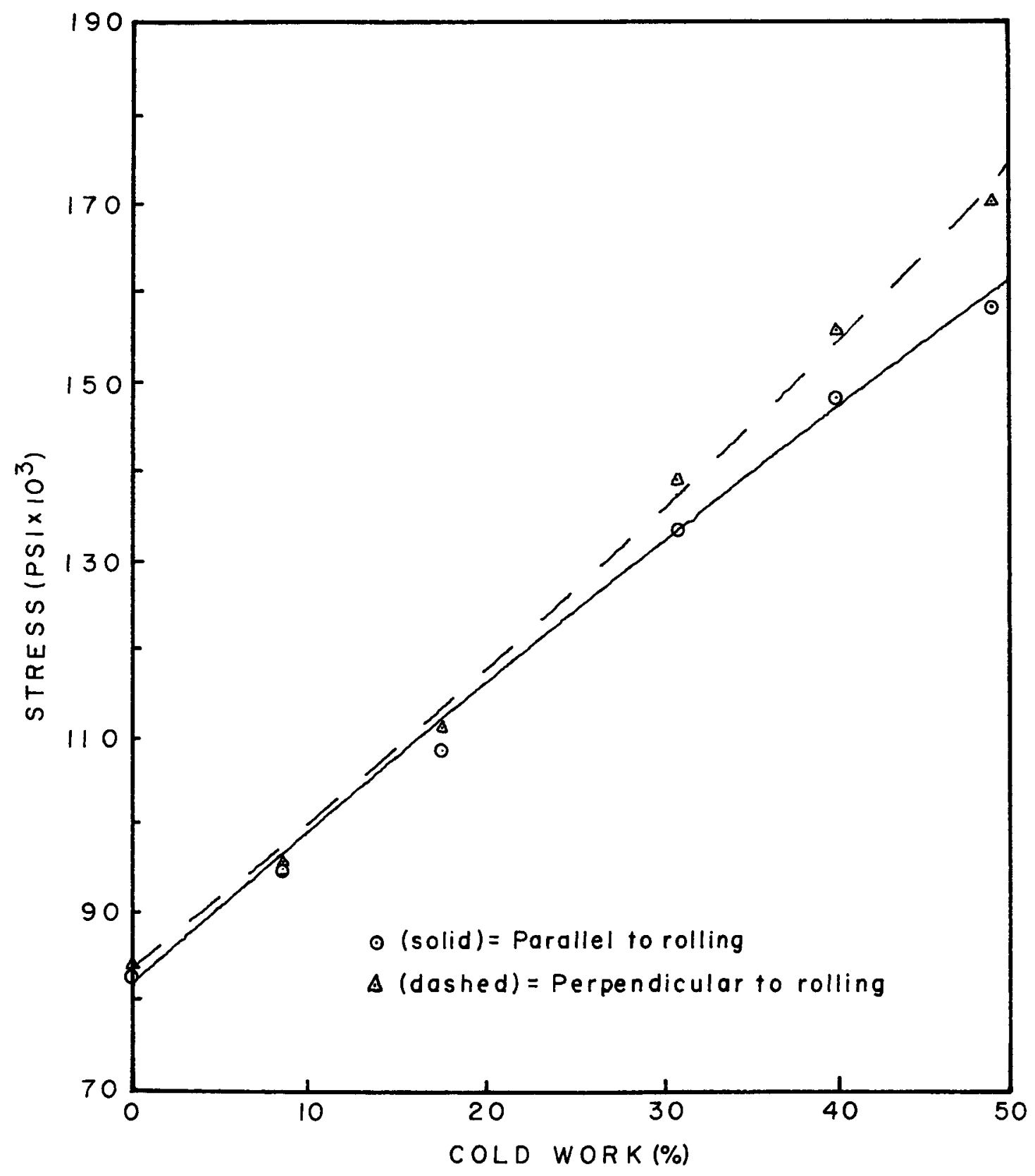

Figure 26. Plot of the Average Tensile Strength versus Percent Cold Work. 


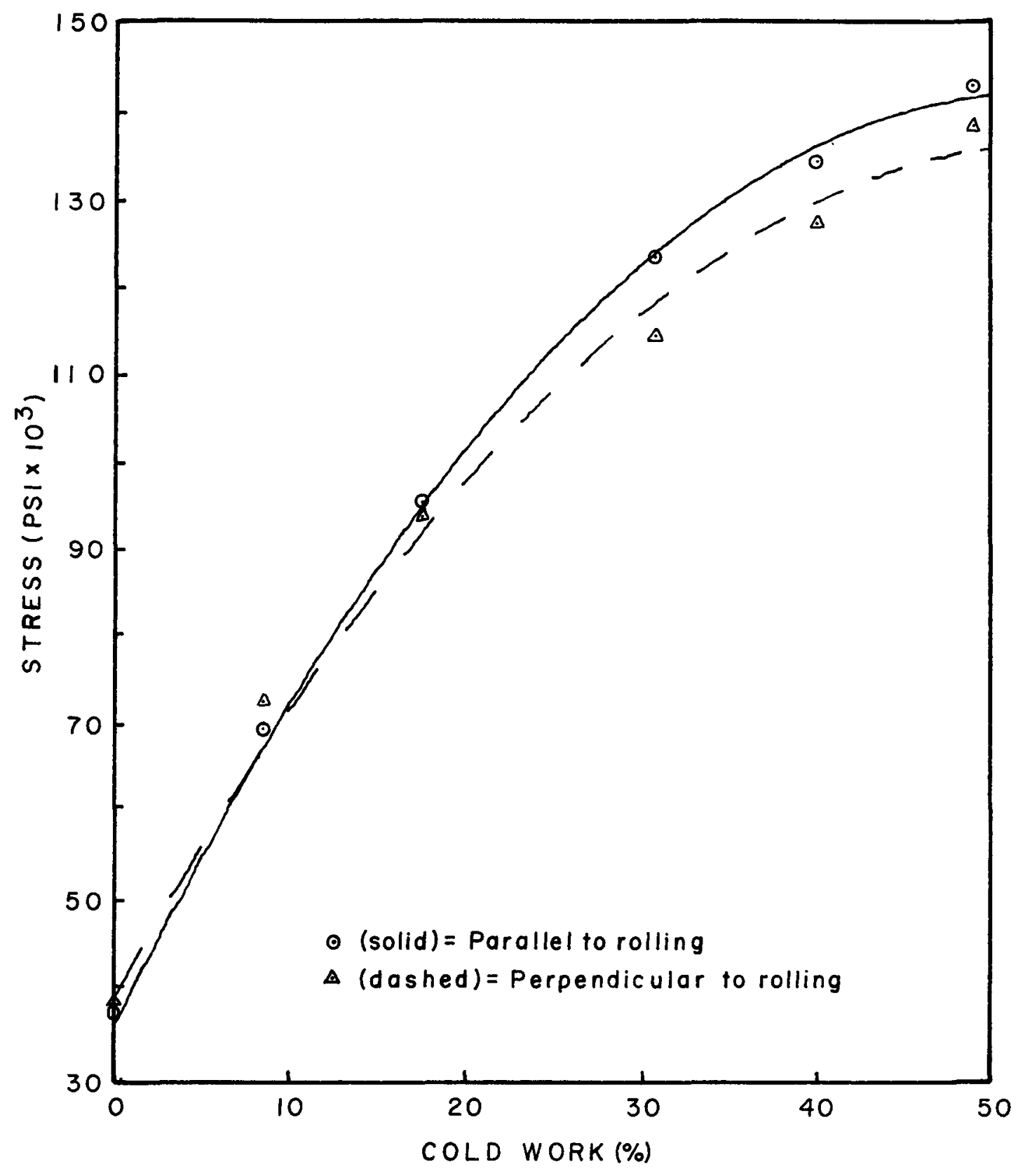

Figure 27. Plot of the Yield Strength at .2\% Offset versus Percent Cold Work. 


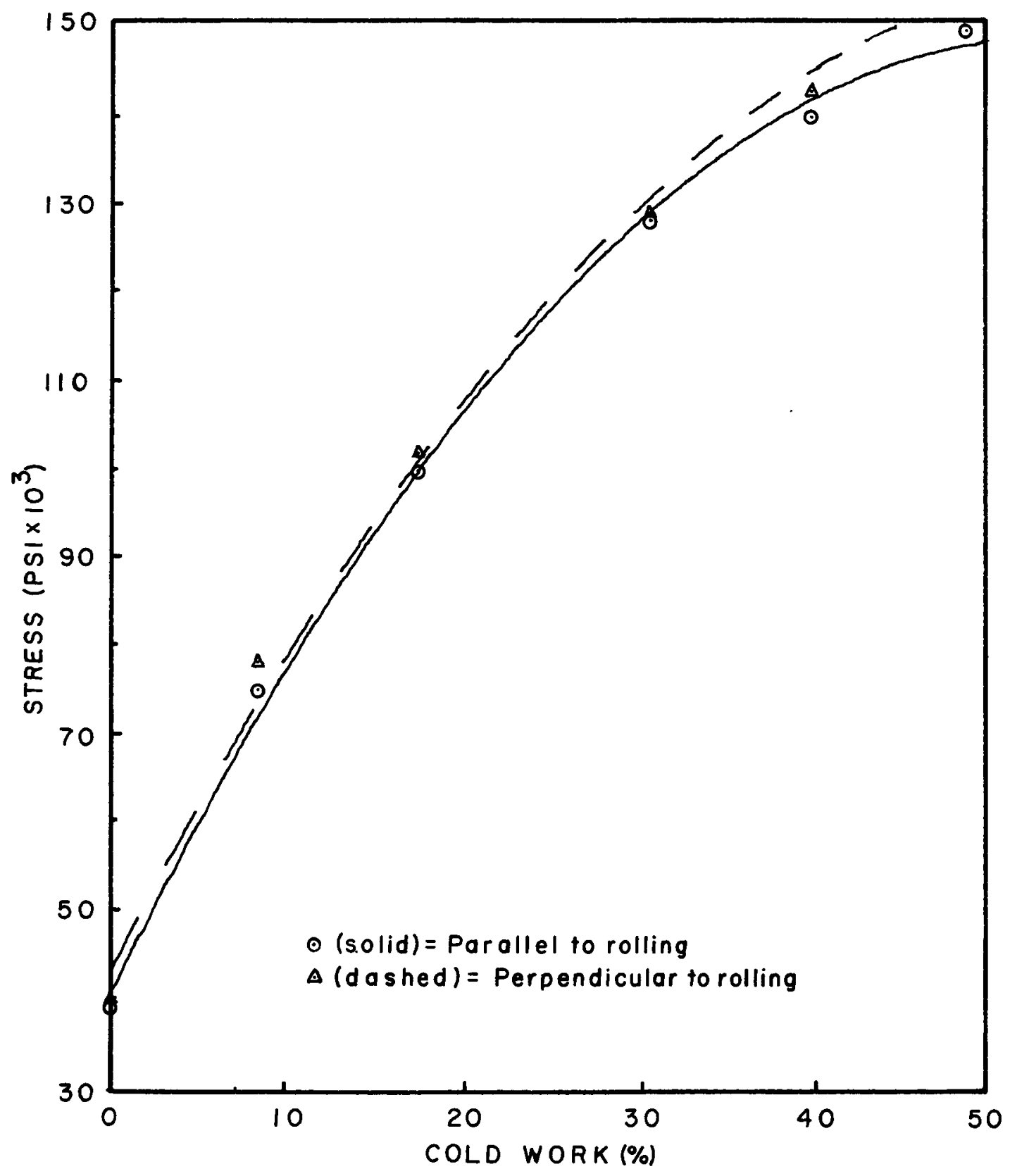

Figure 28. Plot of the Yield Strength at $1 \%$ Extension versus Percent Cold Work. 


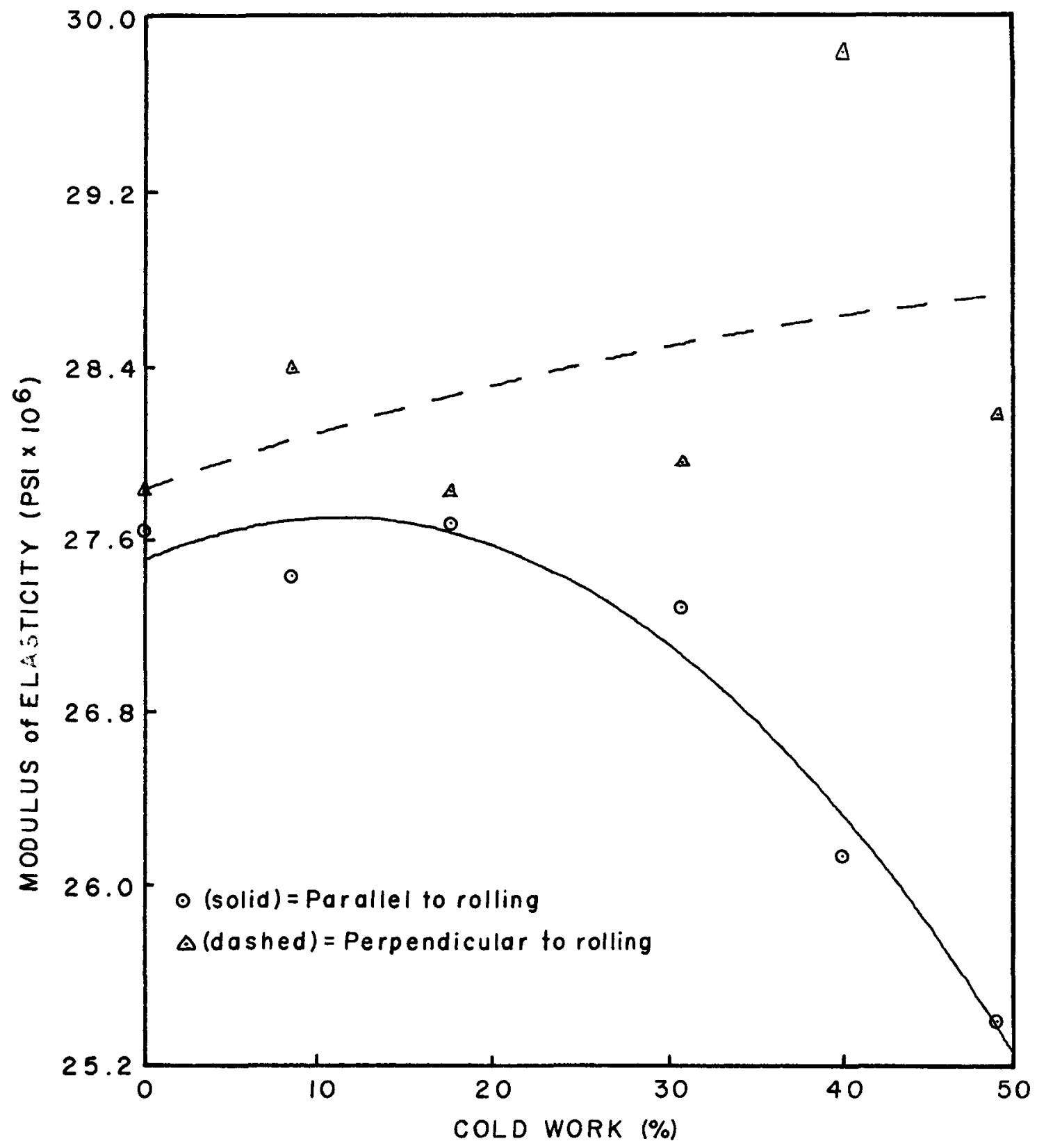

Figure 29. Plot of the Modulus of Elasticity versus Percent Cold Work. 


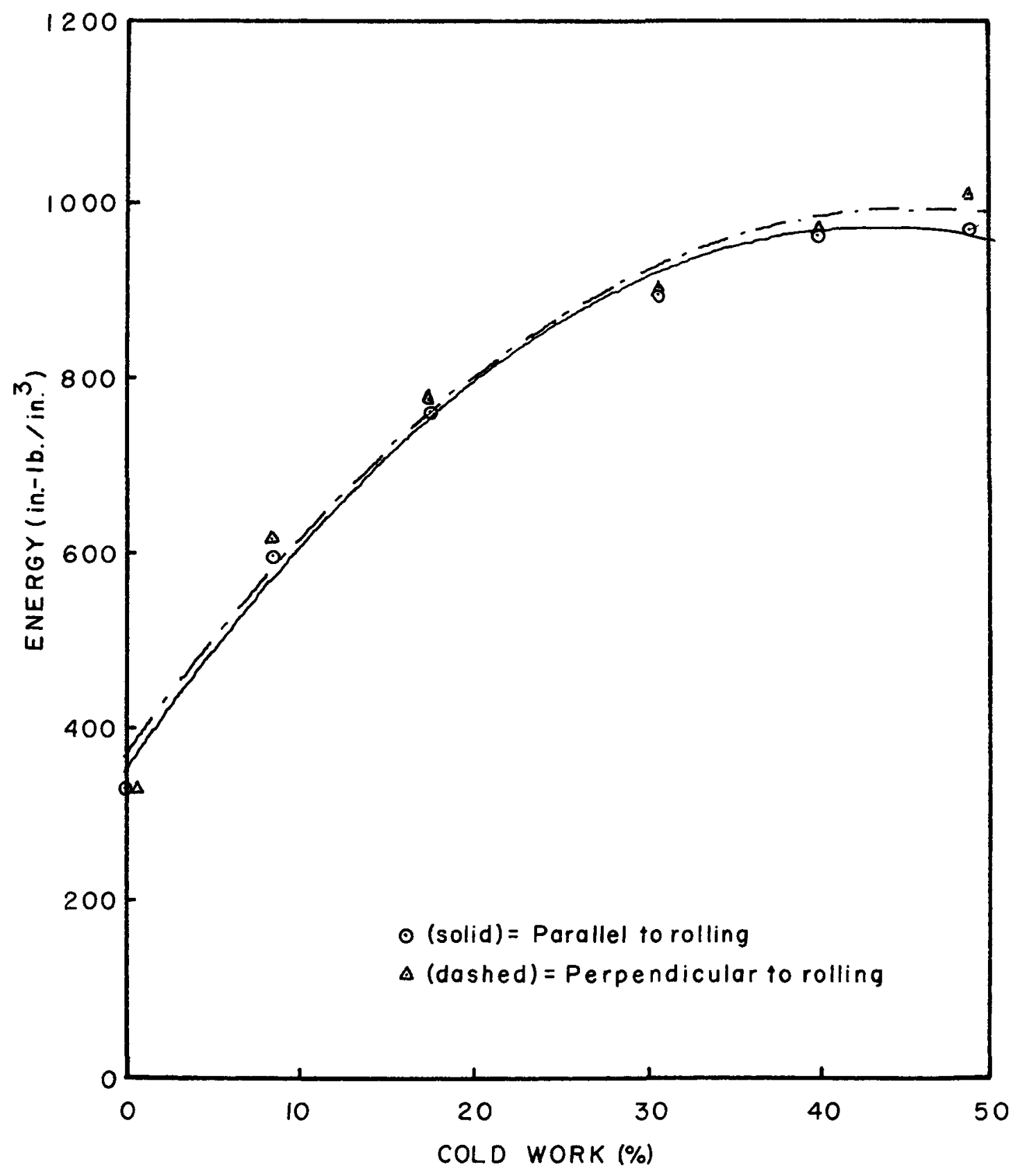

Figure 30. Plot of the Energy to $1 \%$ Strain versus Percent Cold Work. 
TABLE XXVI

FUNCTIONS CALCULATED FROM TIE SECOND ORDER FITS TO

THE MECILANICAL PROPERTY TEST RESULTS

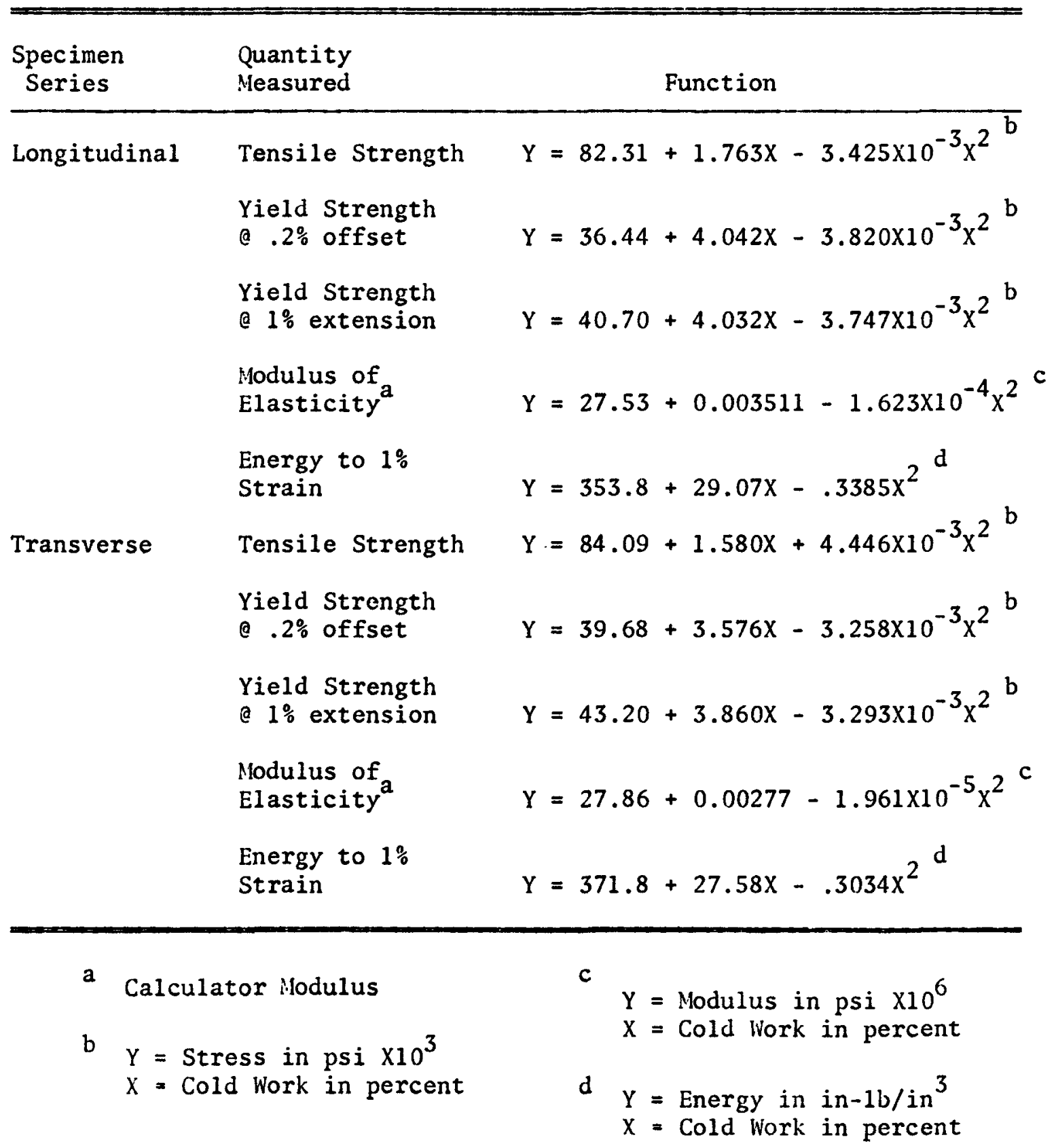


The individual test results used to calculate the averages given in Tables XXI through XXV are given in Table XXVII, along with explanatory notes as to why some of these results were omitted from the calculations. As stated in these notes, more detail on some of these problems may be found in Appendix C. A11 test results were checked by hand calculations, in the manner that is normally used in the laboratory, and these agreed with the computer results to within $1 \%$ in all cases, and to within $1 / 2 \%$ in most cases. A discrepancy was noted between modulus values calculated in this manner, which was the reason that they were redone in the manner described previously. 
TABLE XXVII

SUAMRY OF THE MECIMNICAL PROPERTY TEST RESULTS

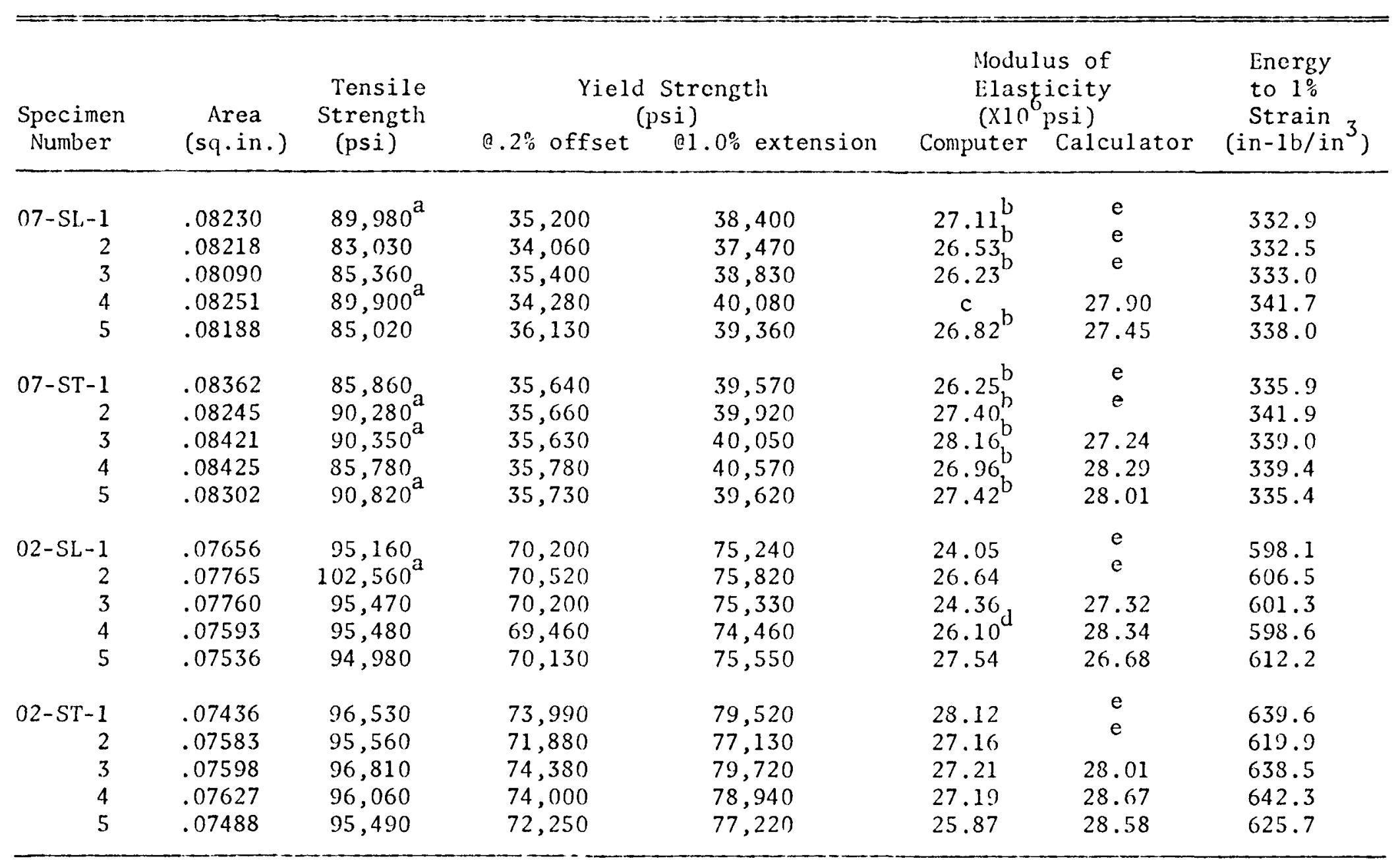


TABLE XXVII (continued)

\begin{tabular}{|c|c|c|c|c|c|c|c|}
\hline \multirow{2}{*}{$\begin{array}{l}\text { Spccimen } \\
\text { Number }\end{array}$} & \multirow{2}{*}{$\begin{array}{c}\text { Nrea } \\
(\mathrm{sq} . \mathrm{in} .)\end{array}$} & \multirow{2}{*}{$\begin{array}{l}\text { Tensile } \\
\text { Strength } \\
\text { (psi) }\end{array}$} & \multicolumn{2}{|c|}{$\begin{array}{l}\text { Yield Strength } \\
\text { (psi) }\end{array}$} & \multicolumn{2}{|c|}{$\begin{array}{l}\text { Modulus of } \\
\text { Elasticity } \\
\left(\times 10^{6} \text { psi) }\right.\end{array}$} & \multirow{2}{*}{$\begin{array}{c}\text { Energy } \\
\text { to } 1 \% \\
\text { Strain } \\
\text { (in-1b/in } 3\end{array}$} \\
\hline & & & a. $2 \%$ offset & e1. $0 \%$ extension & Computer & Calculator & \\
\hline $03-S L-1$ & .06945 & 108,800 & 97,320 & 100,600 & $f$ & e & 762.7 \\
\hline 2 & .07119 & 108,000 & g & 99,650 & $\mathrm{~g}$ & e & 763.9 \\
\hline 3 & .06878 & 108,400 & 95,610 & 99,370 & 25.30 & 27.56 & 768.9 \\
\hline 4 & .07038 & 108,500 & 95,120 & 99,340 & 25.38 & 27.32 & 760.7 \\
\hline 5 & .06877 & 109,500 & 97,080 & 100,600 & 25.50 & 28.20 & 784.6 \\
\hline $03-\mathrm{ST}-1$ & .06867 & 111,200 & 95,520 & 103,600 & 27.38 & e & 783.2 \\
\hline 2 & .06851 & $116,700^{\mathrm{a}}$ & 92,950 & 100,500 & 27.73 & e & 767.4 \\
\hline 3 & .06845 & 109,600 & 93,130 & 100,600 & 27.67 & 28.90 & 772.5 \\
\hline 4 & .06839 & 113,400 & 96,070 & 103,900 & 27.22 & 27.42 & 790.6 \\
\hline 5 & .06887 & 110,840 & 95,150 & 102,000 & 28.42 & 27.20 & 784.7 \\
\hline $04-S L-1$ & .05916 & 137,600 & 125,100 & 129,300 & 24.45 & 27.41 & 904.0 \\
\hline 2 & .05968 & 137,700 & 124,500 & 129,800 & 24.26 & 27.20 & 906.6 \\
\hline 3 & .05963 & 138,000 & 124,300 & 128,700 & 24.50 & e & 905.8 \\
\hline 4 & .05937 & 136,700 & 123,300 & 128,200 & 25.79 & e & 912.8 \\
\hline 5 & .05916 & 138,200 & 124,600 & 129,300 & 25.28 & e & 918.7 \\
\hline $04-S T-1$ & .05814 & $140,300_{h}$ & 115,800 & 129,200 & 27.94 & 29.01 & 908.3 \\
\hline 2 & .05900 & $139,000_{h}^{h}$ & 115,700 & 128,800 & 27.65 & 26.23 & 883.2 \\
\hline 3 & .05970 & $138,600^{h}$ & $114,100^{h}$ & $127,200^{h}$ & 27.75 & e & 895.8 \\
\hline 4 & .05861 & 138,400 & 114,800 & 127,500 & 27.58 & e & 893.2 \\
\hline 5 & .05839 & 140,300 & 116,100 & 129,200 & 28.96 & e & 919.8 \\
\hline
\end{tabular}


TABLE XXVII (continued)

\begin{tabular}{|c|c|c|c|c|c|c|c|}
\hline \multirow{2}{*}{$\begin{array}{l}\text { Specimen } \\
\text { Number }\end{array}$} & \multirow{2}{*}{$\begin{array}{c}\text { Area } \\
(\mathrm{sq} \cdot \mathrm{in} .)\end{array}$} & \multirow{2}{*}{$\begin{array}{l}\text { Tensilc } \\
\text { Strength } \\
\text { (psi) }\end{array}$} & \multicolumn{2}{|c|}{$\begin{array}{c}\text { Yield Strength } \\
\text { (psi) }\end{array}$} & \multicolumn{2}{|c|}{$\begin{array}{l}\text { Modulus of } \\
\text { Elasticity } \\
\left(X 10^{\circ} \text { psi) }\right.\end{array}$} & \multirow{2}{*}{$\begin{array}{l}\text { Energy } \\
\text { to } 1 \% \\
\text { Strain } \\
\left(i n-1 b / i n^{3}\right)\end{array}$} \\
\hline & & & e. $2 \%$ offset & Q1. $0 \%$ extension & Computer & Calculator & \\
\hline $05-\mathrm{SL}-1$ & .05108 & 146,400 & 134,100 & 138,500 & 23.62 & 25.18 & 962.3 \\
\hline 2 & .05050 & $148,400_{i}$ & 135,000 & 139,600 & 23.74 & 27.12 & 963.8 \\
\hline 3 & .05041 & $125,100^{1}$ & 136,700 & 141,900 & 24.89 & e & 969.9 \\
\hline 4 & .05052 & 149,500 & 134,100 & 139,400 & 24.76 & $\mathrm{e}$ & 968.8 \\
\hline 5 & .05156 & 149,300 & 136,400 & 140,800 & 24.30 & $\mathrm{e}$ & 980.3 \\
\hline $05-\mathrm{ST}-1$ & .05174 & 157,200 & 120,100 & 144,100 & 28.21 & 29.70 & 961.2 \\
\hline 2 & .05224 & 154,900 & 128,100 & 142,200 & 27.18 & 30.08 & 970.7 \\
\hline 3 & .05062 & 155,100 & 127,400 & 142,200 & 28.34 & $\mathrm{e}$ & 977.6 \\
\hline 4 & .05090 & 156,600 & 128,100 & 143,000 & 28.82 & e & 976.2 \\
\hline 5 & .05185 & 157,000 & 128,400 & 143,400 & 28.71 & $\mathrm{e}$ & 978.2 \\
\hline $06=S L-1$ & .04377 & $165,200^{a}$ & 146,300 & 152,100 & $25.10_{\mathrm{i}}^{\mathrm{j}}$ & 26.02 & 985.0 \\
\hline 2 & .04302 & 156,800 & 142,500 & 147,900 & $23.72^{j}$ & 25.23 & 965.6 \\
\hline 3 & .04226 & 159,700 & 144,500 & 150,000 & 23.88 & 25.90 & 977.2 \\
\hline 4 & .04246 & $.58,200$ & 142,000 & 148,700 & 23.81 & 25.16 & 973.0 \\
\hline 5 & .04229 & 160,300 & 145,200 & 150,300 & 22.40 & 24.64 & 976.4 \\
\hline $06-\mathrm{ST}-1$ & .04224 & $171,900^{a}$ & $\mathbf{a}$ & $\mathrm{a}$ & $28.47_{i}^{j}$ & 28.00 & 1014.7 \\
\hline 2 & .04232 & $174,100^{\mathrm{a}}$ & 139,200 & 154,900 & $27.28^{\mathrm{J}}$ & 25.75 & 1013.3 \\
\hline 3 & .04269 & 171,600 & 140,200 & 156,700 & 28.04 & 29.12 & 1020.5 \\
\hline 4 & .04230 & 169,400 & 139,200 & 154,600 & 27.35 & 28.91 & 1015.0 \\
\hline 5 & .04184 & 171,200 & 139,100 & 155,600 & 27.96 & 29.17 & 1013.9 \\
\hline
\end{tabular}


TABLE XXVII (continued)

a Strain gage bond ruptured while still in strain control resulting in immediate rupture of the specimen; thus this value is suspect and was not used to compute the average.

b This value may be somewhat low due to a low load value.

c Computer did not calculate a modulus.

d $\quad$ NPT2 $=0$ (see Appendix C).

e No tape was punched for this test.

f Delta $=16$; thus this value is suspect and was not used to compute the average.

$g$ Computer did not calculate a modulus value, and, for this reason, the yield at .2\% offset is in error also.

$\mathrm{h}$ The initial area was entered into the teletype in error, and these data have been corrected to account for this error.

i Bad strain-to-position transfer (see Appendix $C$ ); thus this value is suspect and was not used to compute the average.

j Delta $=10$ and NPT2 $=0$ (see Appendix C); thus this value suspect and was not used to compute the average. 
CHAPTER V

EDDY CURRENT MEASUREMENTS

Introduction and Theory

The use of electromagnetic waves in the role of nondestructive testing has been extensive over the past century. In $1879 \mathrm{D}$. E. Hughes used eddy currents to sort metals in a manner which is very similar to the method utilized in this study, though very little theoretical basis for his work existed at that time. Since 1950 many articles have been published on the use of eddy currents in nondestructive testing, though again these were somewhat limited by the theoretical background which had been developed during that time. Some articles of the era which were prominent were written by Forster (1952), Förster and Stambke (1954), and Förster (1954), and these were the first that actually attempted to derive a theoretical basis for the phenomenon. Other attempts were made by Waidelich and Renken (1956), Hochschild (1959), and Libby (1959).

This theoretical basis was advanced further with the development of a relaxation (iteration) theory by Dodd and Deeds (1963) and Dodd (1965) to calculate the vector potential of a coil with finite geometry using a large digital computer. Dodd (1967), Dodd and Deeds (1968), and Dodd, Deeds, Luquire, and Spoeri (1969) developed a set of integral equations to describe the electromagnetic phenomena associated with many typical examples of eddy current test methods in terms of the vector potential. Computer programs have been written in the BASIC language by Simpson, Luquire, Dodd, Deeds, and Spoeri (1971), which can be used on a digital 
computer to evaluate some of these various integral equations.

Most of these early papers tended to stress measurement of amplitude of the induced current, because it turns out to be the easiest to measure. However, for a plane wave, the current may be written in the form (Smythe, 1968) :

$$
i_{x}=i_{0} e^{-\left(\frac{1}{2} \omega \mu \sigma\right)^{\frac{1}{2}}} \cos \left[\omega t-\left(\frac{1}{2} \omega \mu \sigma\right)^{\frac{1}{2}} z\right] .
$$

Therefore, one can see that the amplitude decreases as an exponential, but that the phase decrease is linear. An early paper by Yates and Queen (1954) described an eddy current phase angle instrument to measure sheet and plating thickness which made use of this fact. A phase sensitive eddy current instrument has also been developed at Oak Ridge National Laboratory, and this type of instrument was utilized for this portion of the study (Dodd, $1964 \&$ 1968). Of course, Eq. (1) is not strictly correct for an eddy current solenoidal coil, for such a probe coil does not produce a plane wave. However, the equation does serve to illustrate the linear phase decrease. Another notable feature of such an instrument is that it should be relatively insensitive to liftoff, since there is very little phase change as the wave passes through air.

Dodd and Deeds (1968) have developed a theoretical basis for the voltage and phase induced in a reflection type coil, such as is used with a phase sensitive instrument, and they have found this to be of the form:

$$
\begin{aligned}
V= & \frac{j \omega \pi \mu n n^{\prime} I \bar{r}}{\left(r_{2}-r_{1}\right)\left(r_{4}-r_{3}\right) L_{2} L_{6}} \int_{0}^{\infty} \frac{1}{\alpha^{6}} J\left(r_{2}, r_{1}\right) J\left(r_{4}, r_{3}\right) e^{-2 \alpha L} \\
& X\left(e^{-\alpha\left(L_{2}-2 L_{5}-L_{4}\right)}-1\right)\left(e^{-\alpha L}-e^{-\alpha\left(L_{6}+L_{5}\right)}\right)\left(1-e^{-\alpha L_{2}}\right)
\end{aligned}
$$




$$
x\left[\frac{\left(\alpha+\beta_{1}\right)\left(\beta_{1}-\beta_{2}\right)+\left(\alpha-\beta_{1}\right)\left(\beta_{1}+\beta_{2}\right) e^{2 a_{1} c}}{(\alpha-\beta)\left(\beta_{1}-\beta_{2}\right)+\left(\alpha+\beta_{1}\right)\left(\beta_{1}+\beta_{2}\right) e^{2 a_{1} c}}\right] d \alpha .
$$

This equation has been solved by Deeds, Dodd, Luquire, and Spoeri (1971) in the form of a computer program and this program is utilized to assist in test set up.

\section{Apparatus}

The reflection-type probe coil is shown pictorially and schematically in Figure 31. Note from the figure that the pick-up coils are wound opposing each other so that in air the signals developed across the pickup coils cancel. However, when the probe is placed on the metal, a "reflected field" is produced by the metal. This field, which, as stated earlier, decreases rapidly with distance from the metal, is detected by the front pick-up coil (nearest the metal) but not by the rear coil (Dodd and Simpson, 1972). It should be mentioned that the phase also varies with such physical properties as electrical conductivity, magnetic permeability and thickness of a metal specimen, and it was on this basis that the measurements were performed.

Shown in Figure 32 is a simplified block diagram of the phase sensitive eddy current instrument, which was employed in this study. The particular instrument was one of the latest design with modular plug-in units, currently being marketed by Kervonics, Inc., of Oak Ridge, Tennessee. The following plug-in modules, as shown by the dotted lines in the figure, were utilized for this study: 


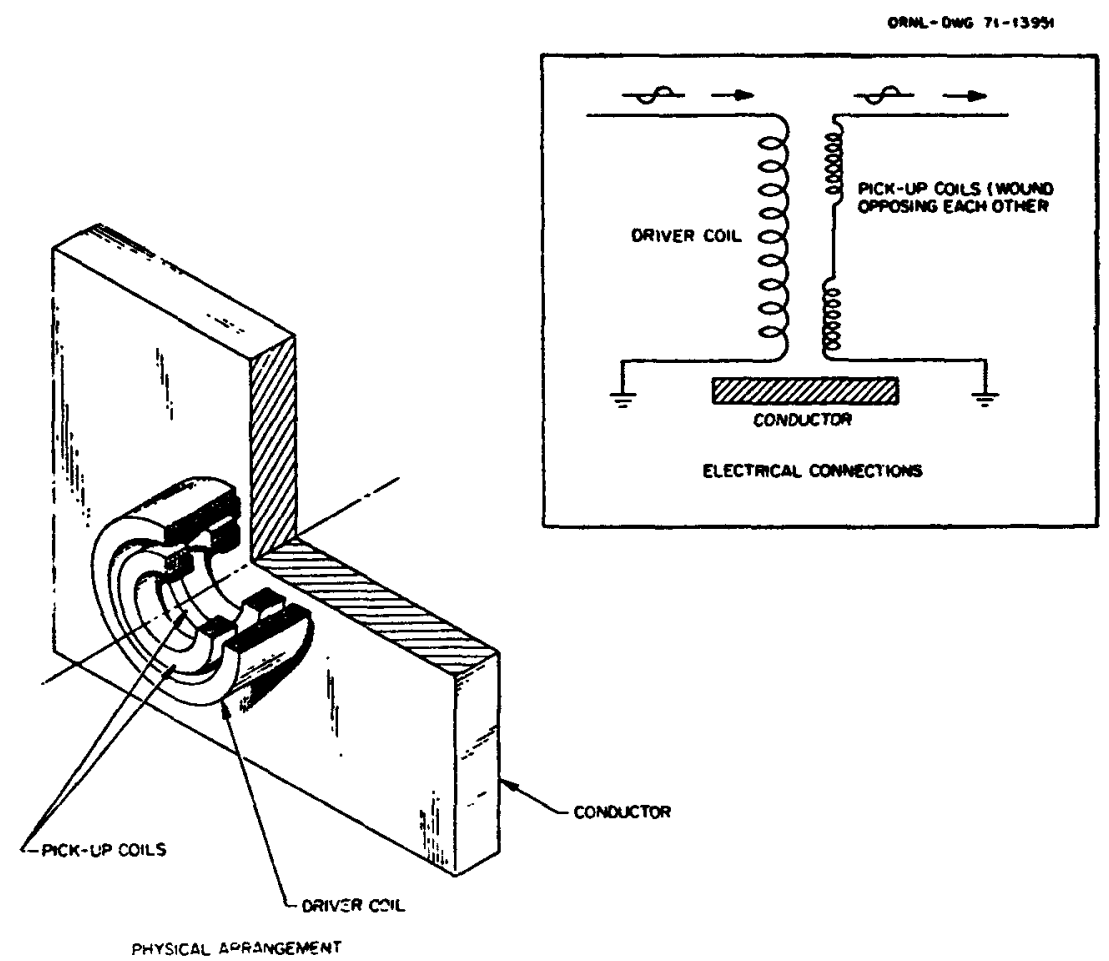

Figure 31. A Reflection-Type Probe in the Presence of a Conductor. 


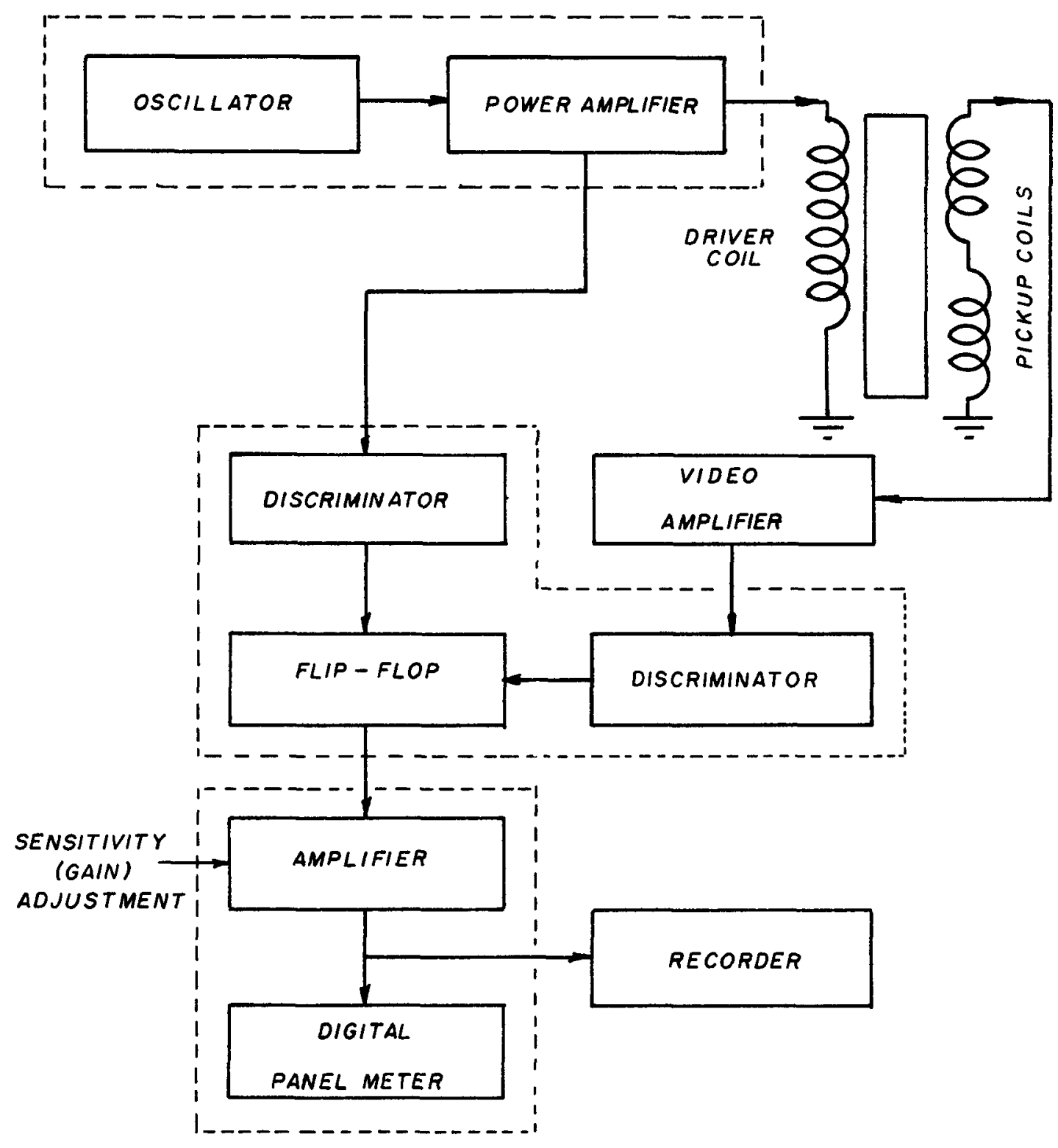

Figure 32. Block Diagram of the Phase Sensitive Eddy Current Instrument. 
1. Oscillator and Power Amplifier - This unit contained twelve fixed frequencies, ranging from $1 \mathrm{KIIz}$ to $5 \mathrm{MHz}$ in a $1,2,5$ sequence. The output was a ten volt peak-to-peak (sine wave) signal with a harmonic distortion of less than $0.02 \%$, and frequency accuracy of plus or minus $3 \%$. The amplitude was adjustable from 3 to 10 volts peak-to-peak.

2. High-Gain Video Amplifier - This unit amplified the signal from the pick-up coil and furnished an undistorted ten volt peak-to-peak signal to the discriminator module. A gain variation of fron 11 to 1000 was available with a 1 megohm input impedance and a frequency response flat plus or minus $3 \mathrm{db}$ from $500 \mathrm{~Hz}$ to $5 \mathrm{MIz}$. Extended efforts toward temperature stability were made, and a phase temperature coefficient of $\pm 0.01^{\circ}$ per degree $C$ was available. The amplitude temperature coefficient was $\pm 0.1 \%$ per degree $\mathrm{C}$.

3. Discriminator Module - This module produced a D.C. voltage proportional to the phase shift between the driver and pick-up signals, and was capable of doing so over a frequency range of $500 \mathrm{~Hz}$ to $5 \mathrm{iHz}$ for signals with a magnitude between 200 millivolts and 10 volts peak-to-peak. The discriminator level was variable between zero and plus and minus 10 volts.

4. Digital Display Module - This unit measured the output of the discriminator module via a digital panel meter. Simultaneous measurement of amplitude and phase of the reflected signal was possible. Voltage amplitude of the power amplifier was also measurable on another small "edgewise" panel meter. 
The discriminator unit of the instrument actually contained two discriminators, and a flip-flop as shown in Figure 32. The signal from the driver coil is fed to one discriminator, and the signal from the pick-up coil is fed to the other. The discriminators can be adjusted so that they give a pulse when the sinusoidal input signal passes through zero. This allows an accurate phase measurement in spite of the fact that the amplitude of the input signal varies as a function of lift-off. The pulses from the discriminators are then used to trigger the flip-flop circuit on and off. The output of the flip-flop is then integrated, and the resultant signal is proportional to the time or phase difference between the two signals. This output is then amplified and displayed by the digital panel meter. The amount of attenuation could be varied from zero to 1000 with front panel gain potentiometers. Thus the output could be made proportional to phase shift, conductivity, permeability, thickness, or any other desired quantity. All measurements in this study were made with the instrument calibrated for direct-reading of phase shift, because adequate standards were readily available for this calibration.

A simplified circuit diagram for the reflection type probe and the associated input and output impedances is shown in Figure 33 (Dodd and Simpson, 1972), and serves to illustrate the complexity of choosing proper circuit parameters prior to experimental set-up.

In practice, the aforementioned computer program was used to assist in determining the following parameters so as to make the set-up more sensitive to conductivity variations than to permeability, lift-off, or specimen thickness: 
ORNL-DWG 72-671

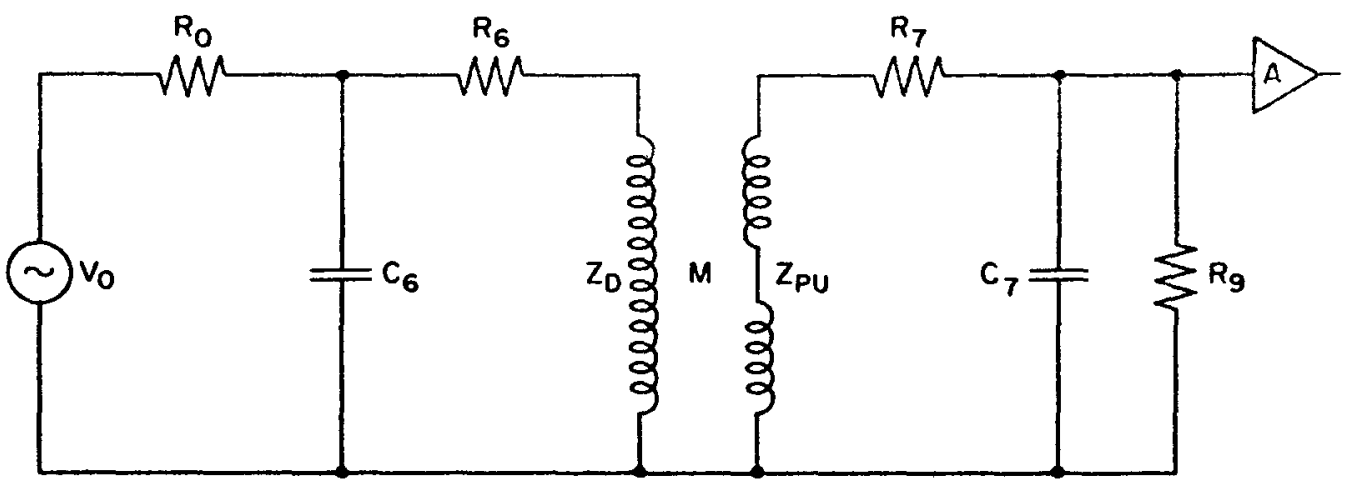

VO ORIVING VOLTAGE

$R_{0}$ SERIES RESISTANCE IN THE DRIVING CIRCUIT

$C_{6}$ SHUNT CAPACITANCE OF THE DRIVING CIRCUIT

$R_{6}$ D.C. RESISTANCE OF THE DRIVER COIL

$Z_{D}^{6}$ IMPEDANCE OF THE DRIVER COIL

$M$ MUTUAL IMPEDANCE BETWEEN THE DRIVER AND PICK-UP COILS

$Z_{\text {PU IMPEDANCE OF THE PICK-UP COILS }}$

$R_{7}$ D.C. RESISTANCE OF THE PICK-UP COILS

$C_{7}$ SHUNT CAPACITANCE OF THE PICK-UP CIRCUIT

$R_{9}$ AMPLIFIER INPUT IMPEDANCE

Figure 33. Simplified Diagram for an Eddy Current Reflection-Type Probe. 
1. Driver coil input impedance,

2. Pick-up coil output impedance (input impedance to video amplifier),

3. Driver coil shunt capacitance, and

4. Pick-up coil shunt capacitance.

Measurements at a high frequency, for instance $500 \mathrm{Kllz}$, are less sensitive to permeability variations, and one can see the reasons for this expectation from Figure 34, which illustrates the phase shift for a five percent conductivity for various ' $M$ ' values for the coil used for this study. This coil was chosen primarily for ease of availability and test frequency. The absissa of the plot is this " $M$ " value, where:

$$
M=\omega \mu \sigma \bar{r}^{2}
$$

From this figure, it can be seen that the maximum sensitivity for conductivity variations occurs near an " $M$ " value of six, though values from one to twelve would certainly be acceptable since the curve is so broad. Also, to minimize error due to lift-off, one would choose an "M" value near seven. The instrumentation allowed frequency choices in this area of 200 or $500 \mathrm{KHz}$, which yield 'M" values for the probe coil used of approximately 4.9 and 12.2 , respectively. However, the lower frequencies were more sensitive to permeability changes, which we wished to avoid, so $500 \mathrm{KHz}$ was chosen as the frequency at which measurements would be made.

However, if we were to desire to separate the effects on the phase shift reading by the permeability and conductivity, we would have to make 


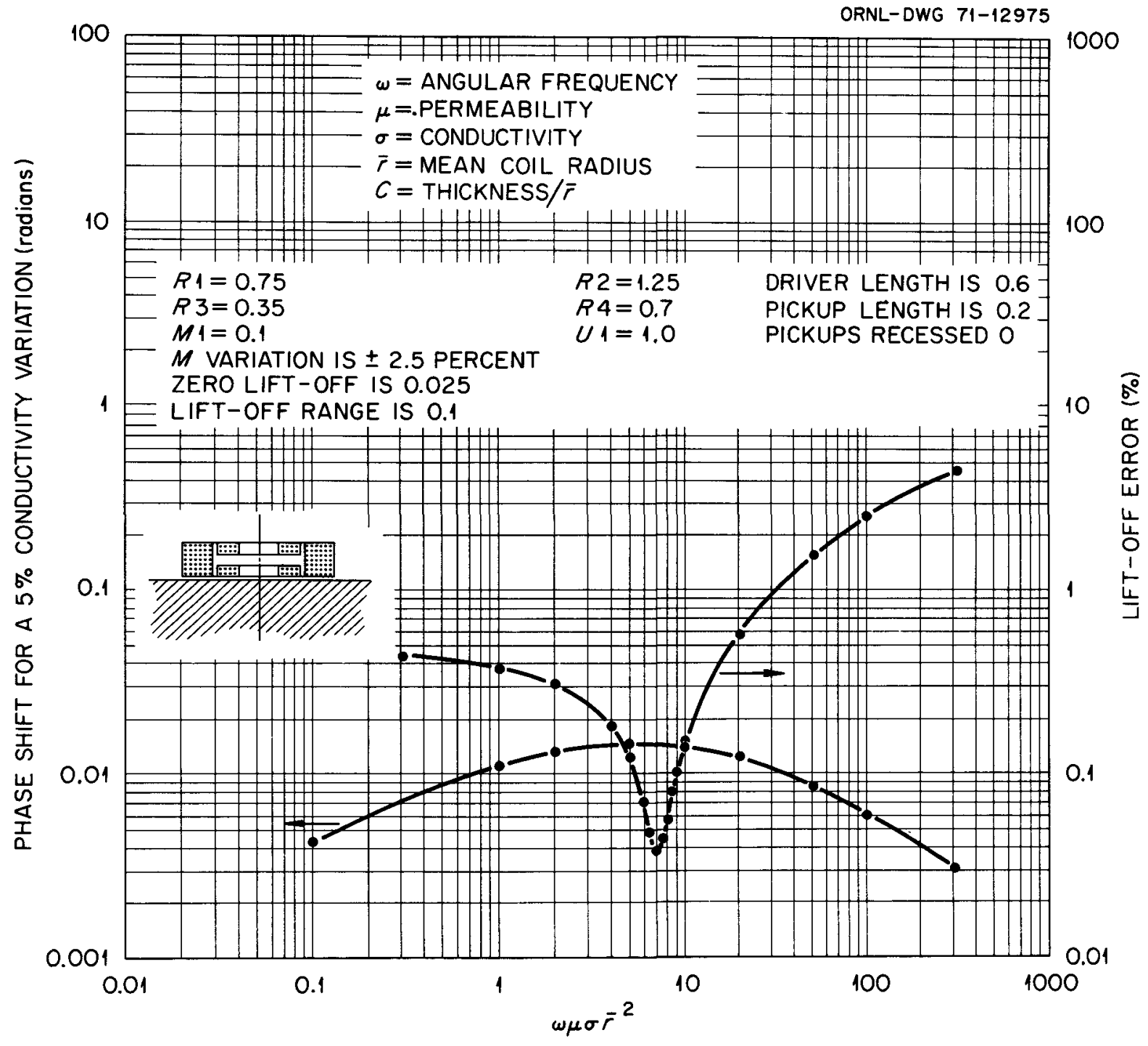

Figure 34. Phase-Shift Due to a $5 \%$ Conductivity Variation, and Percent Error Due to Lift-Off versus "i" Value. 
measurements at two frequencies. One of these should lie in a region more sensitive to permeability changes and the other should lie in a region more sensitive to conductivity changes. Also, we must consider the overall thickness of the material available, and not let the frequency be so low that the thickness of the plate affects the phase shift reading. By some experimentation it was determined that $50 \mathrm{KHz}$ would be the lowest frequency that could be used, and still not have any appreciable effects due to thickness. Further exploration by computer revealed the following relationship for the measured phase shift at the two frequencies:

$$
\begin{aligned}
& \phi_{50 k}=\phi_{\mu}+\phi_{\sigma} \\
& \phi_{500 k}=0.0917 \phi_{\mu}+1.167 \phi_{\sigma}
\end{aligned}
$$

where $\phi_{50 \mathrm{~K}}$ is the measured phase shift at $50 \mathrm{kHz}, \phi_{50 \mathrm{OK}}$ is that at 500 $\mathrm{KHz}$, and $\phi_{\mu}$ and $\phi_{\sigma}$ are the portions of the phase shift due to permeability and conductivity respectively. Solving these for $\phi_{\mu}$ and $\phi_{\sigma}$ yields the following:

$$
\begin{aligned}
& \phi_{\mu}=\frac{1.167 \phi_{50 k}-\phi_{500 k}}{1.0753} \\
& \phi_{\sigma}=\frac{\phi_{500 k}-0.0917 \phi_{50 k}}{1.0753}
\end{aligned}
$$

From equations (5) and (6), it would seem that the effects are interrelated, and that dual frequency measurements must be made in order to separate them. This same information can be gained from Figure 34 also, for $50 \mathrm{KHz}$ corresponds to an " $\mathrm{M}$ " value of 1.2 , which lies as close to the peak of the conductivity curve as does that at $500 \mathrm{KHz}$. However, 
these readings should not be as affected by lift-off variations as those at $500 \mathrm{KHz}$, even though it was believed that this variable could be adequately controlled.

\section{Test Results}

As stated in the Theory part of this chapter, the probe coil used was chosen primarily for ease of availability and for proper impedance match at the first frequency to be used, namely $500 \mathrm{KIIz}$. The probe used was a Kervonics, Inc., Model 60A, serial number 223, with dimensions as shown in Table XXVIII. The locations of these dimensions are shown in Figure 35 , and from these data it can be seen that the model number of the coil designates the mean coil radius in thousandths of an inch. Proper circuit parameters for this coil at the frequencies to be used were found by use of the computer programs and limitations of the available gains of the respective amplifiers of the instrument. These parameters are given in Table XXIX.

Two series of measurements were made, one at $50 \mathrm{KHz}$ and one at 500 KIIz. These measurements were made on the specinens as depicted in Figure 36, which shows a three-inch square specimen and a typical large tensile specimen. Initial measurements were made on the three-inch square specimens, and these were made on both sides of these plates, one side of which had been polished in the same manner as the tensile specimens which were discussed in Chapter III. The other side was not machined or polished in any manner, but was cleaned prior to testing. The purpose of this series was to verify the findings of Chapter III in which it was found that the polishing did indeed remove much of the cold worked material 
TABLE XXVIII

EDDY CURRENT PROBE COIL DIMENSIONS

\begin{tabular}{clc}
\hline Dimension & Description $^{\mathrm{a}}$ & Value $^{\mathrm{a}}$ \\
\hline $\mathrm{R}_{1}$ & Driver Inner Radius & 0.750 \\
$\mathrm{R}_{2}$ & Driver Outer Radius & 1.250 \\
$\mathrm{R}_{3}$ & Pick-up Inner Radius & 0.350 \\
$\mathrm{R}_{4}$ & Pick-up Outer Radius & 0.700 \\
$\bar{R}$ & Coil Mean Radius & 1.000 \\
$\mathrm{~L}_{2}$ & Driver Length & 0.300 \\
$\mathrm{~L}_{6}$ & Pick-up Length & 0.100 \\
$\mathrm{~L}_{5}$ & Pick-ups Recessed & 0 \\
\hline \hline
\end{tabular}

a These values are the normalized (dimensionless) values which are found by dividing each dimension by the mean coil radius. The actual mean coil radius for this probe was 0.060 inch. 


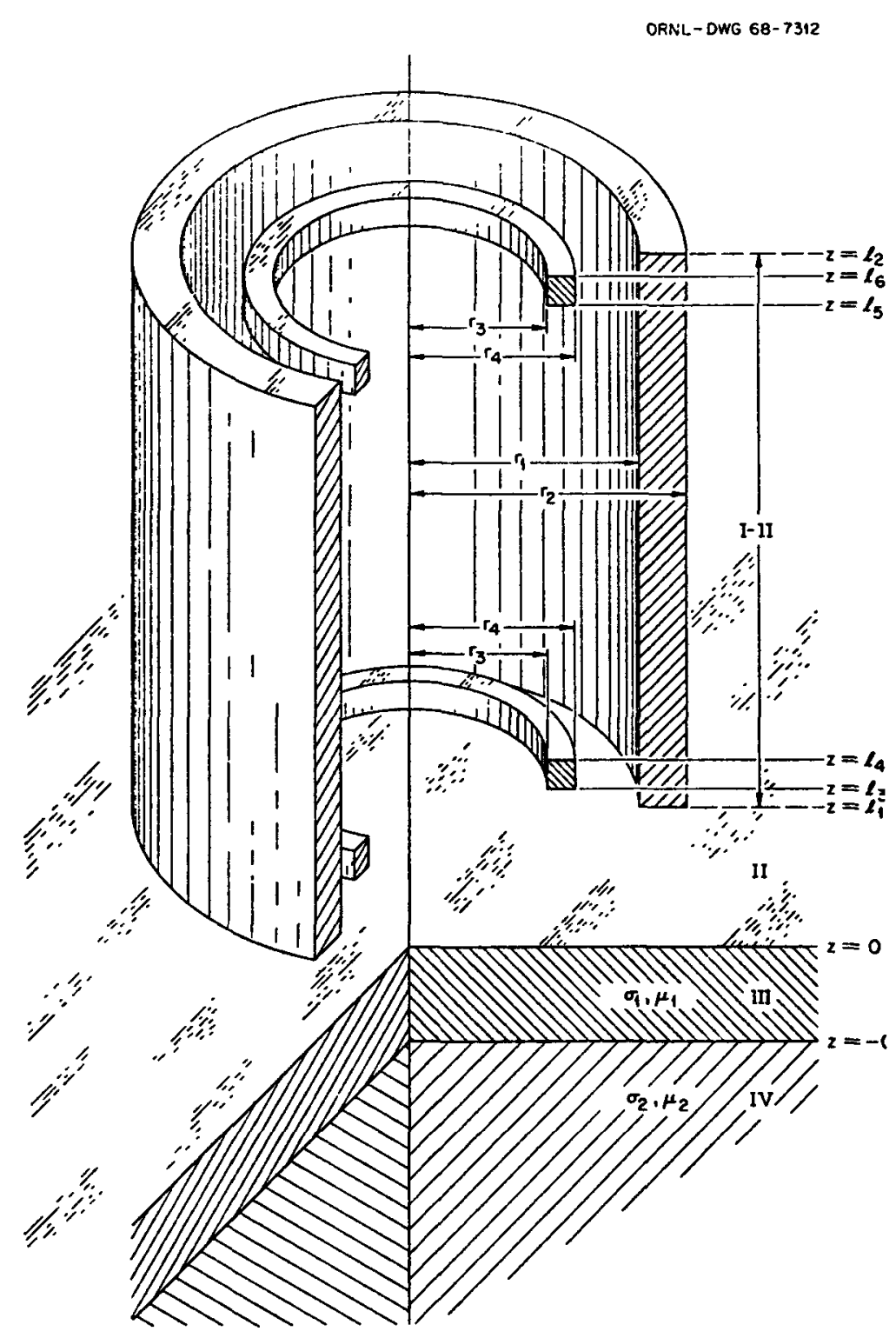

Figure 35. The Reflection-Type Eddy Current Probe Coil Above a Two Conductor Plane. 
TABLE XXIX

CIRCUIT PARANETERS USED FOR THE EDDY

CURRENT MEASUREMENTS

\begin{tabular}{ll}
\hline Quantity & Value \\
\hline Driver Resistance (actual) & 53.12 ohms \\
Pick-up Resistance (actual) & 1344.2 ohms \\
Driver Inductance & 0.222053 millihenries \\
Pick-up Inductance & 0.565105 millihenries \\
Number of Driver Turns & 252 \\
Number of Pick-up Turns & 598 \\
Driver Shunt Capacitance (actual) & $1 \times 10^{-10}$ farads \\
Pick-up Shunt Capacitance (actual) & $1 \times 10^{-10}$ farads \\
Driver Shunt Resistance (500KHz) & 20,000 ohms \\
Pick-up Shunt Resistance (500 KHz) & None \\
Driver Shunt Resistance (50KHz) & 3000 ohms \\
Pick-up Shunt Resistance (50KHz) & None \\
\hline
\end{tabular}

a Except where noted, these values were determined for $500 \mathrm{KHz}$. 


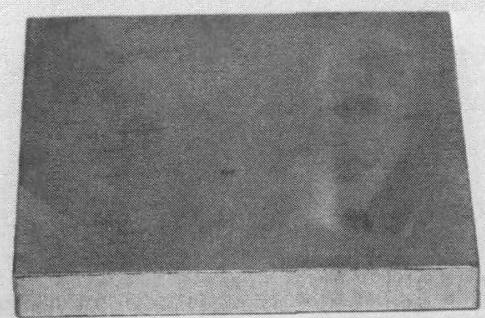

Figure 36. The Specimens used for the Eddy Current Tests. 
from the plates with lower degrees of cold working. The other specimen shown in Figure 36 was originally fabricated to investigate the effects on conductivity as the specimens were cold worked by tension testing, but this was abandoned in favor of other previously reported tests. However, these specimens were utilized for the bulk of the eddy current measurements. Neither side of these had been polished or machined in any manner, but they were cleaned with a Freon degreaser prior to testing. The instrumentation was calibrated before usage to read directly in phase shift in degrees on the digital panel meter. This was accomplished with a RLC calibrator circuit which was installed in place of the probe coil. Values used to calibrate the instrument were determined by the computer and the final calibration should have been accurate to at least 0.01 degrees of phase shift. The digital panel meter was calibrated in 10 degree steps from 0 to \pm 80.00 degrees and also at 0.50 degree. The LC portion of this calibration circuit was 100 millihenries and 505.18 $x 10^{-9}$ farads, respectively. The instrument was adjusted for lift-off compensation so that a five mil lift-off would cause no appreciable variation in response. There were some lift-off effects at the higher frequency, but this was to be expected and was not a great problern.

Shown in Table $X X X$ is a summary of the results from the three-inch square plates, which gives the phase shift for each, the degree of cold work for both the polished and unpolished surfaces, along with the estimate of the standard deviation for each quantity. These are the average of ten readings taken on each plate, as shown in Figure 37 . These data are plotted in Figures 38 and 39, along with a typical one standard deviation error bar. All data were normalized so that the plase shift 
TABLE XXX

SUMAIARY OF EDDY CURRENT TEST RESULTS FROM THE THREE-INCH SQUARE PLATES

\begin{tabular}{|c|c|c|c|c|c|c|c|c|}
\hline \multirow{3}{*}{$\begin{array}{l}\text { Percent } \\
\text { Cold Work }\end{array}$} & \multicolumn{8}{|c|}{$\begin{array}{l}\text { Phase Shift }(\phi) \\
\text { (degrees) }\end{array}$} \\
\hline & \multicolumn{4}{|c|}{ Unpolished } & \multicolumn{4}{|c|}{ Polished } \\
\hline & $50 \mathrm{KHz}$ & $s^{a}$ & $500 \mathrm{KHz}$ & $s^{a}$ & $50 \mathrm{KHIz}$ & $s^{a}$ & $500 \mathrm{KHz}$ & $s^{a}$ \\
\hline 0 & .322 & .022 & .451 & .046 & .214 & .016 & .405 & .016 \\
\hline 8.5 & .202 & .024 & .346 & .017 & .179 & .025 & .342 & .027 \\
\hline 17.6 & .207 & .014 & .277 & .017 & .182 & .018 & .243 & .024 \\
\hline 30.9 & .124 & .015 & .154 & .022 & .098 & .019 & .112 & .010 \\
\hline 40.1 & .058 & .013 & .097 & .016 & .039 & .028 & .038 & .026 \\
\hline 49.0 & 0 & .034 & 0 & .022 & 0 & .021 & 0 & .037 \\
\hline
\end{tabular}

a Estimate of the standard deviation. 


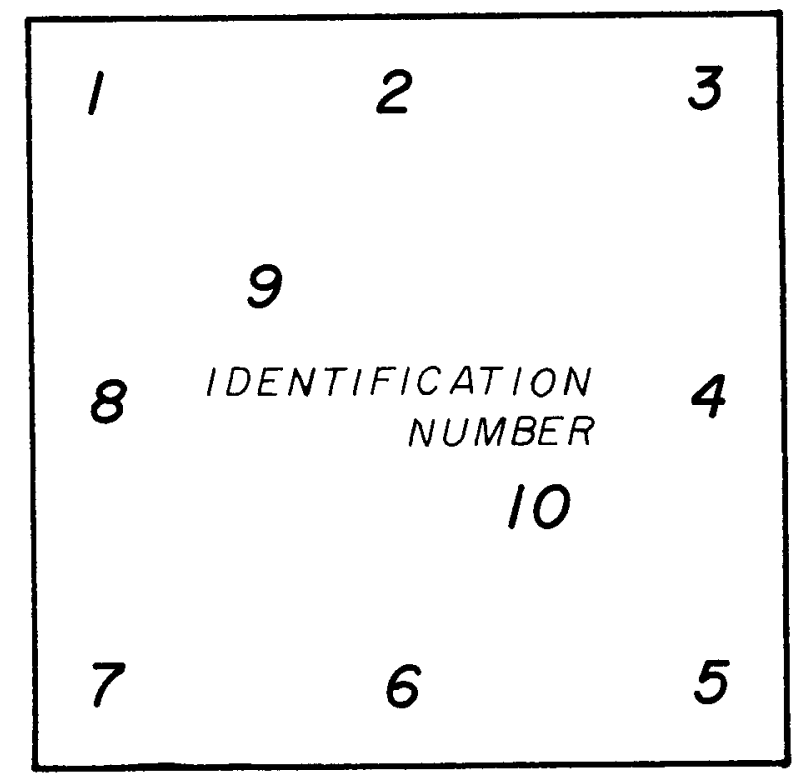

Figure 37. Measurement Locations for the Measurements on the Three-inch Square Plates. 
at the maximum degree of cold work was zero, since this is where attempts were made to set the zero of the instrument. From the raw data as shown in Table XXXI, this obviously was not quite successful due largely to material variations. The $t$ statistic was calculated at each of the degrees of cold work, and the differences between the polished and unpolished surfaces were found to be significant in all cases. The functions calculated for the second order polynomials shown in Figures 38 and 39 are given in Table XXXII. A11 measurements were performed with the eddy current probe placed on the plate at the point desired and held in full contact by the weight of one of the other plates on top of it. Minimal handling of the probe itself was done in order to avoid problems due to thermal drifts in the coil. As all these measurements were made over a two to three hour time period, changes in coil response due to temperature changes should have been small. All equipment was allowed to remain on and hooked up for a period of 48 hours prior to taking these measurements

Shown in Table XXXIII are the portions of the eddy current response due to conductivity and permeability, as calculated from formulas (5) and (6) of the Theory. These are plotted versus percent cold work for both the unpolished and polished surfaces of the plates in Figures 40 and 41, along with the second order functions, which are given in Table XXXIV. Comparison of these with Figures 38 and 39 would seem to verify the results of the D.C. measurements, which were that the polishing did indeed have an effect on the measured conductivity. An even more marked change is seen in the permeability, but discussion of this change is not the subject of this thesis. It is of interest to reflect on these data 


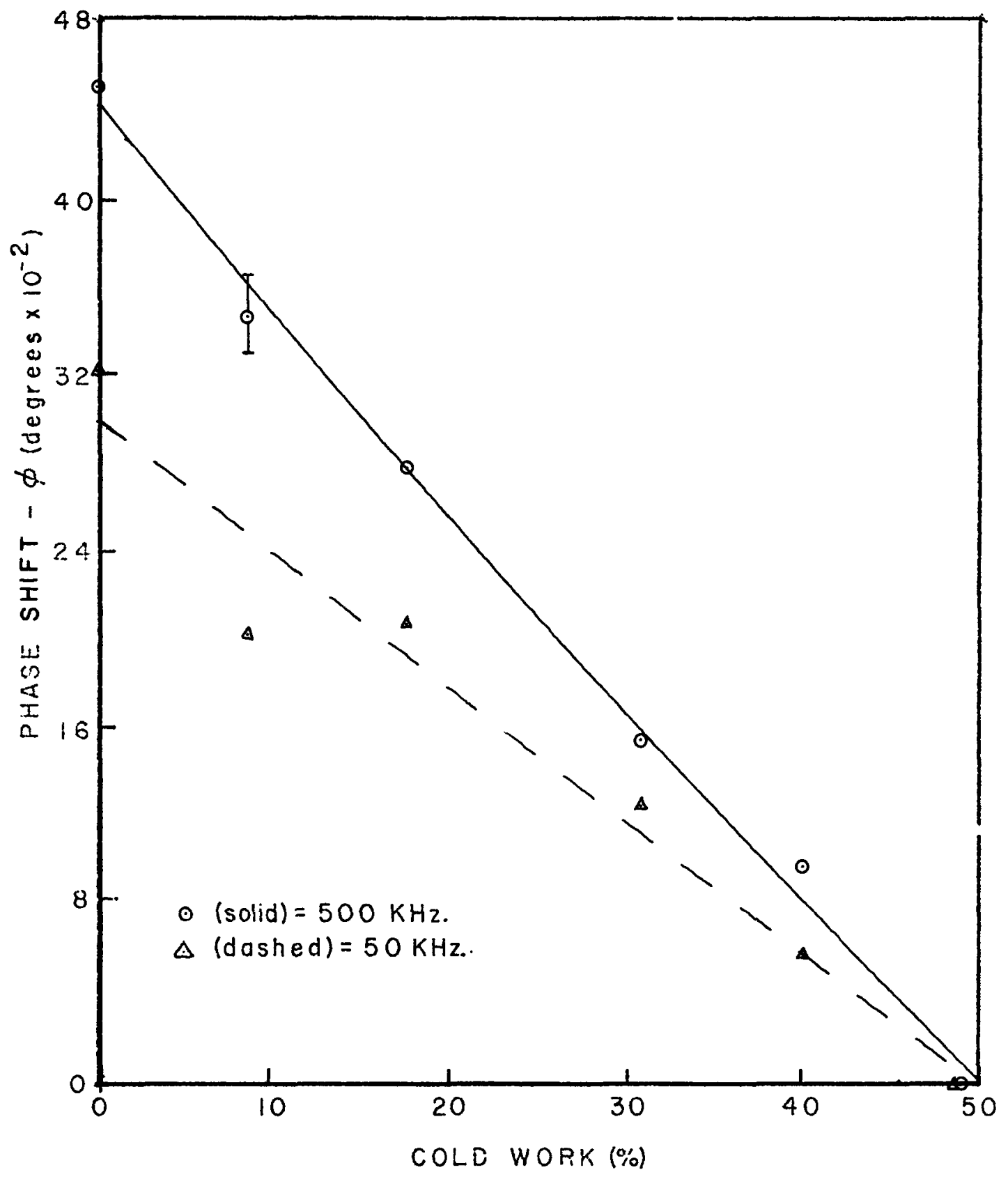

Figure 38. Plot of Eddy Current $r$, ase Shift versus Percent Cold Work at 50 and $500 \mathrm{KHz}$. on the Unpolished Surface of the Three-inch Square Plates. 


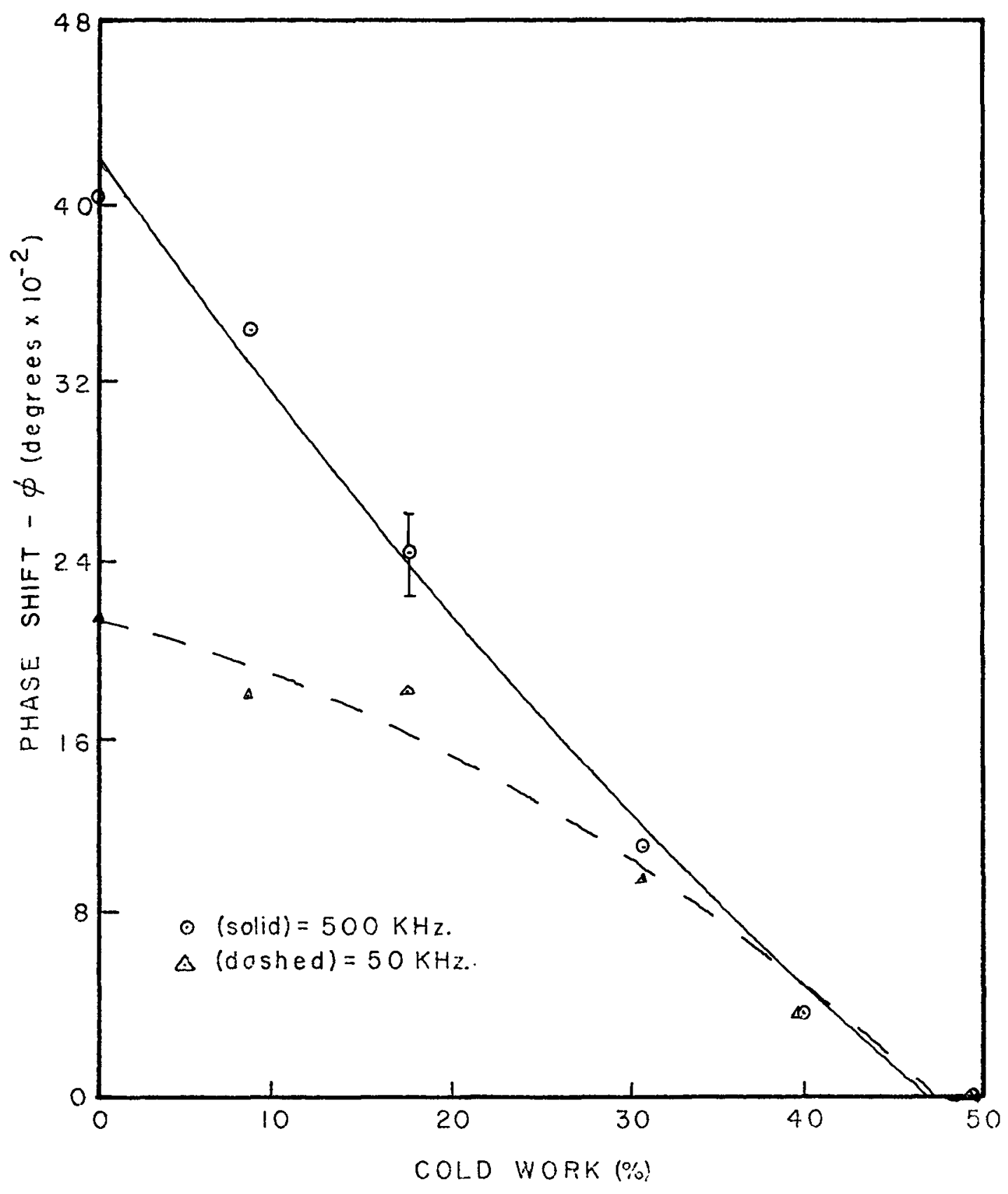

Figure 39. Plot of Eddy Current Phase Shift versus Percent Cold Work at 50 and $500 \mathrm{KIIz}$. on the Polished Surface of the Three-inch Square Plates. 
TABLE XXXI

EDDY CURRENT MEASUREMENTS ON THE

THREE-INCH SQUARE PLATES

\begin{tabular}{|c|c|c|c|c|c|}
\hline \multirow{3}{*}{$\begin{array}{r}\text { Plate } \\
\text { Number }\end{array}$} & \multirow{3}{*}{$\begin{array}{l}\text { Measurement } \\
\text { Number }\end{array}$} & \multicolumn{4}{|c|}{ Phase Shift (degrees) } \\
\hline & & \multicolumn{2}{|c|}{ Unpolished } & \multicolumn{2}{|c|}{ Polished } \\
\hline & & $50 \mathrm{KHz}$ & $500 \mathrm{KHz}$ & $50 \mathrm{KHz}$ & $500 \mathrm{KHz}$ \\
\hline \multirow[t]{10}{*}{07} & 1 & .30 & .39 & .23 & .39 \\
\hline & 2 & .29 & .43 & .26 & .38 \\
\hline & 3 & .26 & .48 & .26 & .38 \\
\hline & 4 & .29 & .43 & .27 & 41 \\
\hline & 5 & .30 & .33 & .22 & .41 \\
\hline & 6 & .28 & .39 & .26 & .40 \\
\hline & 7 & .23 & .37 & .24 & .40 \\
\hline & 8 & .29 & .34 & .24 & .38 \\
\hline & 9 & .27 & .36 & .26 & .37 \\
\hline & 10 & .30 & .42 & .25 & .42 \\
\hline \multirow[t]{10}{*}{02} & 1 & .19 & .30 & .24 & .35 \\
\hline & 2 & .18 & .29 & .20 & .34 \\
\hline & 3 & .16 & .29 & .20 & .31 \\
\hline & 4 & .12 & .27 & .23 & .32 \\
\hline & 5 & .12 & .29 & .23 & .30 \\
\hline & 6 & .16 & .26 & .19 & .28 \\
\hline & 7 & .17 & .31 & .23 & .35 \\
\hline & 8 & .18 & .27 & .25 & .36 \\
\hline & 9 & .17 & .31 & .20 & .36 \\
\hline & 10 & .16 & .30 & .17 & .34 \\
\hline \multirow[t]{10}{*}{03} & 1 & .14 & .22 & .18 & .24 \\
\hline & 2 & .16 & .25 & .23 & .22 \\
\hline & 3 & .17 & .23 & .23 & .18 \\
\hline & 4 & .17 & .23 & .23 & .26 \\
\hline & 5 & .16 & .20 & .23 & .26 \\
\hline & 6 & .15 & .21 & .22 & .23 \\
\hline & 7 & .17 & .19 & .23 & .23 \\
\hline & 8 & .18 & .23 & .20 & .24 \\
\hline & 9 & .18 & .22 & .20 & .25 \\
\hline & 10 & .18 & .22 & .22 & .21 \\
\hline
\end{tabular}


TABLE XXXI (continued)

\begin{tabular}{|c|c|c|c|c|c|}
\hline \multirow{3}{*}{$\begin{array}{r}\text { Plate } \\
\text { Number }\end{array}$} & \multirow{3}{*}{$\begin{array}{l}\text { Measurement } \\
\text { Number }\end{array}$} & \multicolumn{4}{|c|}{ Phase Shift (degrees) } \\
\hline & & \multicolumn{2}{|c|}{ Unpolished } & \multicolumn{2}{|c|}{ Polished } \\
\hline & & $50 \mathrm{KHz}$ & $500 \mathrm{KHz}$ & $50 \mathrm{KHz}$ & $500 \mathrm{KHz}$ \\
\hline \multirow[t]{10}{*}{04} & 1 & .07 & .13 & .16 & .11 \\
\hline & 2 & .10 & .13 & .14 & .09 \\
\hline & 3 & .10 & .06 & .15 & .11 \\
\hline & 4 & .07 & .10 & .13 & .10 \\
\hline & 5 & .09 & .09 & .11 & .09 \\
\hline & 6 & .08 & .11 & .10 & .09 \\
\hline & 7 & .06 & .08 & .12 & .10 \\
\hline & 8 & .09 & .08 & .14 & .10 \\
\hline & 9 & .10 & .10 & .15 & .10 \\
\hline & 10 & .07 & .09 & .13 & .12 \\
\hline \multirow[t]{10}{*}{05} & 1 & .01 & .06 & .04 & .03 \\
\hline & 2 & .04 & .03 & .07 & .02 \\
\hline & 3 & .02 & .03 & .08 & .08 \\
\hline & 4 & .00 & .02 & .08 & .06 \\
\hline & 5 & .03 & .05 & .12 & -.01 \\
\hline & 6 & .01 & .06 & .12 & .03 \\
\hline & 7 & .01 & .05 & .06 & .02 \\
\hline & 8 & .01 & .03 & .04 & .00 \\
\hline & 9 & .01 & .02 & .07 & .02 \\
\hline & 10 & .03 & .05 & .06 & .02 \\
\hline \multirow[t]{10}{*}{06} & 1 & -.02 & -.06 & .04 & -.07 \\
\hline & 2 & -.03 & -.06 & .02 & -.03 \\
\hline & 3 & .02 & -.02 & .04 & -.06 \\
\hline & 4 & -.02 & .00 & .02 & -.05 \\
\hline & 5 & -.02 & .00 & .07 & -.04 \\
\hline & 6 & -.07 & .00 & .03 & -.08 \\
\hline & 7 & -.08 & .05 & .02 & -.10 \\
\hline & 8 & -.09 & .04 & .01 & -.06 \\
\hline & 9 & -.04 & -.02 & .07 & -.04 \\
\hline & 10 & -.06 & -.04 & .03 & -.04 \\
\hline
\end{tabular}


TABLE XXXII

SECOND ORDER FUNCTIONS CALCULATED

FOR FIGURES 38 AND 39

\begin{tabular}{cc}
\hline Quantity & Function $^{a}$ \\
\hline $50 \mathrm{KHz}-$ unpolished & $\mathrm{Y}=.4422-.009854 \mathrm{X}+2.08 \times 10^{-5} \mathrm{X}^{2}$ \\
$500 \mathrm{KHz}-$ unpolished & $\mathrm{Y}=.2993-.006195 \mathrm{X}+4.2 \times 10^{-6} \mathrm{X}^{2}$ \\
$50 \mathrm{KHz}-$ polished & $\mathrm{Y}=.4169-.01110 \mathrm{X}+4.87 \times 10^{-5} \mathrm{X}^{2}$ \\
$500 \mathrm{KHz}-$ polished & $\mathrm{Y}=.2124-.001975 \mathrm{X}-5.13 \times 10^{-5} \mathrm{X}^{2}$ \\
\hline \hline
\end{tabular}

a $Y=$ Phase shift in degrees.

$X=$ Cold work in percent . 
TABLE XXXIII

Calculated values of $\phi_{\sigma}$ ANd $\phi_{\mu}$ From data

FOR THE THREE-INCH SQUARE PLATES

\begin{tabular}{ccccc}
\hline & \multicolumn{4}{c}{ Phase Shift (degrees) } \\
$\begin{array}{c}\text { Percent } \\
\text { Cold Work }\end{array}$ & $\phi_{\sigma}{ }^{\mathrm{a}}$ & $\phi_{\mu}{ }^{\mathrm{b}}$ & $\phi_{\sigma}{ }^{\mathrm{U}}$ & $\phi_{\mu}{ }^{\mathrm{b}}$ \\
\hline 0 & .392 & -.0700 & .358 & -.1440 \\
8.5 & .305 & -.1025 & .303 & -.1240 \\
17.6 & .240 & -.0330 & .210 & -.0285 \\
30.9 & .133 & -.0086 & .0958 & .0022 \\
40.1 & .085 & -.0273 & .0320 & .00699 \\
49.0 & -- & - &.- & - \\
\hline
\end{tabular}

a

$\phi_{\sigma}=$ Phase shift due to conductivity.

b

$\phi_{\mu}=$ Phase shift due to permeability. 


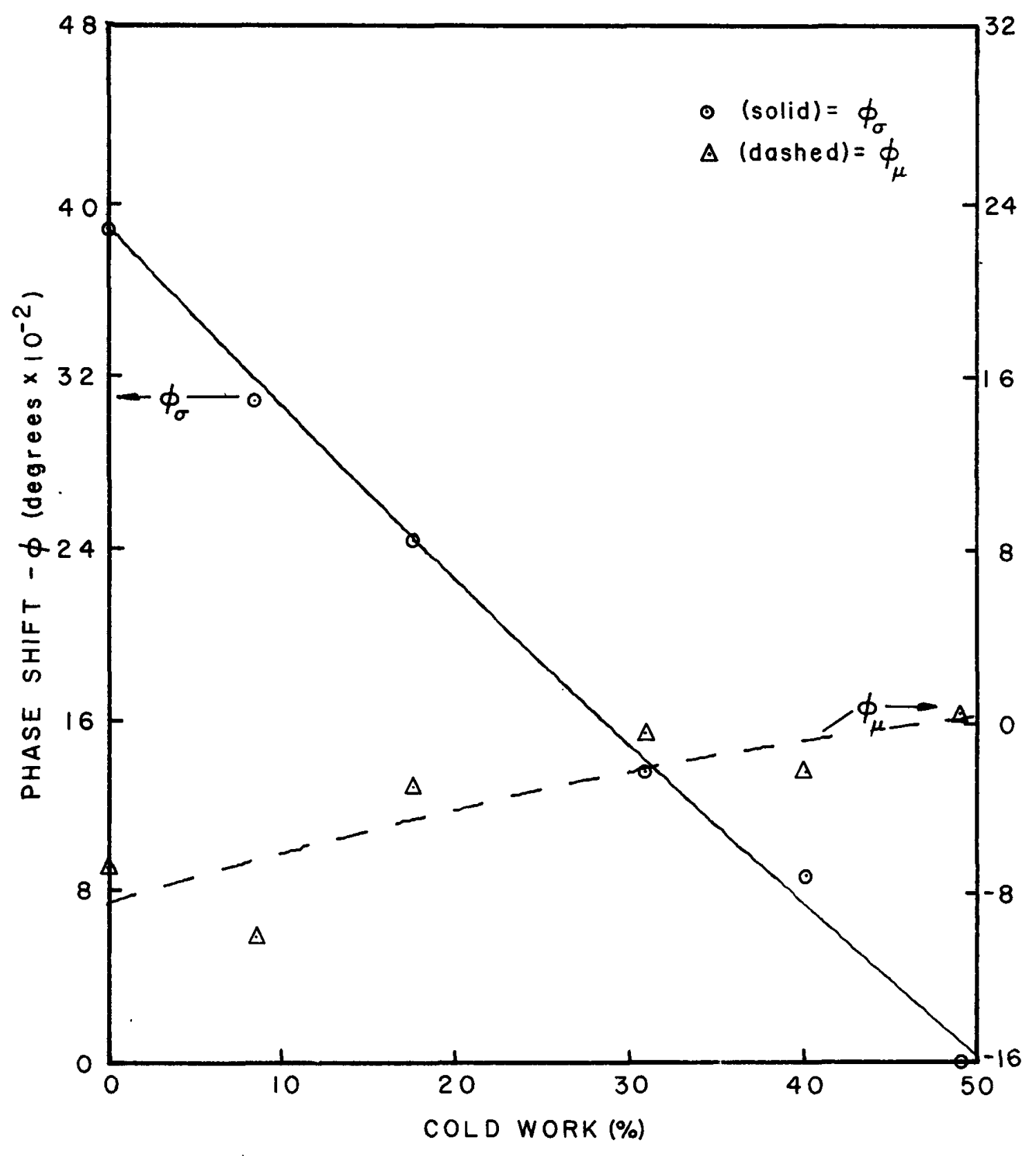

Figure 40. Plot of $\phi_{\sigma}$ and $\phi_{\mu}$ as Calculated from Data for the Three-inch Square Plates versus Percent Cold Work (Unpolished Surface). 


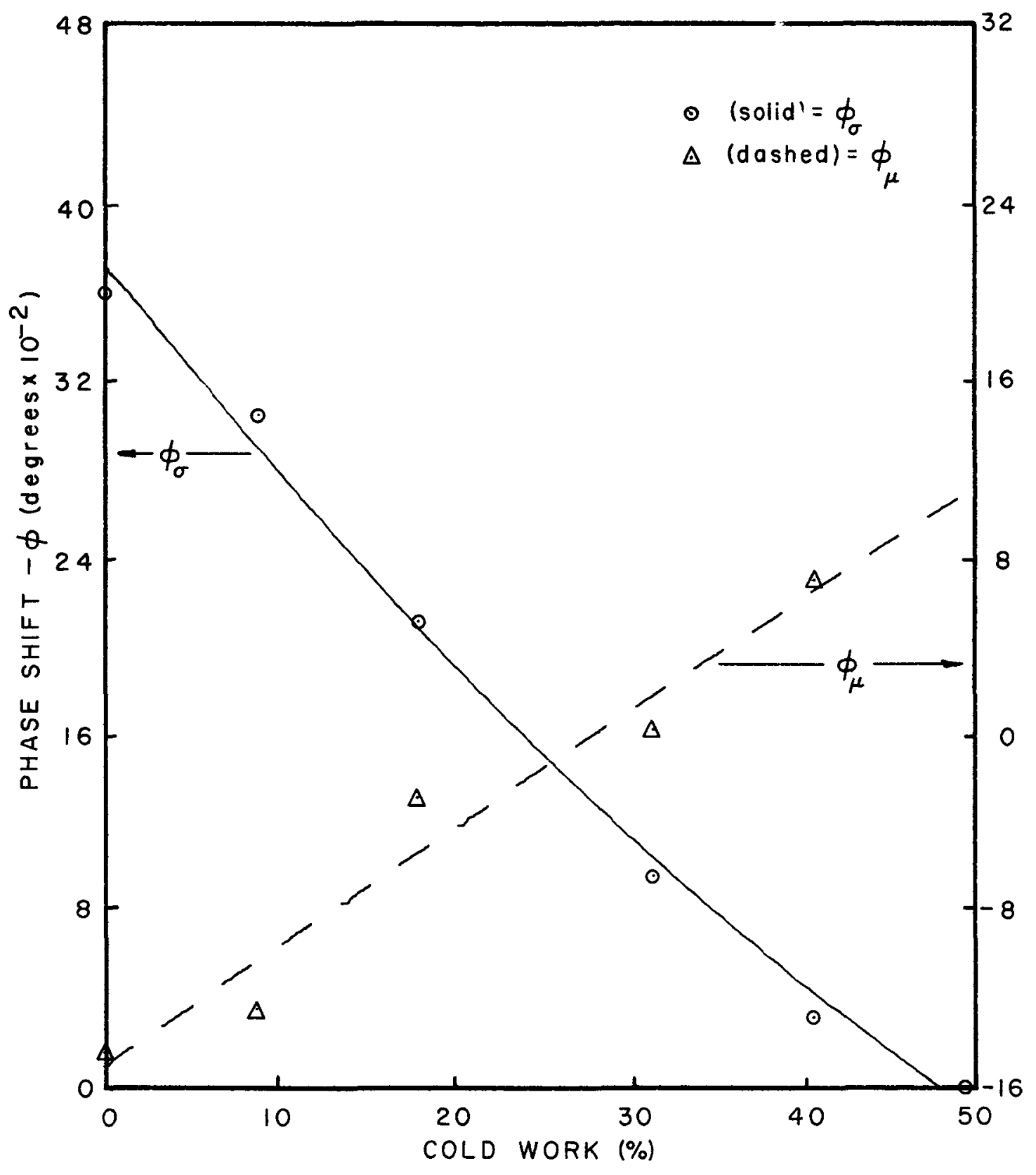

Figure 41. Plot of $\phi_{\sigma}$ and $\phi_{\mu}$ as Calculated from Data for the Three-inch Square Plates versus Percent Cold Work (Polished Surface). 
TABLE XXXIV

SECOND ORDER FUNCTIONS CALCULATED

FOR FIGURES 40 and 41

\begin{tabular}{ll}
\hline Quantity & Function $^{\mathbf{a}}$ \\
\hline$\phi_{\sigma-\text { Unpolished }}$ & $Y=.3859-.008626 \mathrm{X}+1.87 \times 10^{-5} \mathrm{X}^{2}$ \\
$\phi_{\mu-\text { Unpolished }}$ & $Y=.08792+2.851 \times 10^{-3} X-2.67 \times 10^{-5} X^{2}$ \\
$\phi_{\sigma-\text { Polished }}$ & $Y=.3694-.01015 X+4.96 \times 10^{-5} X^{2}$ \\
$\phi_{\mu-\text { Polished }}$ & $Y=.1561+7.929 X-9.39 \times 10^{-5} X^{2}$ \\
\hline
\end{tabular}

a $X=$ Percent cold work.

$Y=$ Phase shift in degrees. 
as compared to the D.C. resistivity data, and this comparison is shown in Figures 42 and 43 for the unpolished and polished surfaces. The relationship for the latter would be highly questionable due to the variability caused by the material removal by polishing. The least squares second order functions found from these curves are given on the figures. The resistivity values used are all an average of those from the parallel and perpendicular to rolling values, since the probe coil would measure such an average. These values were given in Tables $X V$ and XVIII, on pages 60 and 68 .

In order to gain insight into the variability within the plates the eddy current measurements were repeated on the large tensile specimens as were depicted in Figure 36 on page 119. The summary of the results at 50 and $500 \mathrm{KHz}$ is given in Table XXXV, for the five readings that were taken on each of the five specimens cut from each plate. These readings were taken on the side opposite the numbered side with the number one reading being opposite the specimen number. Thus a total of twenty-five measurements were made on each large cold worked plate. Plots of these results are shown in Figure 44 , and the second order polynomials for these are given in Table XXXVI. Again an example of a one Sigma error bar is shown, and it can be noted that this is larger than was the case for Figure 38 on page 124 due to the addition of the specimen-to-specimen variability in these data. The individual readings are given in Table XXXVII. The portions of the phase shift due to conductivity and permeability calculated as explained previously are given in Table XXXVIII, and the resultant plots are shown in Figure 45. The plot of the phase shift versus average resistivity is depicted in Figure 
134

46, and the resultant first and second order functions are given in Table XXXIX. 


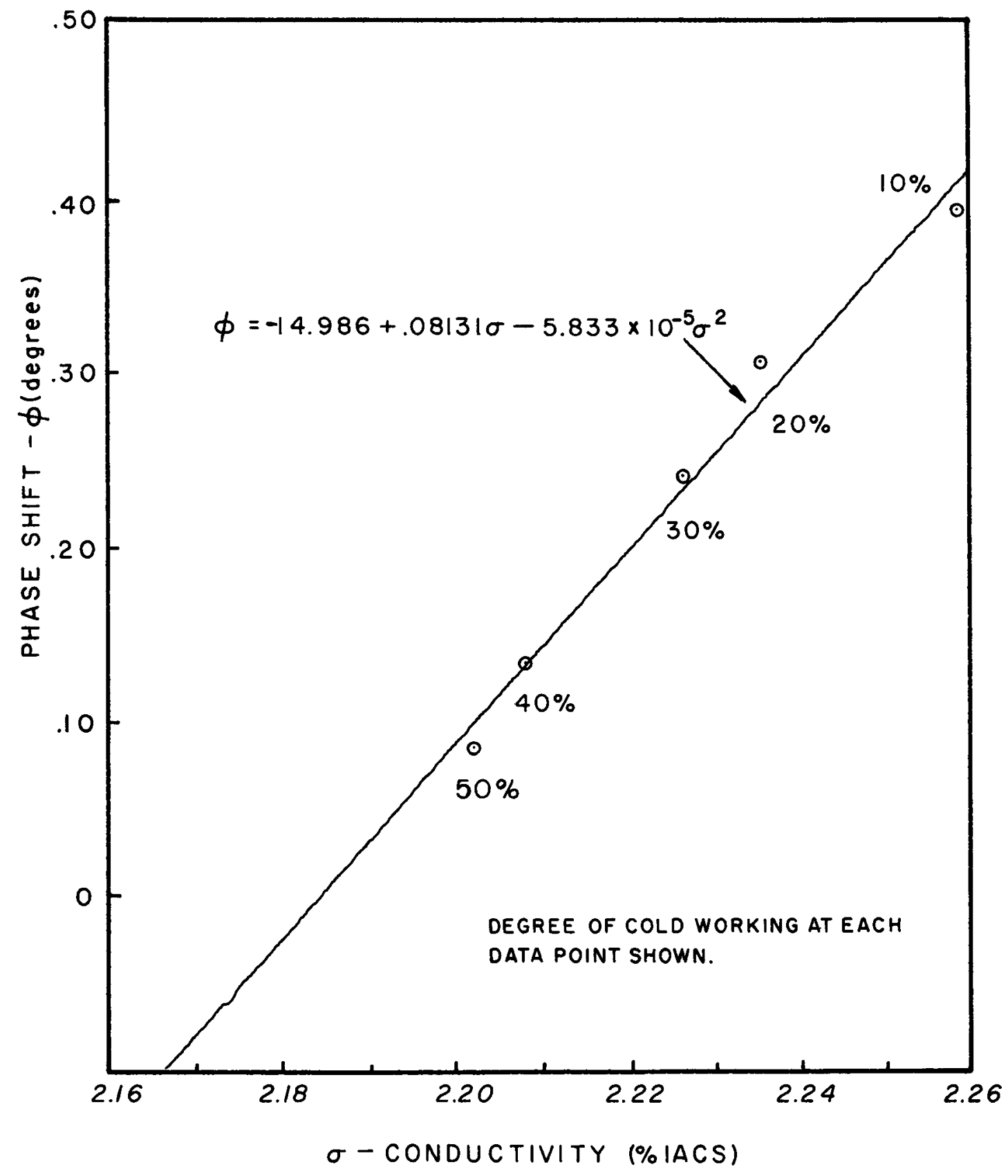

Figure 42. Plot of Phase Shift due to Conductivity versus Average Resistivity (Unpolished Surface). 


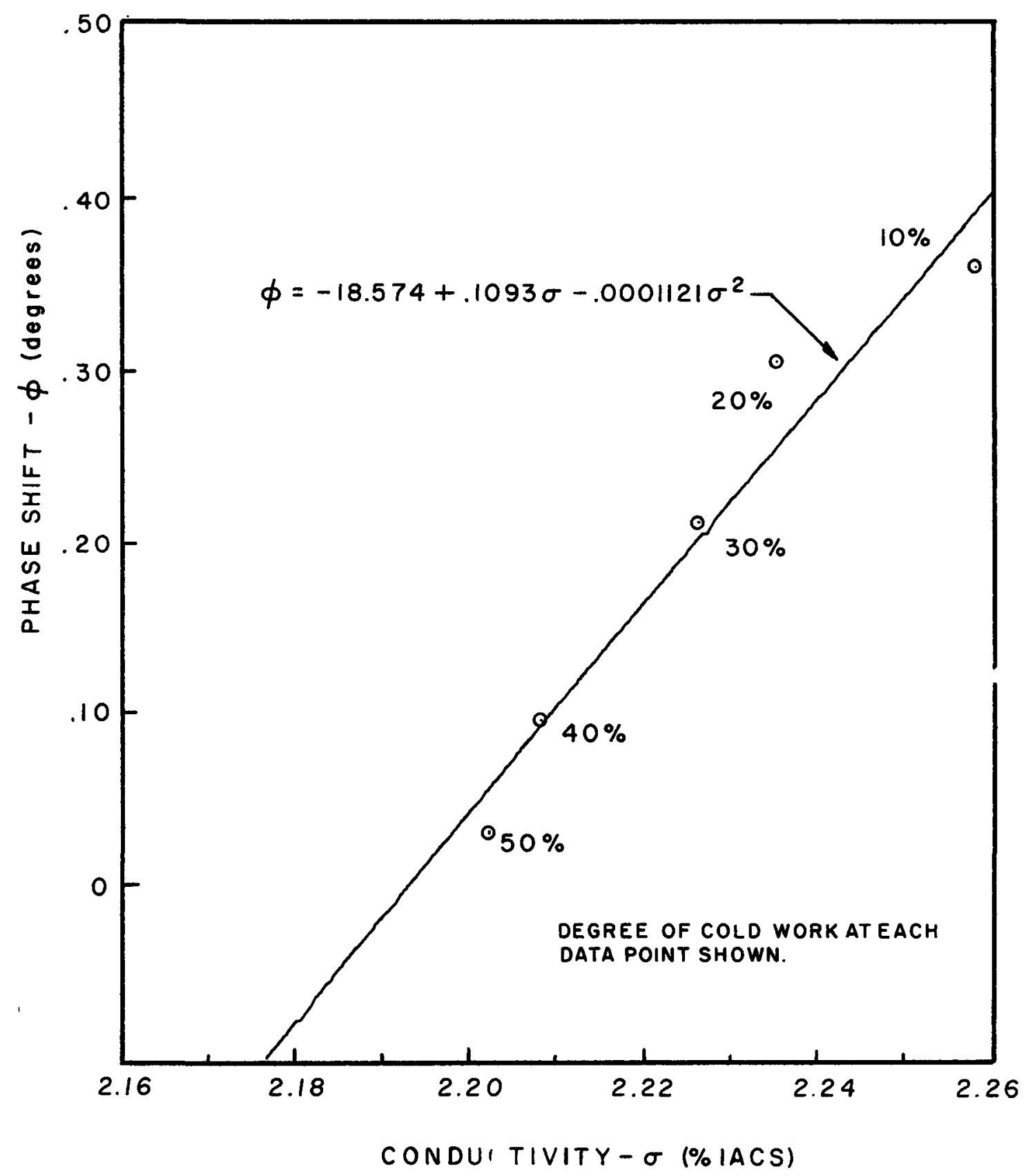

Figure 43. Plot of Phase Shift due to Conductivity versus Average Resistivity (Polished Surface). 
TABLE XXXV

SUMMARY OF THE EDDY CURRENT TEST RESULTS FROM TIE LARGE TENSILE SPECIMENS

\begin{tabular}{ccccc}
\hline \hline $\begin{array}{c}\text { Percent } \\
\text { Cold Work }\end{array}$ & $50 \mathrm{KHz}$ & $\mathrm{s}^{\mathrm{b}}$ & $500 \mathrm{KHz}$ & $\mathrm{s}^{\mathrm{b}}$ \\
\hline 0 & .268 & .065 & .292 & .056 \\
8.5 & .223 & .055 & .256 & .040 \\
17.6 & .174 & .051 & .198 & .031 \\
30.9 & .117 & .040 & .125 & .032 \\
40.1 & .062 & .029 & .066 & .043 \\
49.0 & .000 & - & .000 &.. \\
\hline \hline
\end{tabular}

a Normalized for $\phi=0$ at $49.0 \%$ cold work.

b Estimate of the standard deviation. 


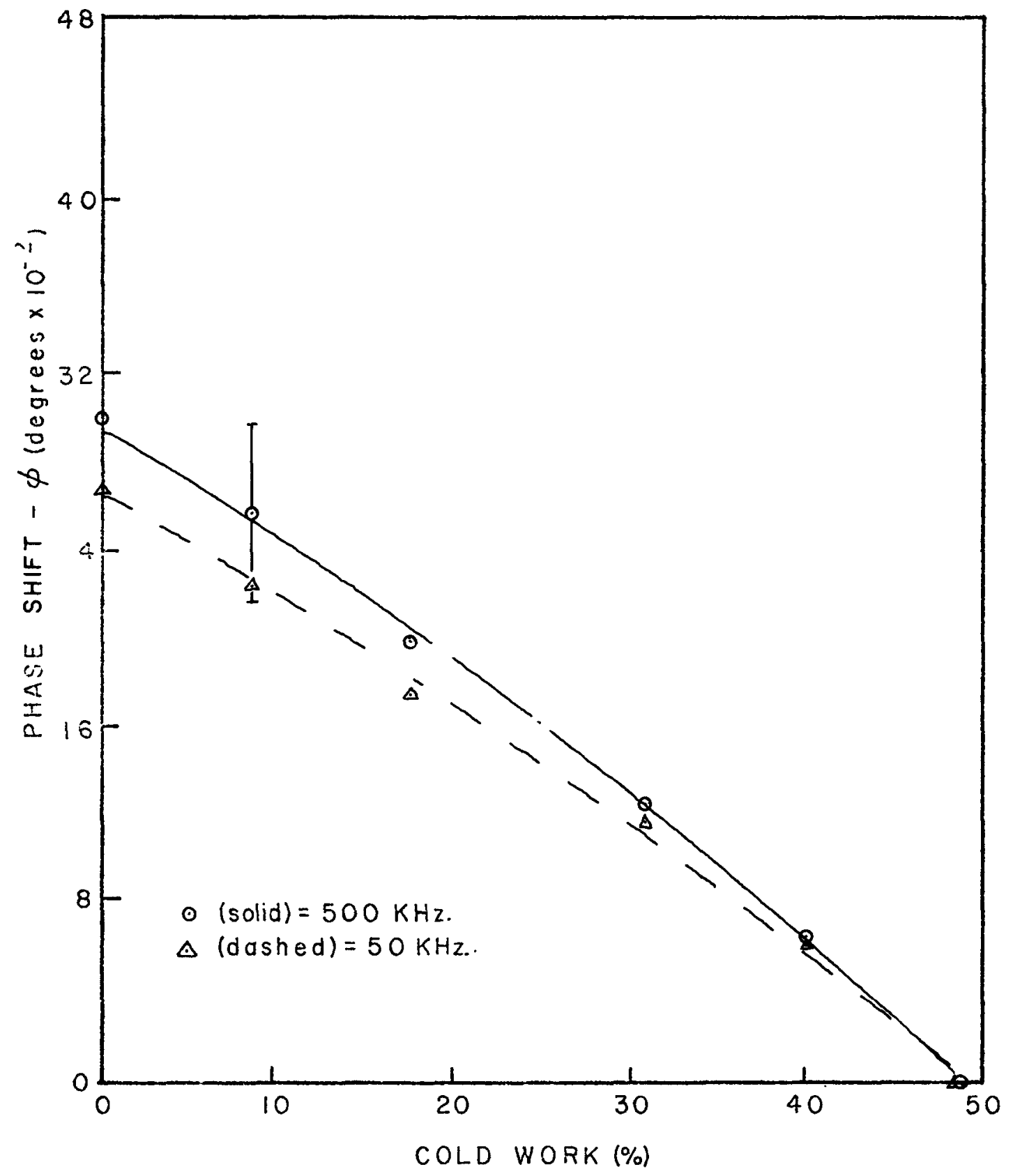

Figure 44. Plot of the Phase Shift versus Percent Cold Work for 50 and $500 \mathrm{KHz}$. on the Large Tensile Specimens. 
TABLE XXXVI

SECOND ORDER FUNCTIONS CALCULATED FOR FIGURE 44

\begin{tabular}{lr}
\hline Quantity & Function $^{2}$ \\
\hline $50 \mathrm{KHz}$ & $Y=.2931-.004644 X-.0000267 \mathrm{X}^{2}$ \\
$500 \mathrm{KHz}$ & $\mathrm{Y}=.2642-.004384 \mathrm{X}-.0000189 \mathrm{X}^{2}$ \\
\hline
\end{tabular}

a $X=$ Percent cold work.

$Y=$ Phase shift in degrees. 
TABLE XXXVII

EDDY CURRENT MEASUREMENTS ON TIE LARGE TENSILE SPECIMENS

\begin{tabular}{|c|c|c|c|c|c|c|c|}
\hline \multirow{2}{*}{$\begin{array}{l}\text { Specimen } \\
\text { Number }\end{array}$} & \multirow{2}{*}{$\begin{array}{l}\text { Measurement } \\
\text { Number }\end{array}$} & \multicolumn{2}{|c|}{$\begin{array}{c}\text { Phase Shift } \\
\text { (degrees) }\end{array}$} & \multirow{2}{*}{$\begin{array}{l}\text { Specimen } \\
\text { Number }\end{array}$} & \multirow{2}{*}{$\begin{array}{l}\text { Measurement } \\
\text { Number }\end{array}$} & \multicolumn{2}{|c|}{$\begin{array}{c}\text { Phase Shift } \\
\text { (degrees) }\end{array}$} \\
\hline & & $50 \mathrm{KHz}$ & $500 \mathrm{KlIz}$ & & & $50 \mathrm{KHz}$ & $500 \mathrm{Kliz}$ \\
\hline \multirow[t]{5}{*}{$07-L-1$} & 1 & .39 & .33 & \multirow[t]{5}{*}{$02-L-1$} & 1 & .28 & .33 \\
\hline & 2 & .41 & .33 & & 2 & .27 & .29 \\
\hline & 3 & .33 & .34 & & 3 & .24 & .28 \\
\hline & 4 & .29 & .33 & & 4 & .24 & .28 \\
\hline & 5 & .36 & .33 & & 5 & .26 & .28 \\
\hline \multirow[t]{5}{*}{$07-L-2$} & 1 & .32 & .37 & \multirow[t]{5}{*}{$02-L-2$} & 1 & .25 & .37 \\
\hline & 2 & .29 & .38 & & 2 & .24 & .34 \\
\hline & 3 & .25 & .35 & & 3 & .23 & .36 \\
\hline & 4 & .24 & .32 & & 4 & .18 & .36 \\
\hline & 5 & .22 & .32 & & 5 & .15 & .29 \\
\hline \multirow[t]{5}{*}{$07-L-3$} & 1 & .28 & .39 & \multirow[t]{5}{*}{$02-L-3$} & 1 & .24 & .37 \\
\hline & 2 & .23 & .40 & & 2 & .26 & .37 \\
\hline & 3 & .30 & .35 & & 3 & .21 & .36 \\
\hline & 4 & .26 & .38 & & 4 & .27 & .37 \\
\hline & 5 & .26 & .37 & & 5 & .26 & .36 \\
\hline \multirow[t]{5}{*}{$07-L-4$} & 1 & .31 & .40 & \multirow[t]{5}{*}{$02-L-4$} & 1 & .28 & .32 \\
\hline & 2 & .29 & .42 & & 2 & .28 & .35 \\
\hline & 3 & .29 & .43 & & 3 & .25 & .31 \\
\hline & 4 & .32 & .42 & & 4 & .28 & .34 \\
\hline & 5 & .31 & .43 & & 5 & .28 & .37 \\
\hline
\end{tabular}


TABLE XXXVII (continued)

\begin{tabular}{|c|c|c|c|c|c|c|c|}
\hline \multirow{2}{*}{$\begin{array}{l}\text { Specimen } \\
\text { Number }\end{array}$} & \multirow{2}{*}{$\begin{array}{l}\text { Measurement } \\
\text { Number }\end{array}$} & \multicolumn{2}{|c|}{$\begin{array}{c}\text { Phase Shift } \\
\text { (degrees) }\end{array}$} & \multirow{2}{*}{$\begin{array}{l}\text { Specimen } \\
\text { Number }\end{array}$} & \multirow{2}{*}{$\begin{array}{l}\text { Measurement } \\
\text { Number }\end{array}$} & \multicolumn{2}{|c|}{$\begin{array}{c}\text { Phase Shift } \\
\text { (degrees) }\end{array}$} \\
\hline & & $50 \mathrm{KHz}$ & $500 \mathrm{KHz}$ & & & $50 \mathrm{KHz}$ & $500 \mathrm{KHz}$ \\
\hline \multirow[t]{5}{*}{$07-L-5$} & 1 & .35 & .41 & \multirow[t]{5}{*}{$02-L-5$} & 1 & .35 & .40 \\
\hline & 2 & .36 & .38 & & 2 & .33 & .37 \\
\hline & 3 & .38 & .40 & & 3 & .33 & .42 \\
\hline & 4 & .36 & .41 & & 4 & .36 & .45 \\
\hline & 5 & .39 & .41 & & 5 & .36 & .42 \\
\hline \multirow[t]{5}{*}{$03-L-1$} & 1 & .25 & .29 & \multirow[t]{5}{*}{$04-L-1$} & 1 & .17 & .20 \\
\hline & 2 & .24 & .26 & & 2 & .17 & .21 \\
\hline & 3 & .26 & .30 & & 3 & .14 & .22 \\
\hline & 4 & .26 & .27 & & 4 & .15 & .21 \\
\hline & 5 & .26 & .31 & & 5 & .16 & .19 \\
\hline \multirow[t]{5}{*}{$03-L-2$} & 1 & .24 & .28 & \multirow[t]{5}{*}{$04-L-2$} & 1 & .15 & .25 \\
\hline & 2 & .24 & .29 & & 2 & .17 & .24 \\
\hline & 3 & .24 & .27 & & 3 & .18 & .24 \\
\hline & 4 & .22 & .29 & & 4 & .18 & .24 \\
\hline & 5 & .24 & .25 & & 5 & .16 & .23 \\
\hline \multirow[t]{5}{*}{$03-L-3$} & 1 & .19 & .35 & \multirow[t]{5}{*}{$04-\mathrm{L}-3$} & 1 & .13 & .21 \\
\hline & 2 & .22 & .34 & & 2 & .15 & .21 \\
\hline & 3 & .19 & .31 & & 3 & .11 & .22 \\
\hline & 4 & .21 & .29 & & 4 & .11 & .23 \\
\hline & 5 & .17 & .28 & & 5 & .10 & .24 \\
\hline
\end{tabular}


TABLE XXXVII (continued)

\begin{tabular}{|c|c|c|c|c|c|c|c|}
\hline \multirow{2}{*}{$\begin{array}{l}\text { Specimen } \\
\text { Number }\end{array}$} & \multirow{2}{*}{$\begin{array}{l}\text { Measurement } \\
\text { Number }\end{array}$} & \multicolumn{2}{|c|}{$\begin{array}{c}\text { Phase Shift } \\
\text { (degrees) }\end{array}$} & \multirow{2}{*}{$\begin{array}{l}\text { Specimen } \\
\text { Number }\end{array}$} & \multirow{2}{*}{$\begin{array}{l}\text { Measurement } \\
\text { Number }\end{array}$} & \multicolumn{2}{|c|}{$\begin{array}{c}\text { Phase Shift } \\
\text { (degrees) }\end{array}$} \\
\hline & & $50 \mathrm{KHz}$ & $500 \mathrm{KHz}$ & & & $50 \mathrm{KHIz}$ & $500 \mathrm{KHz}$ \\
\hline \multirow[t]{5}{*}{$03-L-4$} & 1 & .20 & .28 & \multirow[t]{5}{*}{$04-L-4$} & 1 & .14 & .14 \\
\hline & 2 & .19 & .27 & & 2 & .18 & .16 \\
\hline & 3 & .20 & .25 & & 3 & .12 & .18 \\
\hline & 4 & .20 & .24 & & 4 & .20 & .19 \\
\hline & 5 & .18 & .25 & & 5 & .16 & .22 \\
\hline \multirow[t]{5}{*}{$03-L-5$} & 1 & .21 & .32 & \multirow[t]{5}{*}{$04-L-5$} & 1 & .22 & .24 \\
\hline & 2 & .19 & .34 & & 2 & .21 & .23 \\
\hline & 3 & .20 & .32 & & 3 & .20 & .25 \\
\hline & 4 & .22 & .34 & & 4 & .18 & .28 \\
\hline & 5 & .22 & .32 & & 5 & .19 & .24 \\
\hline \multirow[t]{5}{*}{$05-L-1$} & 1 & .11 & .19 & \multirow[t]{5}{*}{$06-L-1$} & 1 & .03 & .07 \\
\hline & 2 & .08 & .22 & & 2 & .01 & .08 \\
\hline & 3 & .12 & .20 & & 3 & .00 & .08 \\
\hline & 4 & .08 & .20 & & 4 & .00 & .05 \\
\hline & 5 & .11 & .18 & & 5 & -.01 & .06 \\
\hline \multirow[t]{5}{*}{$05-L-2$} & 1 & .10 & .15 & \multirow[t]{5}{*}{$06-L-2$} & 1 & .07 & .08 \\
\hline & 2 & .12 & .16 & & 2 & .04 & .13 \\
\hline & 3 & .10 & .14 & & 3 & .06 & .14 \\
\hline & 4 & .08 & .15 & & 4 & .02 & .05 \\
\hline & 5 & .11 & .13 & & 5 & .03 & .08 \\
\hline
\end{tabular}


TABLE XXXVII (continued)

\begin{tabular}{ccccccc}
\hline $\begin{array}{c}\text { Specimen } \\
\text { Number }\end{array}$ & $\begin{array}{c}\text { Measurement } \\
\text { Number }\end{array}$ & $\begin{array}{c}\text { Phase Shift } \\
\text { (degres) } \\
\text { 50KHz }\end{array}$ & $\begin{array}{c}\text { 500KIIz } \\
\text { Specimen } \\
\text { Number }\end{array}$ & $\begin{array}{c}\text { Measurement } \\
\text { Number }\end{array}$ & $\begin{array}{c}\text { Phase Shift } \\
\text { (degrees) } \\
50 \mathrm{KHz}\end{array}$ \\
$500 \mathrm{KHz}$
\end{tabular}


TABLE XXXVIII

CAlCulated VAlues FOR ${ }^{\phi} \sigma$ AND $\phi_{\mu}$ FROM DATA FOR THE LARGE TENSILE SPECIMEN

\begin{tabular}{|c|c|c|}
\hline $\begin{array}{l}\text { Percent } \\
\text { Cold Work }\end{array}$ & $\phi_{\sigma}^{\mathrm{a}}$ & ${ }_{\phi_{\mu}}^{\text {(degrees) }}$ \\
\hline 0 & .249 & .0193 \\
\hline 8.5 & .219 & .0039 \\
\hline 17.6 & .169 & .0047 \\
\hline 30.9 & .106 & .0107 \\
\hline 40.1 & .056 & .0059 \\
\hline 49.0 & - - & -- \\
\hline
\end{tabular}

a Phase shift due to conductivity.

b Phase shift due to permeability. 


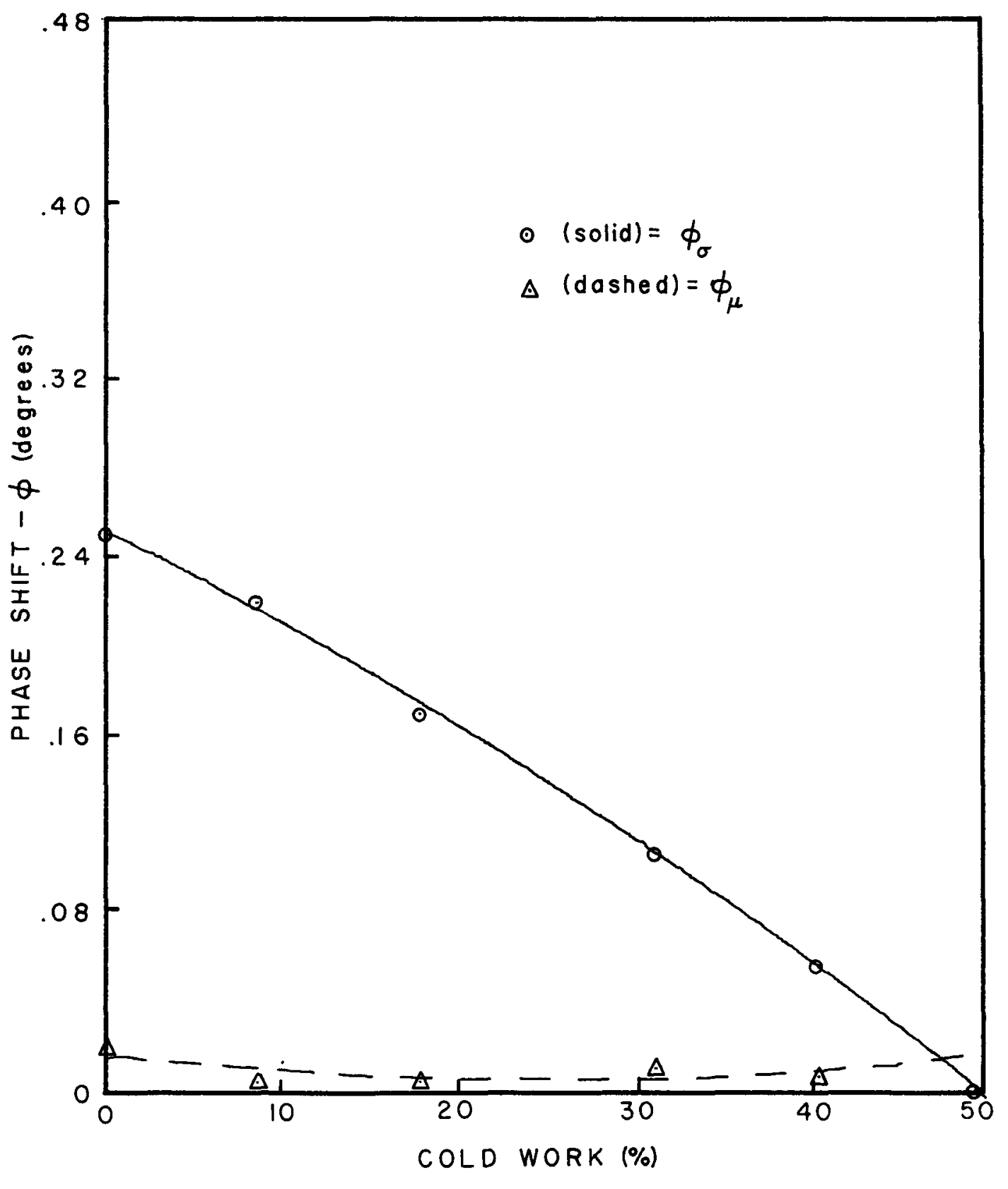

Figure 45. Plot of the $\phi_{\sigma}$ and $\phi_{\mu}$ versus Percent Cold Work for the Large Tensile Specimens. 


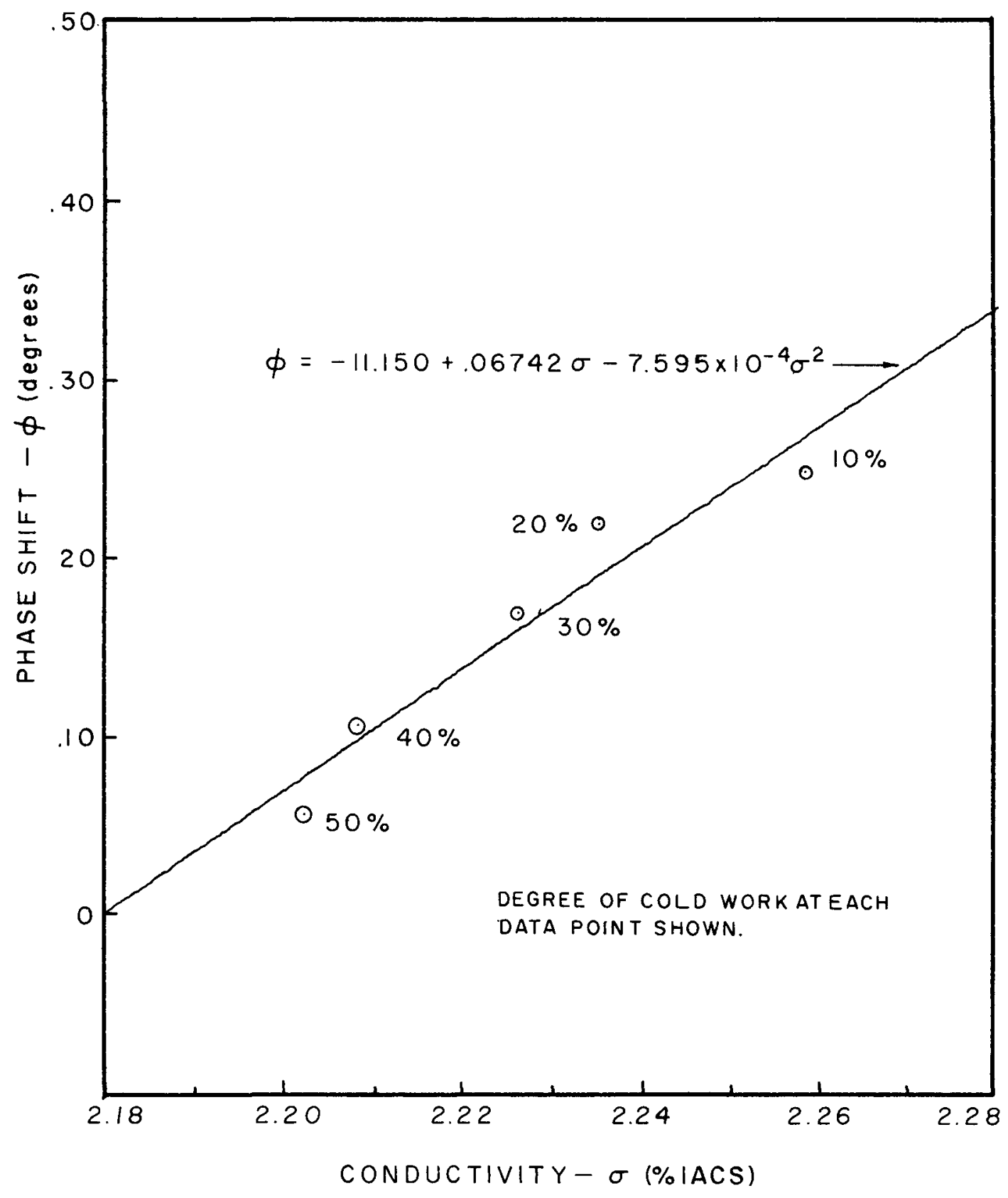

Figure 46. Plot of the Phase Shift duc to Conductivity versus Average Resistivity for the Large Tensile Specimens. 
TABLE $` X X I X$

FUNCTIONS CALCULATED FOR FIGURES 45 AND 46

\begin{tabular}{lc} 
Quantity & Function \\
\hline$\phi_{\sigma} \quad$ versus Percent Cold Work & $Y=.2500-.003944 X-2.33 \times 10^{-5} \mathrm{X}^{2^{\mathrm{a}}}$ \\
$\phi_{\mu} \quad$ versus Percent Cold Work & $Y=.1420-.004400 \mathrm{X}+4.41 \times 10^{-5} \mathrm{x}^{2^{\mathrm{a}}}$ \\
$\phi_{\sigma} \quad \begin{array}{c}\text { versus Resistivity } \\
\text { (second order) }\end{array}$ & $Y=11.1495+6.7415 \mathrm{X}-.7460 \mathrm{X}^{\mathrm{b}}$ \\
\hline
\end{tabular}

a

$X=$ Percent cold work.

$Y=$ Phase shift in degrees.

b $\mathrm{X}=$ Conductivity ( $\%$ IACS).

$Y=$ Phase shift in degrees. 


\section{ANALYSIS OF RESULTS AND DISCUSSION OF ERROR}

As has been indicated by Figures 42,43 , and 46 , on pages 135,136 , and 146 respectively, excellent correlation was obtained between the eddy current conductivity measurements and the D.C. measurements. The correlation is not perfect, but the data points do lie near enough to a good straight line fit to indicate that a definite correlation does exist. Note that in these figures the second order functions are again plotted, but that in all three cases the third coefficient is so low as to make the fit essentially first order. The differences between the three plots are interesting also in that comparison of the plots from the three-inch plates with each other would seem to indicate that the polishing affected the conductivity measurements very little, but comparison of these two with that from the large tensile specimens seems to indicate otherwise. The only explanation for such an occurence is that the polishing indeed affected the eddy current measurements slightly, and that the difference between these results and those from the large tensile specimens was due to the great number of tensile specimens with a resultant larger variance of test results. This variance would thus tend to lower the relative change in conductivity due to averaging effects as the degree of cold work was increased, which would account for the lower slope.

Plots were not made of any of the conductivity data versus any of the mechanical property data, because these plots should have been essentially similar to the aforementioned plots, and thus little additional 
information would be gained. As both the mechanical property results and the conductivity results were second order, any resulting plot should be linear with excellent correlation, just as were the previously mentioned plots.

Sources of Error

Due to the nature of the experimental study, a great deal of emphasis has been placed on the techniques used to gather data. This was the case since the entire purpose of the experiment was to detect any relative change from the annealed state to the maximum degree of cold working. Thus, emphasis in data taking was placed on repeatability and being sure that all data gathered for a particular quantity was gathered in the same manner. It was for this reason that estimates of the standard deviations were made for all data, so that an estimate of the degree of variability could be made for every measurement series. Estimates of the degree of precision can also be made from these data, and this was done for the mechanical property results with the calculation of the $95 \%$ Confidence Intervals. Accuracy estimations are difficult, but some degree of estimation may be made for each major test series based upon knowledge of the standards used to calibrate the instrumentation. It should also be mentioned that the estimates of standard deviation for the overall averages also include deviations due to specimen-to-specimen variability, which was quite large, in most cases, compared to the deviations for a single specimen. In some cases averages of results are given for one specimen, and these should give some indication of the degree of precision of the results. 
1. D.C. Resistivity Measurements

The sources of error for these measurements are shown in Table $X X X X$, and the results given there would tend to indicate that an overall error on the order of $1.0 \%$ could have been expected. The greatest source of error in this measurement was the resistance measurement, and based on the supplied manufacturer's data, and measurements made on a standard resistor, this was $\pm .5 \%$. The actual value could have been slightly better than this, as was described in Chapter III. Thus these measurements should have been in error by no more than $1 \%$

\section{Mechanical Property Tests}

As can be seen from Table XXXXI, the estimated maximum total error for any of these measurements was also $1 \%$. The two main sources of error in these measurements were the load and strain measurements, which could be calibrated to no better than $\pm .5 \%$. The standards used for this calibration were accurate to within $\pm .1 \%$, and were traceable through the Y-12 Standards Laboratory directly to the NBS. The main source of error in the calibration is linearity, and this is the reason for the $\pm .5 \%$ error. A given load or strain value could have been made accurate to the degree of accuracy of the standards, but the tests took place over a range of values, and this type of calibration was not possible.

\section{Eddy Current Tests}

Little may be said about these measurements, for the only sources of error in the measurement was that of the phase 
TABLE XXXX

ESTIMATE OF TOTAL ERROR OF D.C.

RESISTIVITY MEASUREMENTS

\begin{tabular}{cc}
\hline Quantity & $\begin{array}{c}\text { Estimated Error } \\
(\%)\end{array}$ \\
\hline Knife Edge Separation & .06 \\
Area Measurement & .03 \\
Resistance Measurement & .75 \\
Total RMS Value & .753 \\
\hline
\end{tabular}


TABLE XXXXI

ESTIMATE OF ERRORS IN THE MECHANICAL PROPERTY TESTS

\begin{tabular}{cc} 
Quantity & $\begin{array}{c}\text { Estimated Error } \\
(\%)\end{array}$ \\
\hline Area Measurement & .03 \\
Load Measurement & .50 \\
Strain Measurement & .50 \\
Total RMS Error & .708 \\
\hline \hline
\end{tabular}


shift meter read-out and other errors due to lift-off. For reasons described in the chapter on these measurements, the latter was not believed to be a problem. $r_{-}$standard used for calibration of the meter was estimated to have an overall accuracy of $\pm 0.5 \%$ due to the method used to determine calibration values, and that this would be the greatest source of error. Thus overali accuracy of these results could be estimated at $\pm 0.5 \%$. 
CHAPTER VII

CONCLUSIONS

The following conclusions, over and above the ones which should have been intuitive from the start (i.e., the increase in strength with degree of cold work), may be drawn from this study:

1. There is a gradual decrease in electrical conductivity (or increase in resistivity) as the amount of cold working is increased. This change is more marked in the direction parallel to rolling, but there is also a slight change in the direction perpendicular to rolling. This has been verified by two independent measurement techniques for the average of the two directions.

2. Most of the functions calculated seem to follow a parabolictype function with respect to the degree of cold work. This would follow an intuitive reasoning in that the more the material is work hardened, the less is its capability to further work harden, and thus the properties associated with this work or strain hardening should follow similar functions.

3. There are definite indications that what little polishing was done on the specimens did change the measured resistivity/ conductivity values. This change was more marked in the lower degrees of cold work. Whether this was due to a decrease in the amount of cold worked material, or a transformation from austenitic to martensitic or vice-versa, due to the polishing, is not the subject of this study, and was not determined. 
However, it would seem that the former was the prime cause, and that most of the effects of cold working lie at the surface.

4. The modulus of elasticity decreased as the degree of cold work increased in the direction parallel to rolling. There was also a slight increase in the direction perpendicular to rolling, but the large scatter in data makes this conclusion questionable.

5. A nondestructive method has been found which can be used to measure the electrical conductivity and permeability of $316 \mathrm{SS}$, with the result that some estimation of the degree of cold working could be made from other eddy current data. This would be true only if the chemical analysis of the material were identical to that used for this study, and if a sample of the material in the annealed state is available to use as a reference. Deviations from the chemical analysis are probably possible, but this study did not determine what possible deviations exist.

6. A highly accurate, automated method of mechanical property measurements has been proven, and results were found that might not have been found otherwise, as described in paragraph (4) above.

7. A slight anisotropy in D.C. resistivity measurements has been noted, but this difference was not statistically significant. However, the fact that the direction perpendicular to rolling always resulted in a resistivity lower than that in the parallel direction is significant. If measurement techniques were 
improved so that the measurement precision was increased, it is expected that these differences would become significant.

8. A marked change in the load versus strain plots was seen as the degree of cold work was increased. The net effect was that the "Knee" of the curve became less pronounced. This is to be expected since the strain hardening exponent increased as the degree of cold working increased. As was stated previously, some insight into this may be gained from the modulus and energy results. 
BIBLIOGRAPHY 
BIBLIOGRAPIIY

American Society for Testing and Haterials, Standard B-63, "Resistivity of Metallically Conducting Resistance and Contact Materials," Annual Book of ASTM Standards, 8, (American Society for Testing and Materials, Philadelphia, Pa., 1971).

American Society of Testing and Naterials, Standard B-187, "Specifications for Copper Bus Bar, Rod and Shapes," Annual Book of ASTM Standards, 5, (American Society for Testing and Materials, Philadelphiä, Pa., 1971).

American Society for Testing and Materials, Standard E-8, "Tension Testing of Metallic Materials," Annual Book of ASTM Standards, 31. (American Society for Testing and Materials, Philadelphia, Pa.., 1971).

Balicki, M., "A Study of Work-Hardening and Reannealing of Iron," Journal of the Iron and Steel Institute, 151, 181-224 (1945).

Dodd, C. V., and W. E. Deeds, "Eddy Current Impedance Calculated by a Relaxation Method," 300-314 in Proceedings of the Symposium on Physics and Nondestructive Testing, (Southwest Research Institute, San Antonio, Texas, 1963).

Dodd, C. V., "Npplications of a Phase-Sensitive Eddy Current Instrument," Materials Evaluation, $22(6), 260-263$ (June 1964).

Dodd, C. V., A Solution to Electromagnetic Induction Problems, Oak Ridge Nationa1 Laboratory, ORNL-TM-1185 (1965), and M.S. Thes is, The University of Tennessee, 1965.

Dodd, C. V., Solutions to Electromagnetic Induction Problems, ORNL-TM1842 (1967) and Ph.D. Dissertation, The University of Tennessee, 1967.

Dodd, C. V., and W. E. Deeds, J. Appl. Physics, 39, 2829-2839 (1968).

Dodd, C. V., "A Portable Phase-Sensitive Eddy Current Instrument," Materials Evaluation, 26(3), 33-36 (March 1968).

Dodd, C. V., W. E. Deeds, J. W. Luquire, and W. G. Spoeri, Some Eddy Current Problems and Their Integral Solutions, ORNL-4 $\overline{384 \text { (April }}$ 1969).

Dodd, C. V., and W. A. Simpson, Jr., Thickness Measurements Using Eddy Current Techniques, ORNL-3712 (March 1972). 
Fiedler, H. C., B. L. Auerbach and Morris Cohen, "The Effect of Deformation on the Martensitic Transformation in Austenitic Stainless Steels," Transactions of the ASM, 47, 267-290 (1955).

Fórster, Friedrich, Z. Metal1k., 43, 163-171 (1952).

Forster, Friedrich and Kurt Stambke, Z. Meta11k, 45 (4), 166-179 (1954).

Förster, Friedrich, Z. Metal1k, 45 (4), 197-199 (1954).

Guy, A. G., Elements of Physical Metallurgy, (Addison-Wesley Publishing Co., Inc., Reading, Massachusetts, 1959).

Hansen, Erik B., "On the Influence of Shape and Variations in Conductivity on Four-Point Measurements," App1. Sci. Res., 8, 93-104 (1960).

Hochschild, R., "Electromagnetic Methods of Testing Metals," Progress in Nondestructive Testing, Vo1. 1 (Macmillian Co., New York, 1959).

Hughes, D. E., Phil. Mag., 8 (5), 50 (1879).

Libby, H. L., Broadband Electromagnetic Testing Methods, Ilanford Atomic Products Operation, IIN-59614 (1959).

McElroy, D. L., W. M. Ewing, T. G. Kollie, R. S. Graves, and R. M. Steele, "Room Temperature ileasurements of Electrical Resistance and Thermal Conductivity of Various Graphites," ORNL-TM-3477 (1971).

McReynolds, A. W., "Electrical Observations of the Austenite-Martensite Transformation in Steel," Journal of Applied Physics, 17, 823-833 (1946).

National Bureau of Standards, Copper Wire Tables, National Bureau of Standards Handbook 100, (National Bureau of Standards, 1966).

Page, Leigh and N. I. Adams, Electrodynamics, (D. Van Nostrand Co., Inc., 1940).

Perry, C. C. and H. R. Lissner, The Strain Gage Primer, McGraw-Hill Book Co., New York, 1962).

Simpson, W. A., Jr. C. V. Dodd, J. W. Luquire, and W. G. Spoeri, Computer Programs for Some Eddy Current Problems - 1970, ORNLTM-3295 (June 1971).

Smits, F. M., "Measurement of Sheet Resistivities with the Four-Point Probe," The Be11 System Technical Journal, 37, 711-718 (1958). 
Smythe, William R., Static and Dynamic Electricity, McGraw-Hill Book Co., Inc., New York (1968).

Stanley, James K., Electrical and Magnetic Properties of Metals, (American Society for Metals, Metals Park, Ohio, 1963).

Stephens, A. E., H. J. Mackey and J. R. Sybert, "Effects of Contact Placement and Sample Shape in the Measurement of Electrical Resistivity," Journal of Applied Physics, 42 (7), 2592-2597 (1971).

Straalsund, J. L., and H. R. Brager, Effects of Cold Work on Void Formation in Austenitic Stainless Steels, CONF-710601-6 (1971).

Taylor, Lyman (ed.), Metals Handbook, 8th ed., (American Society for Metals, Metals Park, Novelty, Ohio, 1961).

Uhlir, Arthur, Jr., "The Potentials of Infinite Systems of Sources and Numerical Solutions of Problems in Semiconductor Engineering," The Bell System Technical Journal, 34, 105-128 (1955).

Valdes, L. B., "Effect of Electrode Spacing on the Equivalent Base Resistance of Point-Contact Transistors," Proceedings of the I.R.E., 40, 1429-1434 (1952).

Valdes, L.B., "Resistivity Measurements on Germanium for Transistors," Proceedings of the I.R.E., 42, 420-427 (1954).

Vaughn, D. E., "Four-Probe Resistivity Measurements on Sma11 Circular Specimens," British Journal of Applied Physics, 12, 414-416 (1961).

Waidelich, D. L., and C. J. Renken, Natl. Electron Conf., 12, 188-196 (1956).

Zrudsky, Donald R., H. D. Bush, and J. R. Fassett, "Four-Point Sheet Resistivity Techniques," The Review of Scientific Instruments, 37 (7), 885-890 (1966). 
161

APPENDICES 
In the first column, the symbol used is given; in the second column, the name; in the third column, the meter-kilogram-second (MKS) or English units, depending upon the unit. In the last column the dimensions are given in terms of mass $(M)$, length (L), time (T), and electric charge (Q).

\begin{tabular}{|c|c|c|c|}
\hline Symbol & Name & $\begin{array}{l}\text { MKS } \\
\text { or English } \\
\text { Units } \\
\end{array}$ & Dimensions \\
\hline $\mathrm{i}$ & electric current & Amperes (MKS) & $\frac{Q}{T}$ \\
\hline$-\nabla \underset{E}{V}$ or & electric field intensity & & $M^{3}$ \\
\hline$\rho$ & electrical resistivity & ohm-meter & $\mathrm{TQ}^{2}$ \\
\hline$\sigma$ & electrical conductivity & $\frac{\text { mho }}{\text { meter }}$ & $\frac{\mathrm{TQ}^{2}}{\mathrm{ML}^{3}}$ \\
\hline V & voltage & volt (MKS) & $\frac{\mathrm{ML}^{2}}{\mathrm{~T}^{2} \mathrm{Q}}$ \\
\hline$A$ & cross-sectional area & $\begin{array}{ll}\text { meters }_{2}^{2} & \text { (MKS) } \\
\text { inches } & \text { (English) }\end{array}$ & $L^{2}$ \\
\hline$n$ & $\begin{array}{l}\text { number of charges per } \\
\text { unit volume }\end{array}$ & $\frac{\text { number }}{\text { meter }}$ & $\frac{1}{L^{3}}$ \\
\hline e & electric charge & coulombs (MKS) & $Q$ \\
\hline$v$ & velocity & $\frac{\text { meters }}{\text { sec }}$ & $\frac{\mathrm{L}}{\mathrm{T}}$ \\
\hline
\end{tabular}




\begin{tabular}{|c|c|c|c|}
\hline Symbol & Name & $\begin{array}{l}\text { MKS } \\
\text { or English } \\
\text { Units } \\
\end{array}$ & Dimensions \\
\hline \multirow{2}{*}{$\vec{j} \underset{j}{\text { or }}$} & \multirow{2}{*}{ current density } & \multirow{2}{*}{$\frac{\text { coulombs }}{\text { second meter }}{ }^{2}$ (MKS) } & $Q$ \\
\hline & & & $T L^{2}$ \\
\hline$t_{f}$ & mean free time & seconds & $\mathrm{T}$ \\
\hline 1 & length & $\begin{array}{l}\text { meters (MKS) } \\
\text { inches (English) }\end{array}$ & $\mathrm{L}$ \\
\hline$\Sigma$ & $\begin{array}{l}\text { electric conductivity } \\
\text { dyadic }\end{array}$ & $\frac{\text { mho }}{\text { meter }}$ (MKS) & $\frac{\mathrm{TQ}^{2}}{\mathrm{ML}^{3}}$ \\
\hline$\omega$ & angular frequency $(2 \pi f)$ & $\frac{\text { radian }}{\text { second }}$ & $\frac{1}{T}$ \\
\hline$f$ & frequency & Hertz & $\frac{1}{T}$ \\
\hline $\mathrm{j}$ & square root of minus one & & \\
\hline$N$ & number of turns & turn & \\
\hline I & applied current & ampere & $\frac{Q}{T}$ \\
\hline$r_{1}$ & driver coil inner radius & meter & L \\
\hline$r_{2}$ & driver coil outer radius & meter & $\mathrm{L}$ \\
\hline $\bar{r}$ & mean driver coil radius & meter & $\mathrm{L}$ \\
\hline$r_{3}$ & pick-up coil inner radius & meter & $L$ \\
\hline$r_{4}$ & pick-up coil outer radius & meter & $L$ \\
\hline$L_{2}$ & length of driver coil & meter & $\mathrm{L}$ \\
\hline$L_{6}$ & length of pick-up coil & meter & $\mathrm{L}$ \\
\hline$L_{5}$ & $\begin{array}{l}\text { distance the pick-up coils } \\
\text { are recessed }\end{array}$ & meter & $\mathrm{L}$ \\
\hline$\alpha$ & separation constant & meter $^{-1}$ & $\frac{1}{L}$ \\
\hline
\end{tabular}




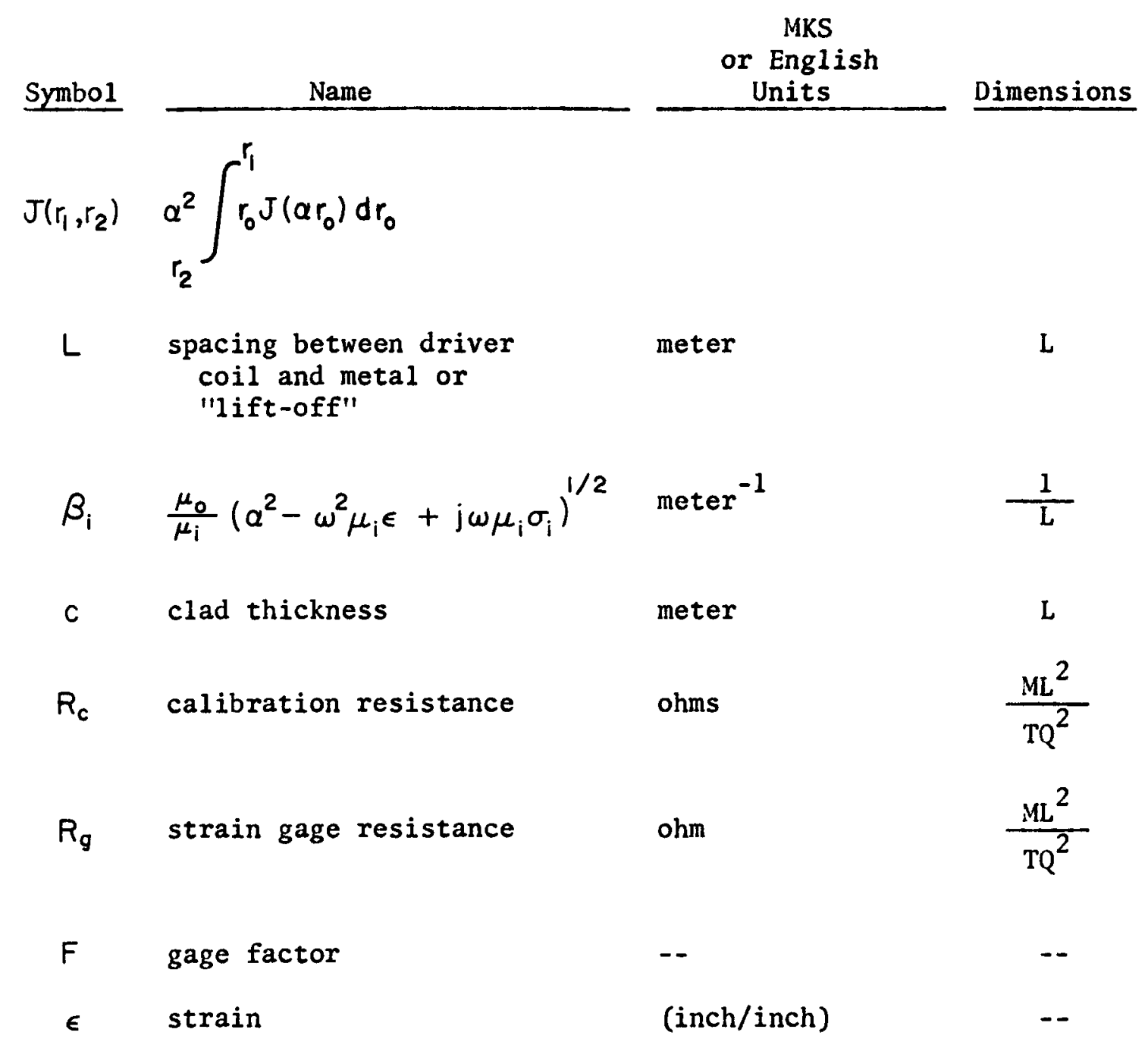




\section{APPENDIX B}

THE CALCULATOR SYSTEM USED FOR TIIS STUDY

Shown in Figure 47 is the electronic calculator and its peripheral equipment which has been mentioned so many times in the course of this study. The components as numbered in the figure and a brief description of each are listed below. The calculator and its peripherals were manufactured by llewlett-Packard, and all items are standard units with no modifications having been made to any of them. The items as shown are:

1. The Model $9100 \mathrm{~A}$ programmable electronic calculator with 14 storage registers capable of storing fourteen numbers with sign, power of ten, and decimal, or 196 program steps or a combination thereof. Programs are stored on magnetic cards which are entered via the front panel. Data output is through the CRT display on the front or the printer as described below.

2. The Model $9120 \mathrm{~A}$ electrostatic printer used for data output and program listing.

3. The Model $9125 \mathrm{~A} X-Y$ plotter, on which plots of the calculated values may be made, as was the case for many of the figures in this thesis.

4. The Model 9104A punched paper tape reader which was used to read the paper tapes for the supplemental modulus calculations for the mechanical property test results.

5. The Model 9107A digitizer which yields $X-Y$ data pairs of any point on the surface relative to any operator selected origin. 


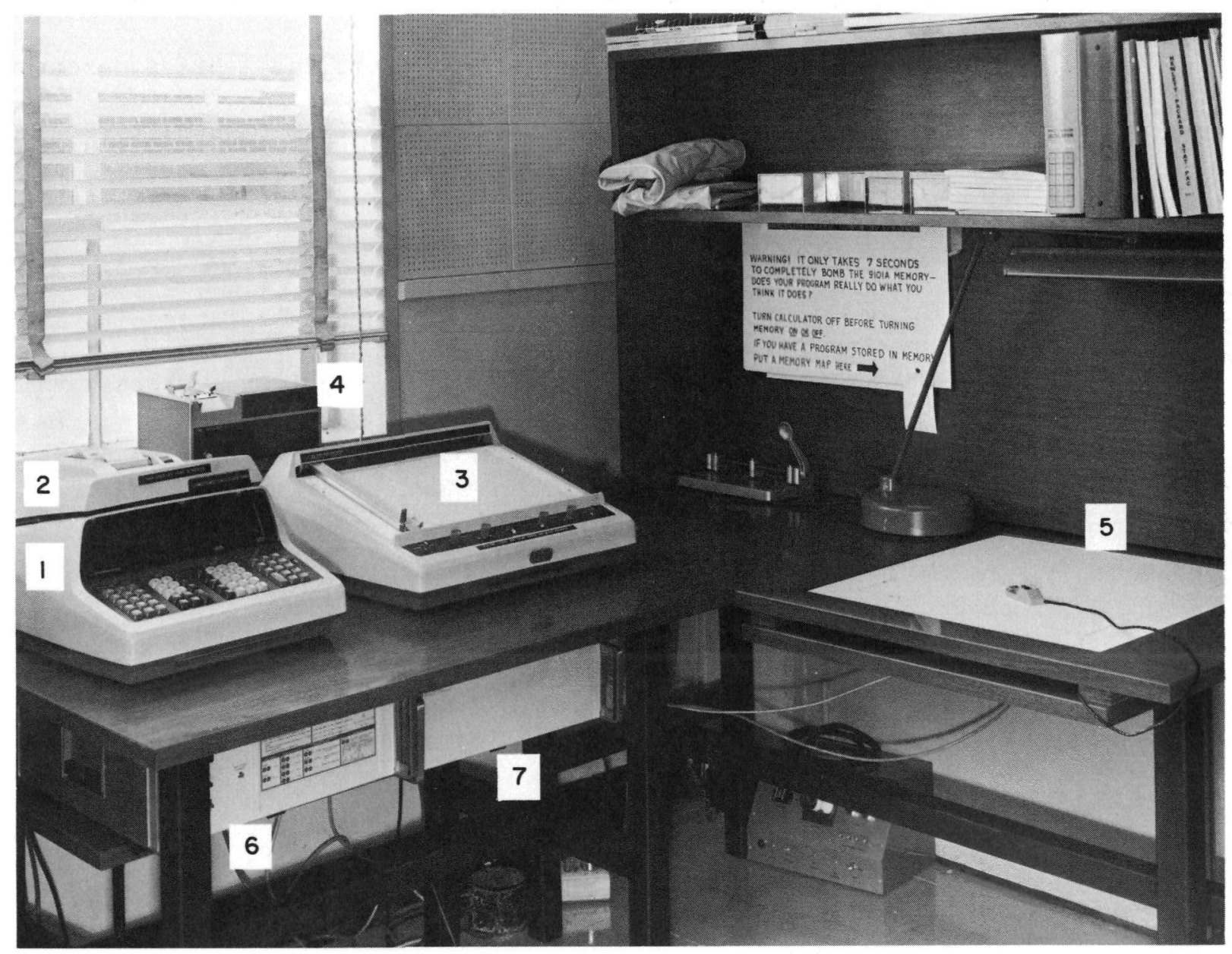

Figure 47. The Calculator System. 
This device was used to calculate areas under tin stressversus-strain curves for the energy to $1 \%$ strain calculation.

6. The Mode1 9101A extended memory which adds another $24 \delta$ registers to the calculator memory, which are each capable of storing a digit number with sign, decimal point and power of ten, or fourteen program steps, or a combination thereof. The memory has an overall storage capacity of 3472 program steps.

7. The power supply and interface for the digitizer.

Some of the programs which were most frequently used in this thesis are listed below, along with a brief description. Most of these were provided by lewlett-Packard, and this fact is indicated if it is applicable. Otherwise the programs were written by the author in the course of this study.

1. Least Squares best fit of data to a straight line (HewlettPackard): The program takes the data points as enterel by the operator at the calculator keyboard and simultaneously plots these on the appropriately scaled graph on the plotter. The least squares line is then calculated, the curve constants are given along with the correlation coefficient, and this line is plotted on the graph. The program has been rewritten by the author to accept data from the tape reader and digitizer.

2. Least Squares Parabolic (Second-Order Polynomial) Fit (HewlettPackard): This program is essentially the same as the previous program except that the fit is second order and no correlation coefficient is calculated. 
3. Eleventh-Order Polynomial Least Squares Fit (Hewlett-Packard): This program utilizes the extended memory and can accept data from the digitizer as well. It has been rewritten by the author to also accept data from the paper tape reader. The operation is essentially identical to the previous two except that in this case the operator can choose at will the degree of polynomial he wishes to plot, from a zeroth to an eleventh order.

4. Area Measurement from curves or photographs (Hewlett-Packard): The digitizer is used to obtain data points around an enclosed area and the calculator provides this area by the trapezoidal method (numerical integration).

5. Averages and Estimate of the Standard Deviation (HewlettPackard): Data is entered by the keyboard, and the average and estimate of the standard deviation is calculated.

6. T Statistic (llewlett-Packard): The data from two separate sets of results which the operator wishes to compare are entered, and the averages, estimates of the standard deviations for each group, and the $t$ statistic indicating significance of the difference, if any, between the two groups are calculated.

7. Area Calculations: The dimensions from three measurements of the width and thickness of a specimen are entered, and the average area and estimate of the standard deviation are calculated. 
APPENDIX C

THE COMPUTERIZED TESTING MACHINE SYSTEM

The testing machine system as utilized for the determination of the mechanical properties of the 316 stainless steel is composed of three identical machines, one of which was shown in Figure 24 on page 83 . All three machines are interfaced with a PDP-8I computer with a 64,000 word core memory and another 64,000 word storage memory in the form of two high speed disk storage units. All programs or software are resident on one of these disks, and the other is used for data storage. The master program in the computer core memory then calls for sub-programs, of which there are many, and/or data as they are needed.

The three machines are sampled or serviced by the computer in cyclic fashion every $1 / 60$ of a second so that very little data is lost while the computer is sampling another machine. The machines are interfaced for both data acquisition and control, so that there are a total of four data input channels and one program output channel which are scanned at each sampling interva1. Two additional machines, which were not yet on line at the time these tests were performed, are interfaced and scanned for data acquisition only.

The testing machine has a load capacity of $\pm 25,000$ pounds of linear or ter;: ./compressi.e force. The hydraulic ram or actuator has a travel limit of \pm 5 inches, and is the source of loading capability in the machine. This type of machine is known as a "closed-1oop, electrohydraul ic machine" because the ram position is controlled by an electromechani:al servo-valve. The command signal to this valve comes from a 
servo controller which generates a drive signal proportional to the difference between the so-called command signal and the signal representing the controlling variable. For instance, if the machine is operating in load control utilizing the signal from the load cell, and we have commanded a tensile load of 25,000 pounds, the servo controller produces a signal proportional to the difference between the actual tensile load and the 25,000 pounds to drive the ram to a level to provide this load. The machine is capable of being controlled from either load, the actual ram position, strain from a Linear-Variable-DifferentialTransformer (LVDT) or from resistance type strain gages, such as were used in this study. A simplified diagram of such a testing machine is shown in Figure 48.

One capability of the system evident from Figure 48 is the mode transfer module, which allows automatic transfer between controlling variables either on manual initiation or computer control without disrupting the test in progress. This is not as easy as it may sound since the signal levels of these two variables nust be the same within at least 10 millivolts for a so-called bumpless transfer to take place. The originating point of command drive signal is either a ramp generator which generates a linearly increasing voltage ramp to drive the controlling variable to some chosen percentage of full scale signal, or the computer which generates a similar drive signal. The computer generates a digital ramp which is changed to an analog ramp through a digital-to-analog converter.

Data acquisition by the computer is in the form of load versus strain data pairs which are converted to stress versus strain pairs and then 


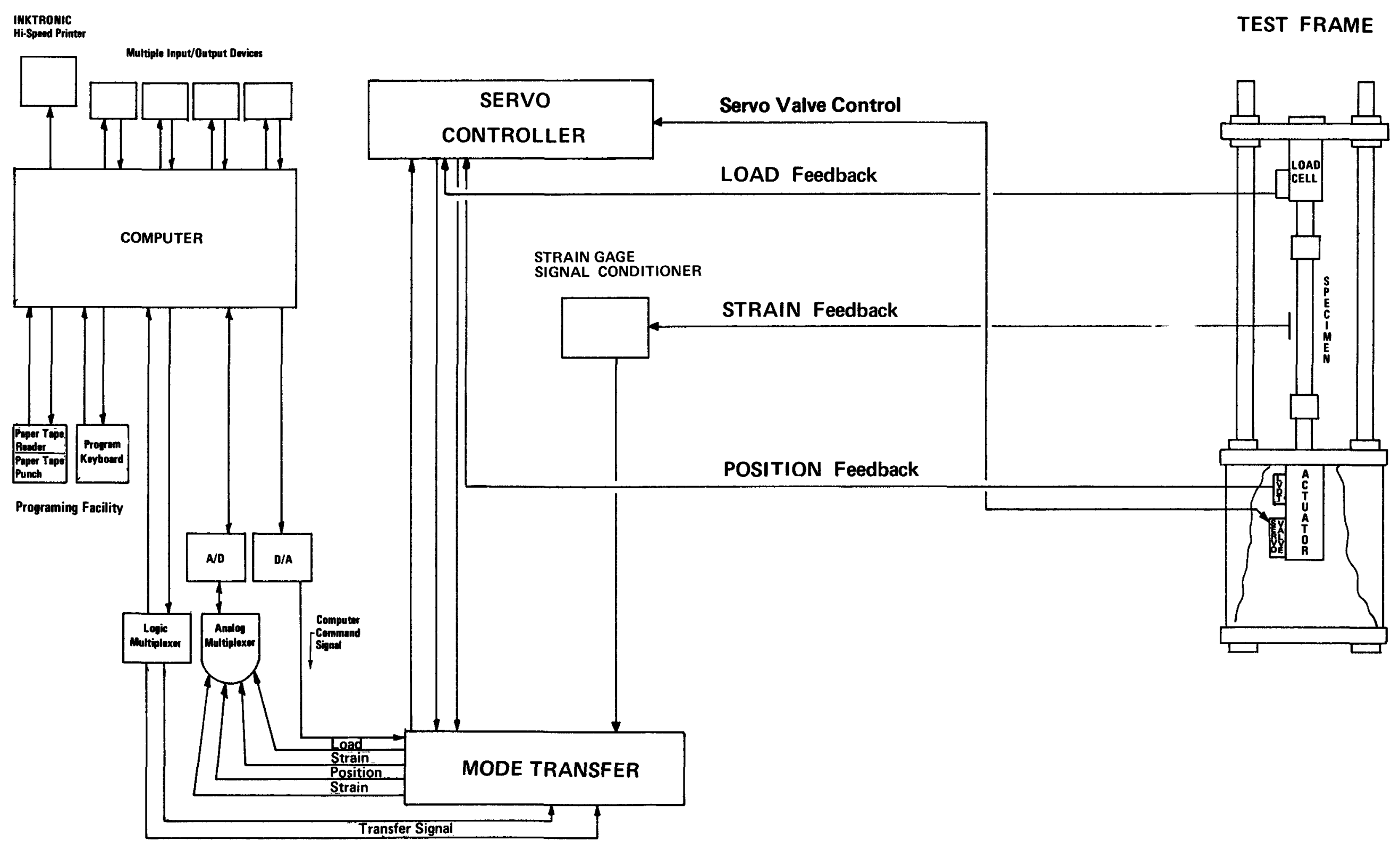

Figure 48. A Simplified Block Diagram of the Testing Machine System. 
stored on one of the disk storage units. These are then used to calculate desired quantities and are punched on paper tape on completion of the test. Data pairs are taken approximately three times a second. llodulus calculations are perforned by the computer software by the method of least squares from the initial linear data points of the stressstrain data pairs. The point at which the computer starts to take data points for the modulus calculation is called ivPT2 and can be chosen for a particular material before the test is begun. The point where the data points are cut off is chosen by the so-called "delta" constant, which is also chosen to suit a particular material. The function of this constant can be seen from Figure 49. The least squares slope of the data points is continuously calculated by the computer as the data points are being taken, and the computer then calculates where the next data point should lie on the line. Whenever the difference between the predicted load level and the actual level exceeds this delta times 6.25 pounds, the calculation is terminated. A delta of 5, which yields an exror allowable of 31.25 pounds, was used for most of the tests on the 316 stainless. An NPT2 value of 500 pounds was also used for most tests. Deviations from these values were noted in the data, and those results were not used in calculations of averages.

Due to the method of modulus calculation, the change in modulus as calculated by the computer which was mentioned in Chapter IV was mainly due to the change in curve shape. It would seem that the computer "tracked" around the curve a little more as the degree of cold working increased, due to the increasingly shallow nature of the curve, which would make the modulus values increasingly lower. A solution to this 


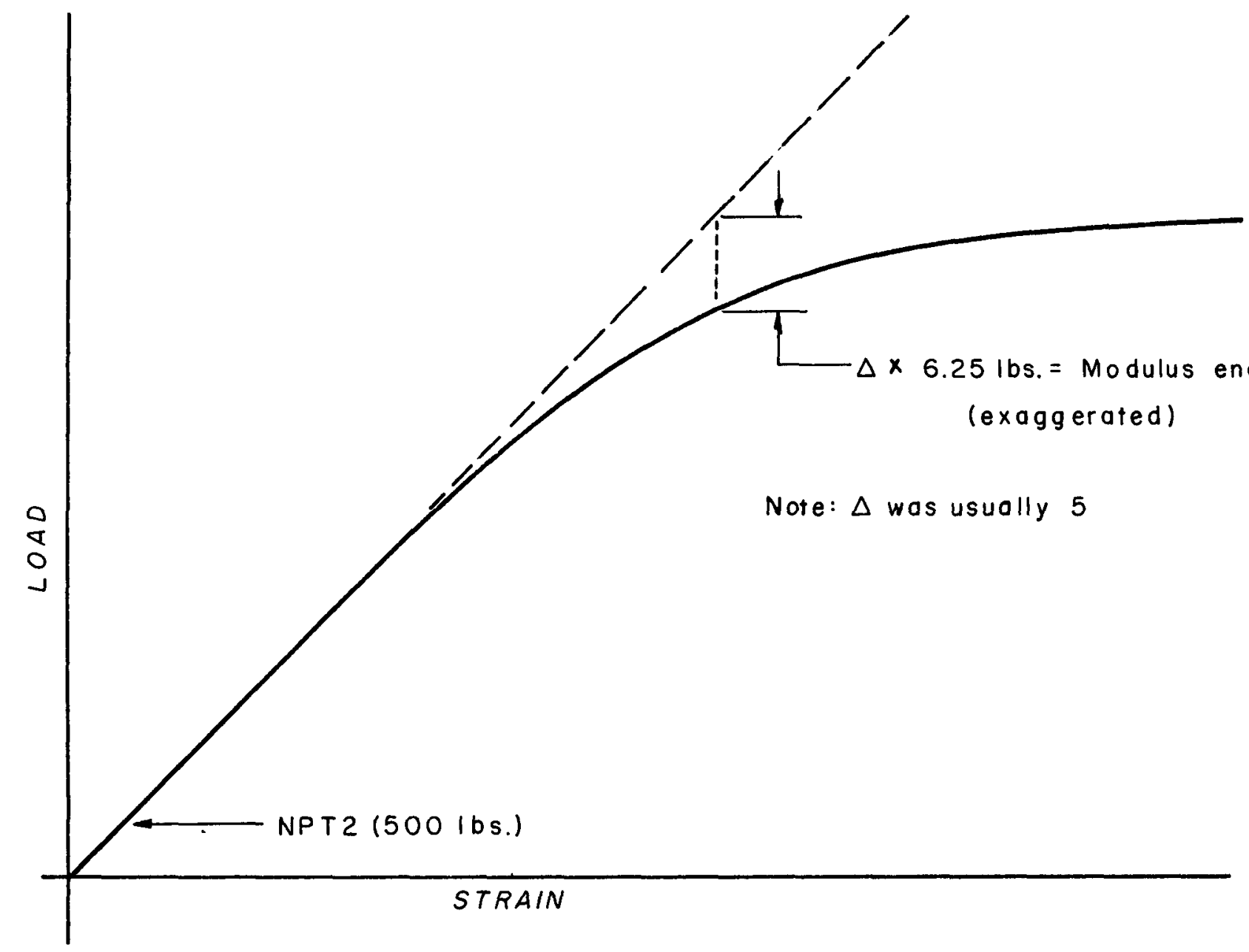

Figure 49. The Delta Function. 
problem would have been to have made the delta value smaller, but this problem was not noticed until well into the test series. Other methods could be used to calculate the modulus values, and the yield strengths should have been more consistent if the delta were not changed. The yield strengths should not have been in error by a great deal due to an incorrect modulus value since the slope of the curve at the . $2 \%$ offset yield strength was very small.

The program utilized for all tests has been described previously in Chapter IV, but very little detail was given. The program for the test was written so that once external control was chosen on the mode transfer module, all data was entered for the test on the teletype. The subroutine used to perform this function was written so that the computer asked for data as needed. A sample of the input, and resulting output data and calculations is shown in Figure 50. As was stated in Chapter IV, tests were performed in strain control at a uniform strain rate of 0.005 inch/inch per minute up to $1.5 \%$ strain, at which point control was transferred to ram position, and the test completed at a ram speed of 0.15 inch/minute. All this was performed automatically by the computer software. 


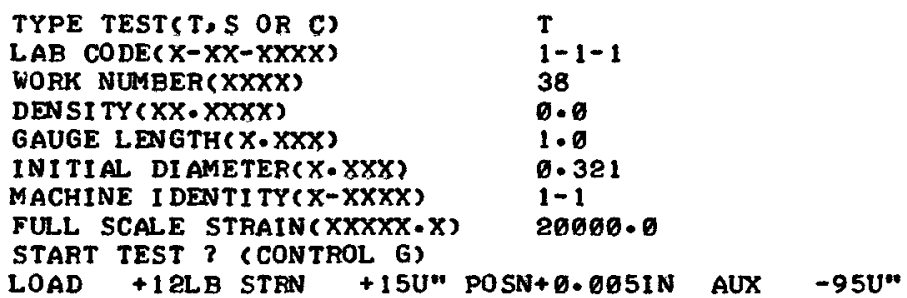

DATA ENTRY COMPLETE

ENTER FINAL DATA

ENTER FINAL LENGTH $(X \cdot X X X) \quad 1.5$

ENTER FINAL DIAMETER $(X \cdot X X X)$ G.2

DATA ENTRY COMPLETE

FINAL RESULTS

$1 / 5 / 71$ D:52:41 TENSION TEST

LABEL; ULTIMATE YIELD STRENGTH YIELD STRENGTH ELASTIC ZFINAL RAREA STRENGTH AT $0.2 \%$ OFFSET AT 12 ELONG. MODULUS ELONG. REDUCE

UNITS: PSI

PSI

PSI 16 EXP6

$+85359$

$+35404$

$+38827$

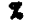

INITIAL OPERATOR ENTERED DATA

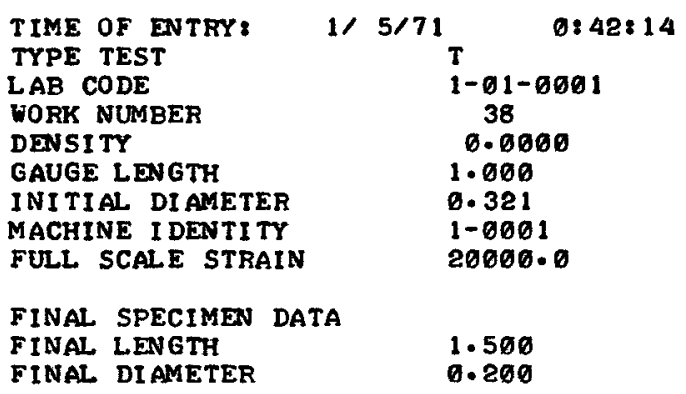

Figure 50. A Sample Printout from the Computer. 
Charles Allison Reeves, Jr., was born in Cookeville, Tennessee, on August 21, 1943. He attended elementary schools and was graduated with honors from Roane County High School in 1961. The following September he entered the University of Tennessee, and he received a Bachelor of Science legree in Engineering Physics in March, 1966. He has been employed by the Union Carbide Corporation - Nuclear Division in Uak Ridge, Tennessee since April, 1966. He has been associated with the Mechanical Properties Laboratory of the Y-12 Plant in various capacities during that time, and is currently a Physicist with the Engineering Test Systems Group. He is a member of the American Society of Testing and Materials (ASTM) and is a nember of that Society's Committee E-28 on llechanical Testing. He is also an alumnus of Sigma Pi Sigma.

He entered the Graduate School at the University of Tennessee in 1966, and received his Master of Science degree with a major in Physics in 1972 .

He is married to the former Betty Jane Hembree, and they have one child, Charles, III. 
DISTRIBUTION

Atomic Energy Commission

Keller, C. A.

Zachry, D. S., Jr

Oak Ridge Gaseous Diffusion Plant

Jordan, R. G.

Wilcox, W. J., Jr

Oak Ridge National Laboratory

Davis, H. L.

Deeds, W. E.

Dodd, C. V. (10)

McClung, R. W.

Oak Ridge Y-12 Plant

Alvey, H. E.

Bernander, N. K.

Briscoe, O. W.

Burditt, R. B.

Burkhart, L. E.

Denny, A. (2)

Ellingson, R. D.

Foulk, D. L.

Garber, J. W.

Hemphi11, L. F.

Jackson, V. C. (4)

Jones, F. W.

Kah1, K. G.

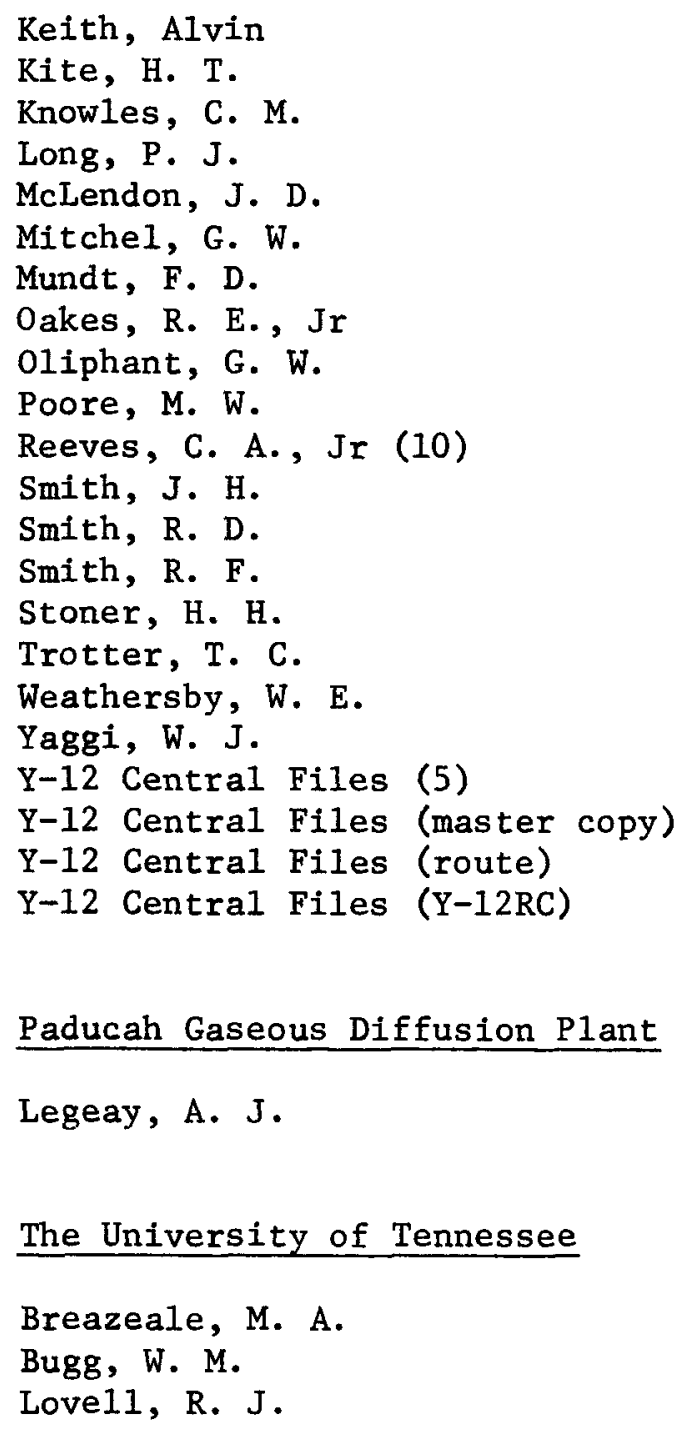

Keith, Alvin

Knowles, C. M.

Long, P. J.

McLendon, J. D

Mitchel, G. W.

Mundt, F. D.

Oakes, R. E., Jr

Oliphant, G. W.

Poore, M. W.

Reeves, C. A., Jr (10)

Smith, J. H.

Stoner, H. H.

Trotter, T. C.

Weathersby, W. E.

Yaggi, W. J.

Y-12 Central Files (5)

Y-12 Central Files (master copy)

$Y-12$ Central Files (route)

$\mathrm{Y}-12$ Central Files $(\mathrm{Y}-12 \mathrm{RC})$

Paducah Gaseous Diffusion Plant

Legeay, A. J.

The University of Tennessee

Breazeale, M. A.

Lovell, R. J.

In addition, this report is distributed in accordance with the category UC-37, Instruments, as given in the "USAEC Standard Distribution Lists for Unclassified Scientific and Technical Reports", TID-4500. 